University of Louisville

ThinkIR: The University of Louisville's Institutional Repository

$5-2017$

\title{
Civic pride or civic duty? : an examination of willingness to support a professional sport stadium referendum.
}

Alicia M. Cintron

University of Louisville

Follow this and additional works at: https://ir.library.louisville.edu/etd

Part of the Sports Studies Commons

\section{Recommended Citation}

Cintron, Alicia M., "Civic pride or civic duty? : an examination of willingness to support a professional sport stadium referendum." (2017). Electronic Theses and Dissertations. Paper 2660.

https://doi.org/10.18297/etd/2660

This Doctoral Dissertation is brought to you for free and open access by ThinkIR: The University of Louisville's Institutional Repository. It has been accepted for inclusion in Electronic Theses and Dissertations by an authorized administrator of ThinkIR: The University of Louisville's Institutional Repository. This title appears here courtesy of the author, who has retained all other copyrights. For more information, please contact thinkir@louisville.edu. 


\title{
CIVIC PRIDE OR CIVIC DUTY? AN EXAMINATION OF WILLINGNESS TO SUPPORT A PROFESSIONAL SPORT STADIUM REFERENDUM
}

\author{
By \\ Alicia M. Cintron \\ B.A., Old Dominion University, 2007 \\ M.A., University of Louisville, 2013

\begin{abstract}
A Dissertation
Submitted to the Faculty of the

College of Education and Human Development of the University of Louisville In Partial Fulfillment of the Requirements

For the Degree of
\end{abstract} \\ Doctor of Philosophy \\ in Educational Leadership and Organizational Development \\ College of Education and Human Development \\ University of Louisville \\ Louisville, Kentucky
}

May 2017 


\title{
Copyright 2017 by Alicia Cintron
}

\author{
All right reserved
}



CIVIC PRIDE OR CIVIC DUTY? AN EXAMINATION OF WILLINGNESS TO SUPPORT A PROFESSIONAL SPORT STADIUM REFERENDUM

\author{
By
}

\author{
Alicia Cintron \\ B.A., Old Dominion University, 2007 \\ M.A., University of Louisville, 2013 \\ A Dissertation Approved on
}

April 11, 2017

by the following Dissertation Committee:

T. Chris Greenwell, Co-Chair

Marion E. Hambrick, Co-Chair

Namok Choi

Anita Moorman 


\section{DEDICATION}

For my grandmother, who cultivated my curiosity of the world.

For my brother, David, who always reminded me that everything will be ok.

For Amber, Lawren, and Regina, thank you for never giving up on me, or allowing me to give up on myself.

Thank you all for watching over me. 


\section{ACKNOWLEDGMENTS}

I would like to thank my advisor and committee co-chair, Dr. Chris Greenwell, for his guidance and mentorship during my graduate school career. Dr. Greenwell constantly challenged my thought process, and I am a better researcher for it. Dr. Marion Hambrick, my other committee co-chair, has also been instrumental in my growth during my Masters and PhD work. Dr. Hambrick took me under his wing as his research assistant, where I learned valuable lessons about the field, and how to balance life and work when your life is work. Thank you both for all you have done for me, and also reminding me not to take myself so seriously. I would also like to thank my other committee members, Anita Moorman and Namok Choi for your patience and flexibility. I am so glad to have had your beautiful minds involved with my dissertation.

This journey would have been much more difficult without the great group of doctoral students I was surrounded by: Sam Schmidt, Dr. Matt Huml, Dr. Jason Rise, Dr. Chris Hanna, Jin Park, Seonghun Lee, Sin-Wook Yoo, Dylan Naegar, James Weiner, and Chulwhan Choi were supportive throughout my entire doctoral program, and I look forward to supporting them as they start their careers in academia.

I am not sure how these years would have been without my cohort partner in crime, Jeff Levine, but I am glad I will never know. I am not sure what I would have done without our coffee shop work sessions, hockey nights in America, or his one-liners. I am happy to have travelled to PhD Mordor with Jeff (and survived!).

I would also like to thank the sport administration faculty and staff at the 
University of Louisville: Erica Camp, Michel Ball, Dr. Mary Hums, and Dr. Megan Shreffler for providing support and encouragement throughout my graduate career. I especially want to thank Dr. Hancock for her mentorship and guidance in research and academia, and Prof. Presley for providing me with an opportunity to develop my teaching and advising experience.

Lastly, I would like to acknowledge all my friends and family who have supported me throughout this journey. Thank you all for remaining by my side, despite all of the times I ignored and/or failed to return your calls. Thank you for your patience and understanding. 


\title{
ABSTRACT \\ CIVIC PRIDE OR CIVIC DUTY? AN EXAMINATION OF WILLINGNESS TO SUPPORT A PROFESSIONAL SPORT STADIUM REFERENDUM
}

\author{
Alicia M. Cintron
}

April 11, 2017

Professional sport stadium subsidization is abundant across the United States, where the voting public is sometimes provided the opportunity to approve the measures through referendum. Many of these referendums are approved by the voters (Kellison \& Mondello, 2014; Mondello \& Anderson, 2004), despite research stating professional sport stadiums bring little to no economic benefit to a municipality (Baade, 1994, 1996; Baade \& Dye, 1988a, 1990; Baade et al., 2008; Coates \& Humphreys, 1999, 2002; Euchner, 1993; Zipp, 1996). Therefore, the purpose of this study was to understand what factors may influence a constituent's willingness to support a professional sport stadium referendum.

Research has suggested economic benefits such as local economic growth (Santo, 2007), noneconomic benefits such as increased quality of life and civic pride (Castellanos et al., 2011; Fenn \& Crooker, 2009; Johnson \& Whitehead, 2000; Johnson et al., 2001; Santo, 2007), stakeholder influence (Friedman \& Mason, 2004, 2005), and team identification (Depken, 2000) may influence a constituent's support when faced with a stadium construction projects. The current study examined how voter perceptions of these areas may influence their willingness to support a stadium project. 
The city of San Diego, California and the 2016 NFL Chargers stadium proposal served as the case study. Ultimately, 182 participants completed the survey. Structural equation modeling was utilized to examine the relationship between the factors. Good model fit was obtained through a number of theoretically acceptable respecifications for both the measurement model and structural model. Results from the structural model supported hypothesis $1(=0.22, \mathrm{p}<.001)$ and hypothesis $4(=0.60, \mathrm{p}<.001)$. A separate mediation analysis utilizing the phantom model approach (macho \& Ledermann, 2011) and bootstrapping found no mediating relationship, failing to support hypotheses 69.

It was ultimately found that voters value the perceived economic benefits associated with the potential professional sport stadium project. Voters' perceptions of community leaders associated with the project also influenced their willingness to support the stadium project. Team identification and perceptions surrounding noneconomic benefits had no effect on their willingness to support the stadium project. 
TABLE OF CONTENTS

PAGE

ACKNOWLEDGMENTS..........................................................

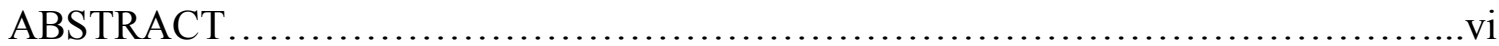

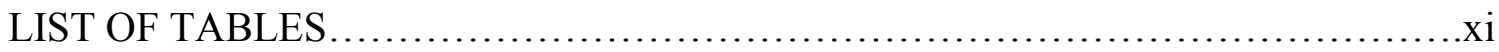

LIST OF FIGURES...............................................................

\section{CHAPTER}

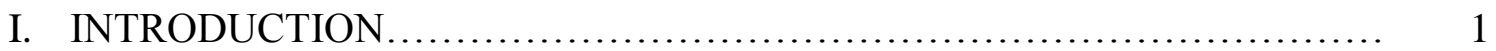

Statement of the Problem................................................ 7

Purpose of the Study ................................................. 8

Research Questions and Hypotheses.................................... 8

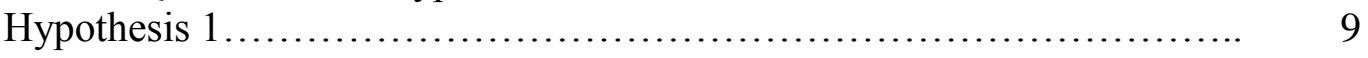

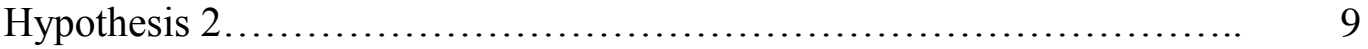

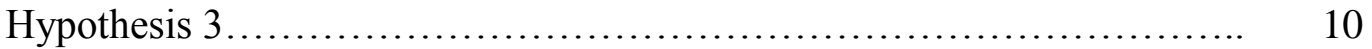

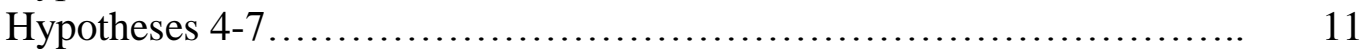

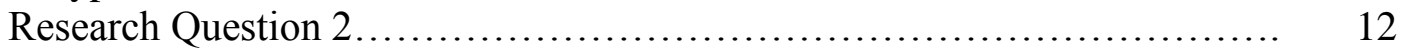

Significance of the Study ........................................... 12

The City of San Diego, California....................................... 13

The San Diego Chargers.............................................. 14

A Brief Review of Recent Publicly Funded Stadiums in San Diego.......... 15

Current Situation................................................. 16

Delimitations...................................................... 18

Operational Definitions............................................... 19

II. LITERATURE REVIEW ................................................. 22

Economic Impact................................................. 22

Summary ............................................................ 32

Noneconomic Benefits of Professional Sport Teams....................... 33

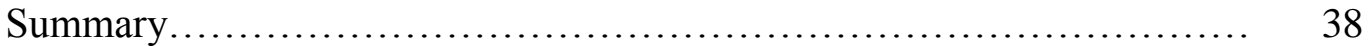

Contingent Validation Method........................................ 39

Criticisms of Contingent Validation Method............................. 44

Contingent Validation Method in Professional Sport Stadium Financing

Research............................................................... 50

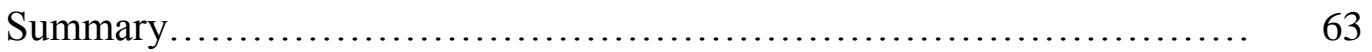

Stockholder Influence............................................. 64

The Urban Regime................................................ 65 


\section{TABLE OF CONTENTS--Continued}

Stakeholder Salience........................................... $\quad 75$

Stakeholders and Stadium Construction Projects...................... $\quad 80$

Team Identification................................................ 95

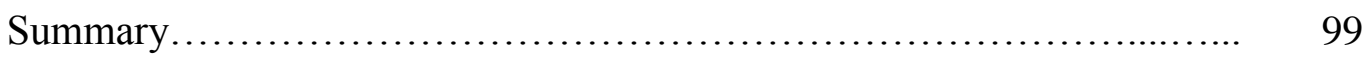

III. METHOD .......................................................... 104

Research Design................................................. 105

Data Collection and Sampling Procedure.............................. 106

Sampling Procedure .............................................. 106

Study Participants................................................ 107

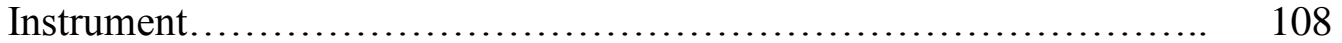

Stakeholder Influence........................................... 110

Perceived Noneconomic Benefits................................... 111

Perceived Economic Benefits................................... 113

Team Identification........................................... 115

Stadium Project Support........................................ 116

Additional Variables............................................... 118

Stakeholder Presence............................................ 121

Field and Pilot Test............................................ 123

Data Collection................................................. 127

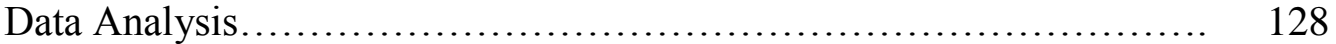

Research Question 1......................................... 128

Research Question 2......................................... 136

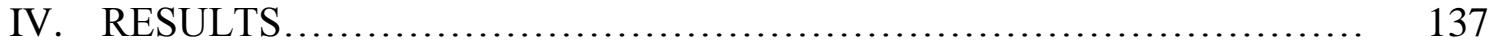

Scale Validation..................................................... 137

Pilot Test........................................................ 137

Data Analysis.................................................... 138

Demographic Information...................................... 138

Descriptive Statistics........................................... 141

Assumptions................................................... 142

Research Question 1......................................... 144

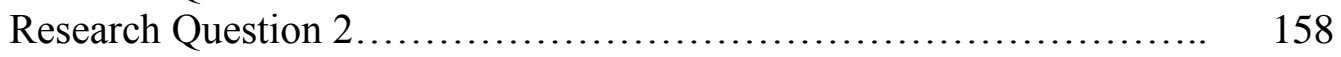

Summary of Results............................................ 162

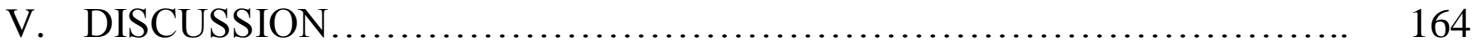

Research Purpose and Questions....................................... 164

Summary of Results............................................... 164

Interpretation of Results........................................... 166

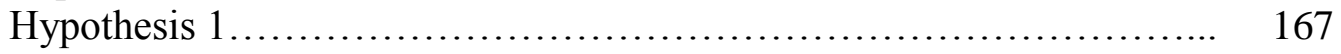

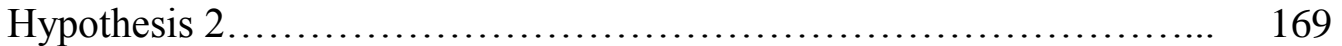

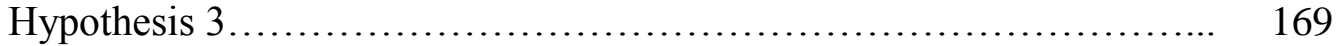

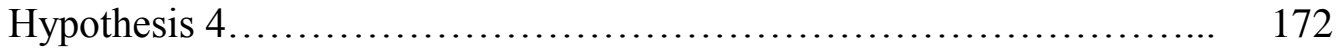

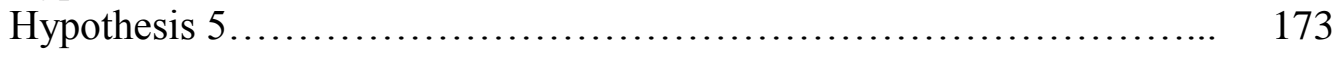




\section{TABLE OF CONTENTS--Continued}

CHAPTER

PAGE

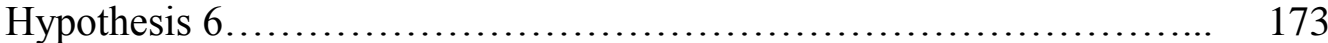

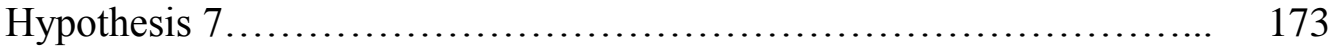

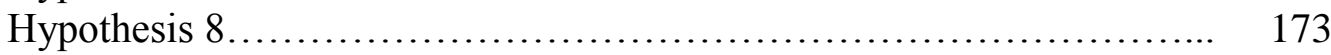

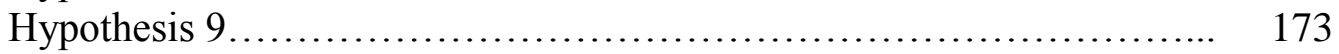

Theoretical Implications........................................ 176

Practical Implications.............................................. 183

Limitations and Future Research.................................... 185

REFERENCES ........................................................... 192

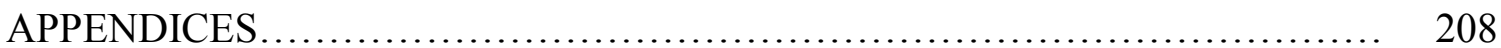

Appendix A................................................... 209

Appendix B..................................................... 211

Appendix C....................................................... 214

CURRICULUM VITAE .................................................... 215 


\section{LIST OF TABLES}

TABLE

PAGE

1. Demographic Characteristics of the City of San Diego, San Diego County, the State of California, and the United States........................... 14

2. San Diego Chargers Annual Attendance Records in Qualcomm Stadium..... 15

3. Breakdown of San Diego Chargers Stadium Proposal.................... 108

4. Stakeholder Influence Item List...................................... 111

5. Perceived Noneconomic Benefits Item List.............................. 113

6. Perceived Economic Benefits Item List.............................. 115

7. Team Identification and Passion Item List................................ 116

8. Proposed Stadium Support Item List.............................. 118

9. Additional Influencing Variable Item List............................ 120

10. Stakeholder Presence Item List..................................... 122

11. Demographics Item List......................................... 123

12. Cronbach's Alpha Statistics from the Pilot Study....................... 137

13. Demographic Frequencies....................................... 138

14. Descriptive Statistics and Reliability Coefficients for Subscales............. 141

15. Factor Correlations............................................. 146

16. Values of Model Fit for Measurement Model............................. 147

17. Values of Model Fit for Structural Model................................ 151 


\section{LIST OF FIGURES}

FIGURE $\quad$ PAGE

1. Hypothesized structural model..................................... 133

2. Measurement model............................................... 150

3. Structural model.................................................. 155

4. Example of structural model with phantom model included.................. 158 


\section{CHAPTER 1}

\section{INTRODUCTION}

The current state of professional stadium construction in the United States continues to flourish as new facilities are built, many of which are funded by the public. For example, the Washington Nationals received a $\$ 615$ million stadium in 2008, where $85 \%$ of the costs were covered by the public (Kellison \& Mondello, 2014). Despite the city of Detroit, Michigan becoming the largest municipality to file for bankruptcy in 2015, the city agreed to provide a $\$ 283$ million subsidy for the new Detroit Red Wings arena, opening in 2017 (Kellison \& Mondello). Citizens of Cobb County, a suburb of Atlanta, Georgia subsidized $67 \%$ of the total cost of the new ballpark for the Atlanta Braves (Kellison \& Mondello), who are leaving behind the barely 20-year old Turner Field. The city of Atlanta and Fulton County are also partially funding the new $\$ 1$ billion Atlanta Falcons football stadium (Chambers, 2016).

There are a variety of reasons for the increase in demand for stadium construction and public dollars to support the projects in the United States. Team owners have been successful in obtaining public funds to build stadiums due to their position in premier professional sport leagues. The leagues are able to control franchise relocation and expansion, and therefore have the ability to operate as unregulated monopolies through the restriction of supply and the limitation of franchise expansion through geographical boundaries (Baade, 2003; Siegfried \& Zimbalist, 2000; Vrooman, 1997). Additionally, 
league revenue sharing deals, along with team owners' increased focus on maximizing profits, have fueled the push towards bigger and better venues (Baade).

The unregulated monopoly power sustained across professional sport leagues also provides professional teams the option of franchise relocation. This can be used as a weapon to threaten their home municipalities to leverage the construction of a new stadium. The loss of a professional sports franchise can potentially damage a municipality's image as much as it may have built it (Kotler, Haider, \& Rein, 1993); therefore, concessions are often made to keep teams from relocating as these threats may come to fruition. For example, at least 22 professional sport franchises moved between 1970 and 1985. Fourteen teams in the National Football League (NFL), National Hockey League (NHL), National Basketball Association (NBA), Major League Baseball (MLB) have relocated since 1990 (Kellison \& Mondello, 2013), including most recently the Seattle Supersonics (NBA), Montréal Expos (MLB), Atlanta Thrashers (NHL), St. Louis Rams (NFL), and the Oakland Raiders (NFL). The leverage from operating within an unregulated monopoly also affords the leagues the bargaining power to make specific demands for a new stadium. For example, leagues often mandate specific criteria such as single purpose baseball and football-only venues instead of multi-purpose facilities when considering new cities for expansion and relocating teams (Mason \& Slack, 1997). Such demands came to fruition in Denver with the MLB expansion of the early 1990s (Sage, 1993).

While professional sport teams and leagues have threatened to abandon their current city for one willing to provide a new stadium, local governments and politicians of cities old and new are solicited to fund the requests. Additionally, cities are often 
pitted against each other for teams to negotiate the optimal stadium project. For example, in the early 1990s, St. Petersburg, Florida was at the short-end of negotiations with MLB teams in Minnesota, Oakland, Texas, and Chicago, as the negotiations were used to garner better stadium deals in the team's respective cities (Vrooman, 1997).

Local politicians and other key stakeholders in cities are often charged with retaining their local professional sport franchise by any means necessary, including providing substantial funding for the construction of new stadiums. For example, at least 15 NFL teams have threatened to relocate to Los Angeles since 1996 (Capps, 2015). From this threat, six new NFL stadiums and four stadium renovations were completed using public subsidies (Capps; Kellison \& Mondello, 2014). Roughly 95 sport facilities were either built or renovated in the United States between 1990 and 2005, and the public subsidized two-thirds of the approximately $\$ 2.7$ billion total costs (Siegfried \& Zimbalist, 2000). Additionally, $90 \%$ of all stadiums under development since 2005 have cost the public about $\$ 8.5$ billion (Kellison \& Mondello). Despite the high costs and frequency, subsidized stadium construction continues to thrive, as politicians and local stakeholders strive to promote municipal growth through these projects (Duquette \& Mason, 2008). Though key stakeholders focus on stadium construction as a way of achieving municipal growth, residents and voters in some cases have questioned the merits of such strategies.

Key stakeholders may exert their influential positions within the community to push stadium construction public policy to promote municipal growth. Fiscal crisis has left cities vying for additional revenues, much of which has flowed outside of the urban core of the city (Baade \& Dye, 1988b). Stadium development, specifically in an urban core, can potentially attract large crowds and spur commercial activities in the city 
(Baade \& Dye). This type of development is attractive to local stakeholders such as politicians, the business community, and the media, as the success of their objectives and operations are often connected with municipal growth. The existence of a professional team may spur municipal growth as teams have the potential to increase the city's revenue, put a city's name on the map (Kotler et al., 1993), and increase the city's status and prestige (Duquette \& Mason, 2008), making the city a more attractive place for people to live and settle down.

Stadium referendum results have varied throughout the recent history. For example, 26 professional stadium referendums were held between 1990 and 2000, where 20 passed and six failed (Mondello \& Anderson, 2004). Additionally, there were at least six professional stadium referendums held between 2005 and 2014, where all but one passed (Kellison \& Mondello, 2014). Those stakeholders who rely on the success of these projects have become more invested in promoting the benefits of such investments. Some of the core benefits of the presence of a professional team and a new stadium potentially include an increase in local jobs and spending, and increased foot traffic in the city (Lansing \& Casper, 2000). Comparatively, some of the costs associated with such projects include opportunity costs, construction costs overruns, additional targeted taxes, and loss of potential federal tax revenues (Lansing \& Casper). Economic factors conjoined with teams' threats to relocation and the debatable balance of costs and benefits of stadium construction may have added on to taxpayer resistance (Baade \& Dye, 1988b).

In some cases, taxpayers have recognized the high cost of stadium construction projects in conjunction with municipal fiscal issues and have prompted resistance to these 
measures (Baade \& Dye, 1988b). For example, opponent groups in Cincinnati (Brown \& Paul, 1999) and Nashville (Friedman \& Mason, 2005) collected enough signatures to force a referendum vote for the respective local stadium projects, allowing the constituents a chance to determine how and where their tax dollars were spent. Wisconsin state senator George Petak was recalled from his seat after changing his vote at the last minute to support (and ultimately approve) the $\$ 250$ million subsidy for the Milwaukee Brewers stadium in 1995 (Friedman \& Mason, 2004). These examples provide additional evidence regarding taxpayer resistance.

To garner support from local constituents, key local stakeholders such as politicians and community leaders have relied on the promotion of measureable economic impact benefits (i.e., tax revenue and job creation) to gain support for public subsidies to build professional sport stadiums. Economic impact reports are often commissioned to provide quantitative evidence supporting the public's future investment in the stadium construction project (Sanderson, 2000). Subsequently, it has been found that professional teams are too small of a component to lead economic changes or to propel large-scale redevelopment efforts within a city (see Baade, 1994, 1996; Baade \& Dye, 1988a, 1990; Baade, Baumann, \& Matheson, 2008; Coates \& Humphreys, 1999, 2002; Euchner, 1993; Zipp, 1996). Despite this information, many key stakeholders continue to pursue and support stadium construction projects. Recently, St. Louis government officials offered $\$ 145$ million towards a new $\$ 1$ billion riverfront stadium for the NFL's Rams while the State of Missouri agreed to cover the rest of the public portion of the costs (Pistor, 2015). This proposed investment was backed by an economic impact report commissioned by the St. Louis Regional Chamber, which stated a new football 
stadium would have a $\$ 177$ million annual impact on the state of Missouri and create over 7,500 jobs (Hunn, 2015). Despite the results of the economic impact report, the Rams stadium proposal was widely opposed by residents (McDonald, 2015), and the Rams were eventually granted relocation to Los Angeles starting in the 2016 season. This example brings attention to the increasing doubt and concerns raised by local residents.

Another avenue politicians and key stakeholders have taken to garner public support from local residents for stadium projects is the promotion of the noneconomic impact of sport teams. Along with an elevated city status and prestige, stakeholders may promote the community as "major league" due to the existence of a professional sports team (Euchner, 1993). In addition, the team may create noneconomic benefits for local residents who do not attend games such as civic pride, an increased quality of life, water cooler conversation with coworkers and friends, and the ability to watch the team on local television or read about them in the newspaper (Siegfried \& Zimbalist, 2000). Further, noneconomic benefits may cause a resident to consider the value of the team to them as an individual as well as for the community, such as elevated status, prestige, and national reputation. Researchers have advocated for focus to shift to noneconomic benefits over measureable economic impact studies when trying to justify the use of public funds for a professional sport stadium (Baade \& Dye, 1988a, 1990; Johnson, 1986; Noll \& Zimbalist, 1997; Rosentraub; 1996; Sanderson 2000; Swindell \& Rosentraub, 1998; Zipp, 1996).

Further, the connection between local residents and a professional sports team is another attribute for potentially gaining support for a stadium construction project. This 
cognitive connection between a person and a sports team is called team identification. The residents who also maintain some level of team identification may consider the existence of the team as a crucial part of their lives, and may provide unwavering support for the team. Researchers have also suggested focusing on team identification as a key noneconomic benefit (Baade \& Dye, 1988a; Walker \& Mondello, 2007).

Key local stakeholders are often charged with retaining their local professional teams, as promoted on the grounds of municipal and economic growth. These stakeholders often rely on promoting the economic and noneconomic benefits of the existence of a team to garner support from the local constituents. Additionally, stakeholders may be able to rely on the cognitive connection residents may have developed with the team in order to gain support for stadium construction projects. Ultimately, there are a number of different factors that may influence a resident to support or oppose stadium construction projects in their community.

\section{Statement of the Problem}

Despite the inconsistency surrounding the support or rejection of a stadium subsidy, this topic remains wholly salient. Stadium subsidy referendums have seen record voter turnouts. There was a $41 \%$ average voter turnout (VTO) across 37 stadium referendums held between 1984 to 2000 , where many of these referendums set local records for VTO (Paul \& Brown, 2001). For example, 15,000 more voters in Arlington, Texas voted in the stadium referendum in 1991 than in an election three years prior (Paul \& Brown). Comparatively, about 58\% of eligible voters in participated in the 2012 presidential election in the United States (DelReal, 2014). Given the saliency of stadium

construction projects, and the rate of new stadium projects across the country, it is vital to 
examine how factors such as economic benefits, noneconomic benefits, team identification, and stakeholder influence affects voters when they are faced with stadium measures.

\section{Purpose of the Study}

The state of stadium construction projects continues to flourish, and often depends on the local publics to fund the venture. While there has been success in garnering support from constituents for local professional stadium construction projects, there have also been major defeats. A number of different approaches have been taken to gain support from the local residents such as the focus on economic and noneconomic benefits, and reliance on the cognitive connection between the fan and the team. Additionally, key stakeholders position themselves as influencers to garner support for stadium measures. Therefore, the purpose of this study is to examine how stakeholder influence, perceived noneconomic benefits, perceived economic benefits, and team identification may influence a constituent's willingness to support a professional sport stadium referendum.

\section{Research Questions and Hypotheses}

In order to examine what influences constituents' willingness to support a stadium referendum, a number of research questions and hypotheses will be posed.

Research Question 1 and Hypotheses. Research question 1 is: What effect do Stakeholder Influence, Perceived Economic Benefits, Perceived Noneconomic Benefits, and Team Identification have on constituents' willingness to support a stadium referendum? Seven hypotheses have been laid out to address this research question. 
Hypothesis 1. The first hypothesis will address Stakeholder Influence. The literature has found a variety of stakeholders potentially influence the outcome of a stadium referendum. Politicians (Danielson, 1997; Paul \& Brown, 2001, 2006; Sage, 1993), the media (Brown \& Paul, 1999; Buist \& Mason, 2010; Delaney \& Eckstein, 2007, 2008; Sage, 1993; Turner \& Marichal, 1998), stadium proponent groups (Brown \& Paul, 2002; Paul \& Brown, 2001), the business community (Danielson, 1997; Delaney \& Eckstein, 2007; Friedman \& Mason, 2004; Kalich, 1998; Mason \& Buist, 2013; Sage, 1993), and team owners (Brown \& Paul, 1999; Fort, 1997) are each key definitive stakeholders in stadium construction projects (Friedman \& Mason, 2004). Additionally, these five groups have historically been proponents of professional stadium construction projects (Brown \& Paul, 2002). Therefore, the first hypothesis states that a respondent's perception of Stakeholder Influence on the stadium project will have a positive direct effect on their willingness to support the referendum.

\section{H1: Stakeholder Influence has a direct positive effect on Stadium Support.}

Hypothesis 2. The second hypothesis will address the perceived noneconomic benefits of the professional sports team and the stadium. This hypothesis stems from the sport-based contingent valuation method (CVM) literature regarding the public good variable, and noneconomic and nonuse benefits. Sport-based CVM research attempted to quantify the public good variable-reading about the team, watching the team play on television, talking about the team with family, friends, and/or coworkers, and quality of life improvement-to determine the measureable existence value of a team(s) or event to the local residents (Atkinson, Mourato, Szymanski, \& Ozdemiroglu, 2008; Castellanos, García, \& Sánchez, 2011; Fenn \& Crooker, 2009; Groothuis, Johnson, \& Whitehead, 
2004; Johnson \& Whitehead, 2000; Johnson, Groothuis, \& Whitehead, 2001; Johnson, Mondello, \& Whitehead, 2006, 2007; Owen, 2006; Santo, 2007).

Additionally, community noneconomic benefits may also exist considering a team's effect on the city's national reputation, status, prestige, and overall quality of life (Castellanos et al., 2011; Fenn \& Crooker, 2009; Johnson et al., 2007; Johnson \& Whitehead, 2000; Santo, 2007). Therefore, this hypothesis will address how a respondent's perception of noneconomic benefits influences their willingness to support a stadium referendum.

\section{H2: Perceived Noneconomic Benefits has a direct positive effect on Stadium} Support.

Hypothesis 3. The third hypothesis will address the perceived economic benefits of the professional sports team and the stadium. The economic benefits of a professional sports franchise and stadium focus on the overall economic impact the team may bring such as new jobs and additional tax revenue (Atkinson et al., 2008; Castellanos et al., 2011; Owen, 2006; Santo, 2007). Often these economic benefits are promoted by stakeholders to justify the investment into stadium construction projects, despite researchers finding little to no economic impact from these projects (see Baade, 1994, 1996; Baade \& Dye, 1988a, 1990; Baade et al., 2008; Coates \& Humphreys, 1999, 2002; Euchner, 1993; Zipp, 1996).

Perceived economic benefits address a respondent's perceptions of the stadium project in relation to the city's overall economic health such as increased jobs, improved municipal economy, and overall financial success for the city (Kellison, 2013). 
Therefore, this hypothesis will address a respondent's perceptions of the economic benefits of a professional team and how it may influence their willingness to support a stadium referendum.

H3. Perceived Economic Benefits has a direct positive effect on Stadium Support.

Hypotheses 4-7. Hypotheses 4-7 presents team identification as a direct and indirect influential variable on constituent's willingness to support a stadium project. A number of sport-based CVM studies included team identification as a noneconomic benefit of a stadium (Fenn \& Crooker, 2009; Johnson et al., 2001; Johnson \& Whitehead, 2000; Owen, 2006). In addition, Walker and Mondello (2007) suggested team identification as a moderator to gauge affective responses towards the team to assess referendum support from fans and nonfans. Team identification refers to the level of psychological connection a person has with a team (Wann, 1997), and the presence of this connection may influence a respondent's willingness to support a stadium referendum. Wann and Branscombe (1993) found that highly identified fans were more involved with the team. Team identification has also been found to influence attendance (Trail, Fink, \& Anderson, 2003; Wann \& Branscombe), and affective responses (Wann \& Schrader, 1997). Therefore, hypotheses 4-7 focus on the direct and indirect effect team identification has on the relationship between stakeholder influence, perceived noneconomic benefits, and perceived economic benefits and willingness to support the referendum.

H4. Team Identification has a direct positive effect on Stadium Support. 
H5. Team Identification has an indirect positive effect on Stadium Support through Stakeholder Influence.

H6. Team Identification has an indirect positive effect on Stadium Support through Perceived Noneconomic Benefits.

H7. Team Identification has an indirect positive effect on Stadium Support through Perceived Economic Benefits.

Research Question 2. Research question 2 directly addresses the stakeholders associated with the stadium construction project. The question asks: Which stakeholder groups do voters believe are campaigning for or against the stadium referendum? As previously discussed in research question 1 , hypothesis 1 , stakeholder groups have been key factors in stadium construction projects. Politicians, team owners, the media, stadium proponent groups, and the local business community have historically been proponents of professional stadium construction projects (Brown \& Paul, 2002). While Stakeholder Influence is included to measure the overall influence on a constituent, this research question aims to identify which specific stakeholders are perceived to be the most vocal in campaigning either for or against the stadium construction project.

\section{Significance of the Study}

This study aims to provide insight as to what influences a voter to support a stadium referendum, considering the costs often outweigh the benefits. This study can help politicians and policymakers understand what their constituents value in relation to the existence of a local professional team. Professional teams can use the information, primarily in regards to team identification, to better understand the local market and how 
the connection with the team may help (or hinder) their mission to construct a new stadium with public dollars, without potentially alienating their local fan base. Overall, the study fills a gap in the literature as an approach to understand municipal investment of professional stadium construction from the constituent's point of view. Extant research in this realm has focused primarily dispelling professional sports team economic impact through an examination of economic indicators such as jobs and taxable sales. Little research examines perceptions of residents and voters who are often directly impacted the most by these projects. The current study relied on a concurrent case to examine voter perceptions of stadium construction projects. Residents of San Diego (city), California were faced with a stadium referendum in the November 2016 election. The following section provides a background of this case.

\section{The City of San Diego, California}

The City of San Diego is the second largest city in California, and the eighth largest city in the United States, with over 1.3 million people (City of San Diego, 2016). Located in southern California, San Diego is about 100 miles south of Los Angeles and 20 miles north of the Mexico border. The city has a somewhat different racial makeup when compared to the United States population, based on U.S. Census data from 2010, as shown in Table 1. There is a higher representation of Hispanics and Asians in San Diego when compared to the U.S. population. There is a lower concentration of African Americans when compared to the U.S. population. Additionally, the household income in the city of San Diego is higher than that of the U.S. population. There are about 660,471 registered voters in the City of San Diego as of July 2016 (G. Gutierrez, personal communication, July 14, 2016). 


\section{Table 1.}

Demographic Characteristics of the City of San Diego, San Diego County, the State of California, and the United States.

\begin{tabular}{|c|c|c|c|c|}
\hline & City of San Diego & $\begin{array}{l}\text { San Diego } \\
\text { County }\end{array}$ & California & United States \\
\hline \multicolumn{5}{|l|}{ Population } \\
\hline 2010 & $1,394,928$ & $3,095,308$ & $37,253,956$ & $308,745,538$ \\
\hline 2000 & $1,223,400$ & $2,813,833$ & $33,871,646$ & $281,421,906$ \\
\hline \multicolumn{5}{|l|}{ Gender } \\
\hline Female & $49.5 \%$ & $49.7 \%$ & $50.3 \%$ & $50.8 \%$ \\
\hline Male & $50.5 \%$ & $50.3 \%$ & $49.7 \%$ & $49.2 \%$ \\
\hline \multicolumn{5}{|l|}{ Race } \\
\hline Caucasian & $58.9 \%$ & $64.0 \%$ & $72.9 \%$ & $72.4 \%$ \\
\hline African-American & $6.7 \%$ & $5.1 \%$ & $6.2 \%$ & $12.6 \%$ \\
\hline American Indian or Alaska Native & $0.6 \%$ & $0.9 \%$ & $1.0 \%$ & $0.9 \%$ \\
\hline Asian & $15.9 \%$ & $10.9 \%$ & $13.0 \%$ & $4.8 \%$ \\
\hline Native Hawaiian or other Pacific Islander & $0.5 \%$ & $0.5 \%$ & $0.4 \%$ & $0.2 \%$ \\
\hline Persons reporting two or more races & $5.1 \%$ & $5.1 \%$ & $4.9 \%$ & $2.9 \%$ \\
\hline Persons of Hispanic or Latino origin & $28.8 \%$ & $32.0 \%$ & $37.6 \%$ & $16.3 \%$ \\
\hline Caucasian persons not Hispanic & $45.1 \%$ & $48.5 \%$ & $40.1 \%$ & $63.7 \%$ \\
\hline \multicolumn{5}{|l|}{ Education } \\
\hline High school graduates & $87.3 \%$ & $85.8 \%$ & $81.5 \%$ & $86.3 \%$ \\
\hline Bachelor's degree or higher & $42.3 \%$ & $35.1 \%$ & $31.0 \%$ & $29.3 \%$ \\
\hline \multicolumn{5}{|l|}{ Income } \\
\hline Per capital money income in past 12 months & $\$ 33,789$ & $\$ 31,043$ & $\$ 29,906$ & $\$ 28,555$ \\
\hline $\begin{array}{l}\text { Median Household Income (in } 2014 \text { Dollars), } \\
2010-2014\end{array}$ & $\$ 65,753$ & $\$ 63,996$ & $\$ 61,489$ & $\$ 53,482$ \\
\hline
\end{tabular}

Note. From 2010 U.S. Census Data and "U.S. Census Bureau Quickfacts," by U.S. Census Bureau (n.d.).

The San Diego Chargers. The NFL Chargers franchise began in the American

Football League (AFL) in San Diego in 1960 ("History," 2016). The Chargers played in the AFL until the league merged with the NFL in 1970. The Chargers began to play in San Diego Stadium, also known as Jack Murphy Stadium (and now known as Qualcomm Stadium) when it opened in 1967 (“Chronology 1959-1969,” 2016). The Chargers played in Qualcomm Stadium for 50 years. Table 2 displays the team's attendance records for each season since 2001. The Chargers maintained an average attendance record over the 15-year span, compared to the rest of the NFL. 
Table 2.

$\underline{\text { San Diego Chargers Annual Attendance Records in Qualcomm Stadium. }}$

\begin{tabular}{lllll}
\hline Season & $\begin{array}{l}\text { Game } \\
\text { Average }\end{array}$ & $\begin{array}{l}\text { Total } \\
\text { Attendance }\end{array}$ & $\begin{array}{l}\text { Average } \\
\text { percentage of } \\
\text { capacity** }\end{array}$ & League Rank \\
\hline 2001 & 59,355 & 474,844 & 83.0 & $\mathrm{n} / \mathrm{a}^{*}$ \\
2002 & 61,871 & 494,973 & 86.5 & $\mathrm{n} / \mathrm{a}^{*}$ \\
2003 & 59,878 & 419,151 & 83.7 & $\mathrm{n} / \mathrm{a}^{*}$ \\
2004 & 60,682 & 485,462 & 84.8 & $\mathrm{n} / \mathrm{a}^{*}$ \\
2005 & 66,239 & 529,916 & 92.6 & $\mathrm{n} / \mathrm{a}^{*}$ \\
2006 & 66,378 & 531,031 & 93.1 & $20 / 28^{*}$ \\
2007 & 65,502 & 524,019 & 91.9 & $20 / 28^{*}$ \\
2008 & 68,138 & 545,107 & 95.6 & $16 / 32$ \\
2009 & 67,543 & 540,345 & 94.7 & $18 / 32$ \\
2010 & 65,530 & 524,241 & 91.9 & $21 / 32$ \\
2011 & 65,392 & 523,143 & 91.7 & $19 / 32$ \\
2012 & 59,964 & 479,716 & 84.1 & $28 / 32$ \\
2013 & 64,205 & 513,641 & 90.1 & $22 / 32$ \\
2014 & 65,432 & 523,457 & 91.8 & $21 / 32$ \\
2015 & 66,772 & 534,180 & 94.6 & $19 / 32$ \\
\hline
\end{tabular}

Note. Figures from ESPN, 2016b.

* Some reported attendance data is missing.

**Based on a capacity of 71,500.

A brief review of recent publicly funded stadiums in San Diego. The city of

San Diego has funded one other professional sport stadium: Petco Park, home of the

MLB San Diego Padres. The Padres shared Qualcomm Stadium with the Chargers until

Petco Park opened in 2004. After a citizen taskforce assessed the Padres financial

statements and determined the team would no longer be financially viable sharing

Qualcomm Stadium, a baseball-only facility was recommended to be built in the East

Village as a part of a larger downtown revitalization project (Shepard, 2014). The

proposed project was put to a vote in November 1998, and was approved by $60 \%$ of

voters (Shepard). The final project cost was $\$ 456.8$ million with $\$ 153$ million from the 
Padres, \$21 million from the Port of San Diego, \$225 million of public funds through hotel taxes, and \$57.8 million from redevelopment funds (Shepard). Petco Park and the surrounding area was financed and managed by a redevelopment agency. The redevelopment agency, an extension of the city of San Diego, was also charged with revitalizing the area and had the capacity to collect all property tax in blighted areas (Halverstadt, 2015). The city hit an economic crisis in 2009 and City Council voted to have the redevelopment agency cover the entire $\$ 11.3$ million in annual ballpark debt through 2032 (Halverstadt). Then in 2012, the governor of California made a move to shut down all redevelopment agencies across the state in order to retain taxes lost, leaving the repayment of Petco Park construction up for question, and potentially in the hands of the taxpayers (Potter, 2015).

In addition to Petco Park, Qualcomm Stadium has received a number of publicly funded renovations in the past 30 years. The city of San Diego, which owns and operates Qualcomm Stadium, funded two renovations to the stadium - 1984 and 1997 ("Stadium history," 2016). The 1984 renovations cost $\$ 9.1$ million and added almost 10,000 seats and 50 suites. The 1997 expansion added 10,500 seats, 34 suits, 4 club lounges, and two video boards for $\$ 78$ million. This renovation also included a separate practice facility for the Chargers. After the 1997 renovation, Qualcomm purchased the naming rights for the stadium through 2017 for \$18 million ("Stadium history," 2016).

Current situation. In January 2015, the San Diego Chargers declared its intention to relocate to Los Angeles, California, along with the Oakland Raiders and the St. Louis Rams. NFL ownership voted and approved the Rams to relocate to Los Angeles, and provided the Chargers with the option to declare relocation within a year 
(Farmer \& Fenno, 2016). With the threat of relocation looming, San Diego political elites offered financial support. Initially, San Diego County pledged \$125 million upfront to get the stadium project started, for a total of $\$ 150$ million towards the project, and the city of San Diego pledged to provide $\$ 200$ million towards the $\$ 1.1$ billion stadium project (Lewis, 2015).

The Chargers took matters into their own hands, and presented a stadium financing plan to the public in March 2016 for a $\$ 1.8$ billion downtown stadium and upgrades to the convention center (McSwain \& Weisberg, 2016). The plan, deemed the Citizen's Initiative, proposed a $4 \%$ increase to the hotel room tax from the current rate of $12.5 \%$ to $16.5 \%$ (McSwain \& Weisberg). The Chargers and the NFL were to contribute a total of $\$ 650$ million to the overall project. The city was slated to raise $\$ 1.15$ billion from the increased hotel room tax, which should cover the stadium, adjoining convention center, and land costs (Garrick, 2016a). If approved, the city would own the stadium and the Chargers would commit a 30-year lease (McSwain \& Weisberg), ensuring the team's longevity in San Diego. Interestingly, the city council and mayor's office declined to offer support to the Charger's plan, despite their initial offer of support (Halverstadt \& Keatts, 2016).

In order to be included on the November 2016 ballot, the Chargers were required to petition for voter approval. The team needed to obtain at least 66,447 valid voter signatures supporting the proposal, which is $10 \%$ of the registered voters in the city of San Diego, a feat the team was able to achieve (Schrotenboer, 2016). Voters were able to vote for or against the Chargers plan in the November 2016 election. 
A somewhat competing proposal was also included on the ballot in November 2016. This competing proposal was submitted by environmental attorney Cory Briggs and former city councilwoman Donna Frye (Tatro \& Togerson, 2016). This plan, deemed the Citizen's Plan, proposed a tax increase from $12.5 \%$ to $15.5 \%$ on hotel rooms (Tatro \& Togerson). Instead of using this tax hike to fund a new stadium for the Chargers, the plan proposed to set aside 100 acres of land in Mission Valley where Qualcomm Stadium stands, and encouraged the city to repurpose the area for public use, an education center, and a stadium that would likely be designed to share with the San Diego State University football program and a Major League Soccer (MLS) team (Tatro \& Togerson; Weisberg, 2016). Importantly, if approved, the Citizen's Plan would have blocked any public money from going to the Chargers proposed stadium plan, preventing the expansion of the convention center and the development of a downtown stadium proposed in the Chargers' plan (Tatro \& Togerson). The Citizen's Plan did not call for raising public funds for a new Chargers stadium, but rather for an opportunity to fund another service in need of support. Voters were able to cast their ballots on both measures in the November 2016 election.

\section{Delimitations}

A number of delimitations exist in the current study. Primarily, this study is focusing on one market to examine the willingness to support a stadium construction project--San Diego, California. This case was selected because of its timeliness and fit with the purpose of the current study. The current study aims to examine professional sport stadium, public policy, and voter outcomes. San Diego may provide a snapshot of 
these issues as it faces a stadium referendum in the November 2016 election. Because of the case focus, the sample of the study is limited to the voting population in San Diego.

The current study's primary focus is the November 2016 stadium referendum; therefore, the study is bound in time to this instance, as the goal is to examine respondents' willingness to support the stadium referendum. There is a possibility that other cities and cases may arise in the next year. The researcher included San Diego as the focus due to timeliness and magnitude of the stadium construction project.

\section{Operational Definitions}

CVM: Contingent valuation method (CVM) is an environmental economic survey-based method frequently used for placing a quantifiable value on environmental goods and services not bought and sold in the marketplace such as park conservation and animal habitat maintenance (Carson, 2000).

Metropolitan statistical area (MSA): A core area with a high degree economic and social integration, which, along with bordering communities, contains a large population ("Metropolitan and Metropolitan, 2016).

Noneconomic/immeasurable/public good: Grounded in CVM environmental economic research, these terms will be used interchangeably to describe the variables and factors that do not carry any measurable value to them. For example, there is no quantifiable value attached to the quality of life a team may bring to a city or the civic pride one feels due to the existence of a local professional sports team. 
Economic/measureable value: Grounded in CVM environmental economic research, these terms will be used interchangeably to describe the variable and factors that maintain a certain value to them (e.g., job creation, economic impact, and new businesses).

Passive use/nonuse: Grounded in CVM environmental economic research, passive and nonuse is where individuals derive satisfaction from a product's mere existence but make no active use of the good or product, and may never intend to make active use of it (Arrow et al., 1993). For example, citizens of the United States may derive satisfaction from the existence and preservation of the Grand Canyon, though many may never visit the park.

Referendum: "A referendum is a direct vote by the people on a proposed law or an amendment. They are placed on the ballot usually by state legislatures or city councils" (Brown \& Paul, 2002, p. 255).

Stadium/venue/arena/ball park/facility: These terms will be used interchangeably to describe the home of the local professional team. Typically, a stadium is an open-air facility or domed venue with a seating capacity of over 20,000, an arena is a closed-air facility with a seating capacity of less than 20,000 , and venue and facility are general terms. Ballpark is typically synonymous with a baseball stadium.

Use/existence value: Grounded in CVM environmental economic research, use and existence value exist when individuals are able to make active use of the good or product. For example, an oil spill would affect the financial capacities of fisherman, as they would no longer have active use of the body of water due to the spill. 
Voters/constituents/residents: These terms will be used interchangeably to describe the local population affected by stadium construction project. 


\section{CHAPTER II}

\section{LITERATURE REVIEW}

Local governments have been spending valuable tax dollars on stadium construction projects to keep professional teams from leaving the area. The following literature review will examine a number of key factors in this study. First, stadium construction economic impact reports will be presented as a measure of quantitative benefits of a new stadium. Second, the qualitative benefits of stadium construction projects, called noneconomic benefits or public good, will be introduced and discussed, including the various attempts at quantitatively measuring these benefits. Third, a full body of research behind the contingent valuation method (CVM), an economic approach to measuring noneconomic benefits will be covered, and its criticisms will be presented. This method has been applied specifically to stadium construction projects, and the body of research is presented directly after the CVM criticisms. To build upon previous stadium research, the stakeholder approach is presented where various stakeholders involved in stadium construction projects are examined and classified. Finally, team identification as a potential influencer in a voter's willingness to support a stadium construction project referendum.

\section{Economic Impact}

Local governments and politicians have been placed under pressure to find a source of funding for a new stadium as franchise relocation looms, while still remaining 
loyal to the voting constituents. To gain support to use public funds to build professional sport facilities, politicians and key stakeholders have promoted the tangible economic impact benefits team and facilities may bring to an area such as new tax dollars and added job opportunities. Sanderson (2000) defined tangible benefits as,

A set of quantitative benefits such as increased business activity, greater employment and tax revenues in general, being able to import revenues from (or export services to) regional or national constituents, or the revitalization of a particular area of the city. (p. 176)

In relation to sport stadium construction projects, tangible, or economic benefits may be new construction jobs, in-stadium jobs, income taxes associated with player salaries, or tax revenue generated from in-stadium sales, to name a few. For example, the new NFL Minnesota Vikings stadium, which opened in 2016, was projected to provide 3,400 full and part-time jobs and generate over \$26 million per year in tax revenue (Conventions, Sports, \& Leisure, 2009).

The purpose of economic impact studies is to measure the change in economic activity from a specific program or project (Hudson, 2001). Specifically, with sport, economic impact is the net economic change a host community experiences due to new spending in the area, which can be attributed to a sport event, team, or facility (Crompton, 1995). Economic impact reports tend to come in two forms: ex ante and ex post. Ex ante studies are developed to estimate and project the number of out-of-town visitors an event or team is expected to draw, the number of days each spectator is expected to stay in the city, and the amount each visitor will spend each day (Baade et al., 2008). A typical ex ante study is commissioned by community officials, team, or event organizer to garner support from local residents. Politicians and key stakeholders utilize 
these studies to persuade the local population to support the stadium project proposal. For example, Cuyahoga County commissioners and local businesses promoted the significant economic development that would come along with the approval of the Gateway Project in Cleveland, Ohio, which proposed public funds to build a new baseball stadium, a new football stadium, and additional surrounding development plans (Mason \& Buist, 2013). Economic impact reports are also generated in response to the increasing pressures to hold local governments and politicians accountable for allocation and use of tax dollars (Crompton, 1995).

Governments rely on ex ante commissioned economic impact reports, which typically tell the municipalities what they want to hear-a team and/or facility will bring in enough new dollars to pay for the facility and then some (Dunnavant, 1989 as cited by Crompton, 1995; Noll \& Zimbalist, 1997). Ex ante reports offer economic impact estimations that often rely on poor methodology and suffer from several theoretical problems such as overestimation of the number of potential guests and their spending habits, the substitution effect, crowding out, and leakages (Baade et al., 2008; Hudson, 2001). For example, an ex ante economic impact study completed for the Commonwealth Games in Victoria, British Columbia in 1994 neglected to include a defined geographical region as a part of its analysis, which affected the magnitude of the multiplier (Crompton).

These methodological and theoretical issues have caused researchers to further investigate the economic impact of teams, stadiums, and mega-events such as the Olympics. In his analysis of 20 sport-related economic impact reports, Crompton (1995) found 11 various sources of economic impact report inaccuracies where most of the 
errors fell into two categories: (a) not differentiating new economic spending from total spending, and (b) incorrectly applying or interpreting multipliers (Zipp, 1996). An example of the errors found across economic impact reports can be found in the Knight Ridder News Service report (as cited by Baade et al., 2008) where the 1997 National Collegiate Athletic Association (NCAA) Women's Basketball Final Four was estimated to have an economic impact of $\$ 7$ million on Cincinnati, Ohio's local economy, but the same event was predicted to have an impact of $\$ 32$ million on the city of San Jose, California just three years later. When the MLB San Francisco Giants were looking to potentially relocate to San Jose in 1992, both cities commissioned economic impact studies. San Francisco's study found the team would bring \$3.1 million in economic impact while San Jose found the team to potentially bring in \$40-100 million each year (Crompton).

While commissioned ex ante economic reports have relied on imprecise measures of direct spending, ex post academic research has generally avoided estimating direct spending because of the difficultly in doing so (Zipp, 1996). Ex post studies are typically completed after the event, and are usually independent studies (Baade et al., 2008). Researchers rely on somewhat broad indicators of a municipality's economic well-being such as job growth and per capita income in ex post studies, though not in a consistent manner (Zipp). Ex post economic impact studies have resulted in far different conclusions than ex ante reports, specifically with economic impact developing from stadiums and franchises. The ex post economic impact studies frequently report that professional sports do not generate positive measurable economic impact on a 
municipality (see Baade, 1994, 1996; Baade \& Dye, 1988a, 1990; Baade et al., 2008; Coates \& Humphreys, 1999, 2002; Zipp).

In seminal work done by Baade and Dye (1988a) and Baade (1996), employment data was used to measure the economic impact of professional sports teams and facilities. Baade and Dye examined eight metropolitan statistical areas (MSAs) to examine a stadium's impact on the manufacturing sector. The manufacturing sector was chosen because hypothetically local stadium development should accelerate the national trend toward a service-based economy (Baade \& Dye). The authors posited that if local manufacturing is stimulated by professional sports entertainment, then stadium development may affect the service-manufacturing or occupational mix (Baade \& Dye). Manufacturing employment, manufacturing value added, and new capital expenditures were used to measure local manufacturing activity. Results showed that San Diego, California was the only city of the eight MSAs had a positive correlation between the existence of the professional baseball stadium and manufacturing employment and capital expenditures, while Cincinnati, Ohio was the only other city that showed a positive correlation with the professional football stadium and capital expenditures. Based on these results, Baade and Dye concluded that measurable benefits are not large enough to justify stadium subsidies. Baade and Dye also proposed that instead of focusing on the measureable benefits of a stadium or team, "stadium construction debates should focus on intangibles, or public good benefits accruing to taxpayers" (p. 47).

Comparably, Baade (1996) used employment data and per capita income to analyze the effect of a professional sports franchise on a metropolitan area's economic development. Employment data was based on the city's share of state employment in the 
amusement and recreation industry or the commercial sports industry to examine if sports teams and stadiums had a significant effect on the jobs in the commercial sport industry. Forty-eight cities (including 13 control cities with no professional teams) were analyzed over a 30-year period to examine whether the change in a city's real per capita income (adjusted for trends in economic activity) correlated with a change in either the number of new stadiums or new professional sports franchises a city acquired. The sample was also used to examine which professional sport team increased city spending and income through improving its balance of trade positions with the outside world. The results for per capita income were statistically insignificant for most of the cities due to statistical error. The results based on the employment data showed that in general, there was not a positive correlation between professional sports and job creation. Rosentraub (1996) later argued that Baade's inclusion of employment data provided skewed results due to the small nature of the professional sport industry. The professional sport industry in a city provides about $.06 \%$ of the jobs across 161 counties in the United States with at least 300,000 residents (Rosentraub). Chema (1996) also questioned Baade's inclusion of primarily suburban facilities, which were not intended to spark economic development. Chema suggested that the public should consider professional stadium construction as an investment in infrastructure, when a development strategy is in place.

There are a number of ex post economic impact studies focused on per capita income instead of employment data. Baade and Dye (1990) used per capita income to determine if the construction or renovation of a stadium or the adoption of a professional sports franchise correlated with an increase in a city's economic activity, and if a new or refurbished stadium for an NFL team or MLB team increased the municipality's share of 
regional economic activity. Nine MSAs were examined, and the researchers found that the presence of a new or renovated stadium had an insignificant impact on area income for all but one MSA (i.e., Seattle, Washington). Overall, the researchers concluded that the presence of a professional football team showed a significantly negative effect while the presence of a professional baseball team showed a significantly positive effect on area income; however, the number of games a professional baseball team hosts widely outnumbers the number of home games a professional football team hosts (i.e., 81 home games and 8 home games, respectively). In addition, four of the nine MSAs analyzed (Cincinnati, Ohio, Detroit, Michigan, Kansas City, Missouri, and Tampa Bay, Florida) showed that stadium construction or renovation was significantly correlated with a reduction in that metropolitan area's share of regional income. In other words, professional stadium construction may actually have negatively impacted a region's development (Baade \& Dye). It appears as though the presence of a new or renovated stadium has an uncertain impact on economic activity and possibly negative impact on local development (Baade \& Dye).

Coates and Humphreys (1999) extended the research done by Baade and Dye (1990) by examining per capita income in 37 MSAs that hosted a professional football, basketball, or baseball team over a 25 -year span to examine if the changes in the sport environment affected the level of per capita income in the MSA. In addition to the larger sample of MSAs, Coates and Humphreys also added variables-franchise entry and exit, stadium construction, and stadium capacity-while also accounting for the presence of an NFL, MLB, and/or NBA team. After including over 28 variables, results showed the sports environment in cities had a negative impact on average real level of income per 
capita, and the changes in the sports environment had no measureable impact on the growth rate of real per capita income over the 25-year span (Coates \& Humphreys). Since the results were less than appealing from a measurable economic impact concern, the authors suggested, "sports-led development strategies may not be effective engines of economic growth, but the presence of professional sports in a city may increase the overall well-being of the residents" (p. 622), which insinuated the focus of economic impact studies should shift towards the noneconomic benefits professional sport teams can produce.

Baade (1994) also conducted an empirical analysis on per capita income in 36 MSAs over a period of 30 years, focusing on "before and after" a professional sport team entered a market to measure the economic change in the MSA. This study included NFL, MLB, NBA, and NHL teams. Only five of the 30 MSAs were found to have statistical significance, leading to the conclusion that professional sports teams generally have no significant impact on a metropolitan economy, while $63 \%$ of the MSAs showed stadiums had a negative impact on the economic growth. Both Baade (1994) and Baade and Dye (1990) found that stadium construction tends to have a negative effect on a local economy. Even with this evidence, stadium construction remains a part of local and sometimes state-wide public policy.

Coates and Humphreys (2002) took a seemingly different approach to examining the economic impact a professional sports team has on a municipality by exploring how a team's post-season appearance may impact the local economy. Real per capita income for 39 cities that contained either NFL, NBA, or MLB teams over a 29-year span was examined against the home team's appearance in its respective post-season play. It was 
found that a local professional sports team that makes the playoffs does not affect the real per capita income of its home city unless the team wins the Super Bowl, specifically. The Super Bowl may cause change in the real per capita income as it may increase the productivity of labor following the game or it was simply an anomaly (Coates \& Humphreys). Interestingly, this study also found that hosting the Super Bowl had no measureable impact on real per capita income on the host city (Coates \& Humphreys).

In another approach, Zipp (1996) took advantage of the MLB player's strike of 1994 to examine the economic impact of local teams on their municipalities. The sevenweek absence of play during August and September 1994 was the parameter of time, while nondurable goods, retail sales, and hotel/motel room sales were used as the indicator of economic impact. The time during the strike was used to examine the degree to which the strike affected the economic sectors that should have captured most of the spending outside the ballpark (e.g., hotels, restaurants, gas stations, merchandise stores), which is key because economic impact is measured based off the spending of nonresidents. Twenty-four MLB cities were included in addition to four control cities without MLB teams. Results showed that the baseball strike of 1994 had little, if any, economic impact on host cities. Retail trade was almost completely unaffected by the strike, while greater-than-average increases in nondurable goods sales and total retail sales occurred during the two months of strike in over $70 \%$ of the cities with teams (Zipp). Hotel room sales were lower in ten of the 24 cities in both strike months. The relationship between a city's economic performance before and during the strike essentially was no different for cities that hosted teams and those that did not. Zipp also implored future research and additional emphasis on the noneconomic benefits that sport 
teams provide a city such as civic pride, living in a major-league city, and local residents' overall psychological health.

Comparably, Baade et al. (2008) used taxable sales data to estimate the economic impact in select MSAs in Florida (i.e., Miami-Fort Lauderdale, Tampa-St. Petersburg, Orlando, and Jacksonville) over a 35-year span. Similar to Zipp (1996), the researchers examined the effect of sport labor interruptions on the local economy. Taxable sales were utilized because it is the single largest component of gross domestic product. Taxable sales reports are also published monthly or quarterly and can cover areas as small as cities, unlike per capita income and employment data used in the previous studies, which is available annually and on larger scales (Baade et al.). Forty-three variables were used to examine the economic impact and included each of the professional sports leagues--NFL, MLB, NHL, NBA, and Major League Soccer (MLS)-any new facilities constructed, any labor interruptions in the leagues, and whether or not the MSA hosted all-star games and championship events, including those of the NCAA. Similar to Baade (1994) and Baade and Dye (1990), results showed in general, new stadiums, arenas, and franchises as well as mega-events appeared to be as likely to reduce taxable sales as to increase them. Similarly, labor interruptions in professional sports did not systematically reduce local taxable sales. This finding coincides with Zipp (1996) examination of how the MLB strike of 1994 affected the economic impact of host cities when examining retail and taxable sales.

Although many empirical studies have found no statistically significant positive correlation between professional teams and economic impact, and some have found a negative economic impact from teams and facility construction, facilities continue to be 
built on the notion of providing economic impact to a municipality. There are many reasons why professional sports do not have a large impact on a local economy, as outlined by Zipp (1996). First, most, if not all, sport teams are clustered in the top 30 markets while other industries are dispersed throughout the nation, making the sport team existence less impactful on the local economy. Additionally, the internal structure of the sports industry limits its local impact as most jobs associated with teams and the stadium construction project are low-wage, part-time/seasonal positions, and many of the professional athletes do not live locally (Zipp). Finally, fan spending associated with teams leaves the area almost instantly due to nature of the concession and merchandise business (Zipp). Siegfried and Zimbalist (2000) built upon this rationale with additional reasons why sport teams do not promote economic development for a city: its small business size, the substitution effect, extensive leakages, and the likely negative effect on local government budgets. When comparing revenues, the professional sport industry in a city provides about $.06 \%$ of the jobs across 161 counties in the United States with at least 300,000 residents, and pales in comparison to other companies located in cities, including universities (Rosentraub, 1996), thus building upon the reasons why economic impact studies have become moot.

\section{Summary}

Economic impact reports are commissioned to provide quantitative evidence supporting the public's investment into the stadium construction policy and to hold local

governments and politicians accountable for allocation and use of tax dollars (Crompton, 1995). Economic impact reports are typically commissioned by governments who want to attract a team, local business interests who want to build an arena, or a professional 
sport team that want public subsidies to fund stadium construction (Danielson, 1997).

Alas, many of these reports have found that professional teams are too small a component of any economy to lead economic changes or to propel large-scale redevelopment efforts (Rosentraub, 1997). In addition, a large body of economic impact studies have yet to find positive impact of a team on a municipality (Baade, 1994, 1996; Baade \& Dye, 1988a, 1990; Baade et al., 2008; Coates \& Humphreys, 1999, 2002; Zipp, 1996), further contrasting from economic impact reports commissioned ex ante. Nevertheless, ex post academic economic impact reports have also been widely ignored, discredited, or criticized according to qualitative data collected from over 70 political leaders, corporate executive, team owners, and leaders of stadium construction opposition groups (Delaney \& Eckstein, 2003). Additionally, these reports exclude any data from the local constituents, many of who will eventually fund these stadium projects. Because of this, some sport economists have stressed a shift of focus from measureable economic impact to the noneconomic benefits to garner support for stadium construction projects (Baade \& Dye, 1988a, 1990; Coates \& Humphreys, 1999; Noll \& Zimbalist, 1997; Sanderson, 2000; Zipp, 1996).

\section{Noneconomic Benefits of Professional Sport Teams}

While the value of measureable positive economic impact of professional sports teams and their facilities is debatable, the question of the value of noneconomic benefits remains wholly unanswered. Noneconomic benefits or public goods created by the existence of local professional sports teams have been offered as an alternative to promoting measureable benefits by numerous sport economists (Baade \& Dye, 1988a, 1990; Noll \& Zimbalist, 1997; Sanderson 2000; Zipp, 1996). 
The use of the social constructions of community self-esteem and community collective conscience by political and business elites is a more recent strategy used by powerful stakeholders to garner support for public funds to achieve their own interest (Eckstein \& Delaney, 2002). Noneconomic benefits like civic pride, living in a major league city, and increased quality of life have shifted the conversations when it comes to professional stadium construction projects as economic impact reports become moot due to their inaccuracies and inconsistent methods.

The existence of local professional sport teams as a noneconomic and unobserved construct can potentially provide stakeholders with an opportunity to promote a stadium construction project that may be valued by constituents but is not necessarily connected to a monetary value. In other words, the existence of a local professional team may be invaluable to a local resident, whether they attend games or not. These noneconomic benefits highlight the value of the existence of the team, rather than the potential financial gains highlighted in economic impact reports that may (or may not) bring to the local economy. Focusing on noneconomic benefits has proved successful in various stadium construction projects across the United States including Cincinnati, Ohio (Brown \& Paul, 1999). Therefore, it would benefit political, business elites, and key stakeholders to focus more attention on evaluating the noneconomic benefits impact in order to garner support for public subsidies for stadium projects. The major concern with utilizing the noneconomic benefits strategy is the unobserved and unquantifiable nature of these benefits.

Noneconomic benefits, also called public goods include civic pride, increased quality of life, the enjoyment of reading about and discussing the team, national publicity 
for the city, and living in a major league city. Carson (2000) defined pure public goods as "those for which it is impossible to exclude people from enjoying the good and from which enjoyment by one person does not degrade another person's enjoyment of the good" (p. 1414). A fan's enjoyment of reading about the local team or discussing the team does not reduce the opportunity for other fans to partake in the same activities.

Though none of the previously discussed economic impact research attempted to directly measure public goods, the value does not go unnoticed or without merit as Johnson (1986) discussed:

The recognition by local officials of a sports team's intangible value should not be criticized. Municipalities invest in many activities that have no direct payoff but presumably are of intangible value. Concert halls, theaters, museums, and even zoos are good examples. The "psychological health" of a city is just as important as its fiscal condition. Thus, investment in cultural and recreational activities is a common and expected practice of municipal government. (p. 423)

The noneconomic value of professional sports teams cannot be ignored. Crompton (2004) proposed four alternative sources of spillover benefits to support stadium construction projects: increased community visibility, enhanced community image, stimulation of other local development, and psychic income. Crompton also proposed that stadium construction project proponents invest funds in commissioning studies that measure the psychic income created by professional teams or events instead of funding faulty economic impact studies, placing a high value on the noneconomic benefits that a professional team can provide.

There have been a number of attempts toward examining the noneconomic value of professional sports teams. Using a hedonic regression approach, $\mathrm{Tu}$ (2005) and Carlino and Coulson (2004) attempted to estimate the existence value of stadiums and 
professional teams using property values and rent and wages, respectively, as measures for quality of life. Tu used the property values based on sale prices around FedEx Field, home of the NFL Washington Redskins, before, during, and after the stadium was built and found that the closer the property was to FedEx Field, the greater the price improvement. Utilizing rent values, Carlino and Coulson found the presence of an NFL team raised the annual rent in the central part of the city by $8 \%$. This finding suggests that the presence of an NFL team can prompt economic growth and development. Though both studies were found to have significant methodological issues with data and statistical analysis (Coates, 2007; Coates, Humphreys, \& Zimbalist, 2006), and the exclusion of other venues as they would relate to property values (Coates), their attempt to value a team's public good should not go unwarranted. Tu, and Carlino and Coulson were able to bring attention to the value of external and noneconomic benefits that the presence of a professional team can provide to the local citizens such as higher property values.

Irani (1997) also attempted to quantify the noneconomic value of professional sports teams. Irani measured the dollar value of a city's welfare gain from the existence of a professional sports team through net consumer surplus. Net consumer surplus was operationalized as the difference between what sports fans would be willing to pay for a sporting event versus what they actually pay. Using a time-series of seat-weighted MLB ticket prices for each ball park from 1972 to 1991 in a Marshallian demand curve, Irani found the net consumer surplus of a stadium ranged between $\$ 2.2$ million and $\$ 54.1$ million, concluding that stadiums provide substantial welfare gain to a city, but not enough to cover the costs of stadium construction projects. 
To extend the work of Irani (1997), Alexander, Kern, and Neil (2000) endeavored to estimate the private consumption benefits acquired from attending professional league games. Private benefit was operationalized as the consumer's surplus from attendance at the games. Relying on a sample of professional sports teams that recently had a new stadium proposed or completed, Alexander et al. used ticket sales revenues from 1996 with a price elasticity of demand ranging from .5 to 1.5 to uncover that for most franchises in the NFL, MLB, NBA, and NHL, the consumer surplus from attending games may be insufficient in justifying building a stadium at the expense of the public, based on the benefit-cost concept.

Swindell and Rosentraub (1998) reviewed the economic benefits from local sport teams in Indianapolis, Indiana and other civic assets of the area and analyzed the noneconomic benefits. Although museums generated the most civic pride in the sample (4.27 average out of 5), the NBA Indiana Pacers were ranked right behind it at 4.26, while the NFL Indianapolis Colts were ranked third with 4.07. Respondents held the annual Indy Car event, the Indianapolis 500, in the highest regard in terms of civic pride, defining the area's national reputation, when mentioning something that represents the area, recommended to visitors, and would hurt the area's reputation if it were to relocate. It is evident that the residents of Indianapolis value the existence of professional sports beyond measureable value. Likewise, Rosentraub (1996) compared the value of sports for identity, development, and the quality of life to performing arts, museums, libraries, or visual arts in relation to economic impact. These civic assets are often paid for and supported through government funds, yet provide little economic impact to a municipality. 
Further into his response to the research completed by Baade (1996), Rosentraub (1996) focused on promoting professional sports as a public good, a defining part of life and culture in the United States, an outlet used to convey political messages, and an opportunity to build emotional attachments. Specifically, the marketing and public relations efforts of cities through hosting professional teams are incomparable, as cities have received nationwide exposure without paying any direct public relations or marketing fees (Rosentraub).

Rappaport and Wilkerson (2001) recommended three different ways to measure the quality of life benefits hosting a major league sports franchise may bring. One way is to survey residents to determine their willingness to pay to keep their team from moving via the economics-based contingent valuation method (CVM). Another way is to compare quality of life benefits of a major league sports franchise with other attributes such as weather or cost of living. Finally, Rapport and Wilkerson suggested examining the experience of a city that has lost a professional sports team since they can compare happiness both with and without a team.

\section{Summary}

Despite the contrasting research and results regarding the economic impact of professional sport stadiums, public funds continue to be invested into these projects. Weary of team relocation, local government and stadium proponents often support public subsidy measures, many of which are approved by the voting population. Researchers have suggested focusing on the noneconomic benefits of a team (Baade \& Dye, 1988a, 1990; Johnson, 1986; Noll \& Zimbalist, 1997; Rosentraub; 1996; Sanderson 2000; Swindell \& Rosentraub, 1998; Zipp, 1996) instead of relying on faulty ex ante economic 
impact studies or ex post studies that concede that stadium investment is not a valuable economic investment. Instead, these projects should be looked at as an investment in infrastructure and quality of life for local constituents. Now it becomes a matter of how to measure these noneconomic benefits. Contingent valuation method (CVM) has been widely recommended as the next step (Baade, 2006; Coates, 2007; Rappaport \& Wilkerson, 2001; Walker \& Mondello, 2007).

\section{Contingent Valuation Method}

To broach the topic of measuring noneconomic benefits such as civic pride and quality of life, some sport management researchers have suggested utilizing the economic-based contingent valuation method (CVM or CV). Coates (2007) recommended the use of CVM as an avenue to examine the use and nonuse value of professional teams in an area. Crompton (2004) proposed that CVM is a potentially useful tool for measuring the public good value of a sports team. Baade (2006) suggested, "If a rationale exists for the funding of sports mega-events and professional sports teams, it will have to rely on contingent valuation" (p. 67). When compared to other valuation methods such as hedonic price models and the travel cost method, Walker and Mondello (2007) considered CVM to have more flexibility, while it also has the ability to estimate nonuse values and ex ante willingness to pay (WTP) when working with consumer uncertainty. Because there is overwhelming evidence that stadiums do not provide positive measureable economic impact, CVM has the potential to quantify the noneconomic benefit construct.

$\mathrm{CV}$ is a survey-based method frequently used for placing monetary values on environmental goods and services not bought and sold in the marketplace (Carson, 2000). 
CVM first came into use in the early 1960s when economist Robert K. Davis used questionnaires to estimate the benefits of outdoor recreation in a Maine backwoods area (Mitchell \& Carson, 1989). This method is called "contingent" because respondents are asked to give an amount they would be willing to pay, contingent on the hypothetical situation presented to them in the survey (Whitehead, 1995). Primarily, CVM has been widely used to measure the value of environmental public goods such as national parks, habitat conservation, and endangered species protection (Mitchell \& Carson; Owen, 2006).

$\mathrm{CV}$ is a technique based upon either observed behavior toward some marketed good (such as a sport team) with a connection to the nonmarketed good of interest (such as a stadium or stated preferences) in surveys with respect to the nonmarket good (Freeman, 2003). In economic terms, markets allow consumers to make choices based on the amount they are willing to pay for a good or service (Bate, 1994). CVM is an attempt to bypass the workings of this true market process, since the market does not exist in these cases (Bate). In other words, there is no available market process for stadium construction projects as this product is not exchanged in a market.

CVM provides the researcher an approach to explore the public's willingness to pay (WTP) for a public good and allows economists to place a dollar value on goods or services not exchanged in a market (Loomis \& Walsh, 1997). The WTP value can be used to estimate an aggregated value for the sample population by calculating the sample mean and multiplying by the sample population (Freeman, 2003). Because of this, the WTP value elicited from CV surveys has been utilized in sport stadium financing research. CVM has been used to elicit the level of subsidy that residents would be 
willing to pay to support a new sports facility or to keep a team from leaving town (Atkinson et al., 2008; Castellanos et al., 2011; Fenn \& Crooker, 2009; Groothuis et al., 2004; Johnson \& Whitehead, 2000; Johnson et al., 2001; Johnson et al., 2006, 2007; Owen, 2006; Santo, 2007).

Although this method has been used in research prior to the 1990s (see Carson, 1995), one of the leading reference points is the National Oceanic and Atmospheric Administration (NOAA) Report on CVM completed by a panel of expert economists (Arrow, Solow, Leamer, Portney, Radner, \& Schuman, 1993). The panel was summoned in reaction to the Oil Pollution Act of 1991 to establish procedures for assessing damages to or the destruction of natural resources resulting from an oil spill covered by the Act (Arrow et al.). Oil spills and similar natural disasters can affect use value because individuals are able to make active use of the good. For example, an oil spill would affect the financial capacities of fisherman, as they would no longer have active use of the body of water due to the spill. There is also the issue of passive use (herein referred to as nonuse value), where individuals make no active use of the good but derive satisfaction from its mere existence, even if they never intend to make active use of it (Arrow et al.).

The NOAA Report was also commissioned to further examine if CVM was a valid approach to measuring compensable losses in damage lawsuits involving environmental destruction, in a response to the State of Ohio v. Department of the Interior, 880 F.2d. 432 (D.C. Cir. 1989) case where nonuse damages were found to be among the losses for which trustees could recover (Arrow et al., 1993). After a series of CVM literature reviews and method analyses, the panel concluded that " $\mathrm{CV}(\mathrm{M})$ studies 
can produce estimates reliable enough to be the starting point for judicial or administrative determination of natural resources damages-including passive-use value" (Arrow et al., p. 43).

In addition to the overall recommendation that CVM could be used to determine the monetary compensation in judicial decisions, the panel provided a series of standard practices for CVM research. The report recommended the use of in-person interviews, binary discrete choice questions, careful description of the good and its substitutes, and suggested several different tests that should be included in the report on the survey results, among other things (Carson, 2000). A few of these recommendations were outlined by Portney (1994) and included (but were not limited to):

- relying upon personal interviews over the use of telephone surveys, and telephone surveys over the use of mail surveys;

- utilizing a referendum format where respondents should be asked how they would vote if faced with the issue at hand;

- beginning the survey with a scenario that accurately and understandably describes the expected effects of the program under consideration;

- reminding respondents that a willingness to pay for the program will reduce the amount they would have available to spend elsewhere in addition to reminding respondents of the substitutes for the good in question; and

- including follow-up questions to ensure that respondents understood the choice they were being asked to make.

Carson (2000) outlined an approach to assessing CVM studies, based on the NOAA Report and a review of existing CVM studies. Primarily, the survey instrument 
should contain face validity where the respondent is provided a clear and accurate scenario, and the WTP decision should be a plausible one. The respondent should be provided with enough information to make an informed decision but not overwhelmed with information regarding the good or the scenario. According to Carson, a quality CVM study should include the following:

- an introduction section that helps set the general context of the decision to be made;

- a detailed description of the good to be offered to the respondent;

- institutional setting in which the good will be provided;

- how the good will be paid for, including the payment period (e.g., taxes, voluntary payments, payroll deduction, lump sum, payment plan);

- method by which the survey elicits the respondent's preferences with respect to the good (e.g., open-ended, dichotomous, binary discrete);

- debriefing questions about why the respondents chose their specific response;

- questions regarding the respondent's attitudes and demographic information;

- implementation of focus groups and in-depth interviews to help determine the plausibility of the good and the scenario being tested;

- a sample population that is relevant for evaluating the benefits and/or costs of the proposed project;

- a sample size of several hundred to a couple thousand is necessary to achieve reliability;

- the mode of survey administration in relation to the survey's potential response rate (mail-in, telephone, in-person, etc.); 
- an equation that predicts WTP for the good as a function of several other variables in the survey (e.g., income, attitudes, use versus nonuse);

- a plan of action for dealing with outliers as CVM studies can be very sensitive to outliers; and

- the aggregated economic value of the good on per capita basis should appear reasonable (e.g., city, county, MSA, statewide).

Carson (2000), Arrow et al. (1993), and Portney (1994) are among the few economists that have outlined recommended guidelines when working with CVM. Unfortunately, many inconsistencies remain with this approach and criticisms flourish.

\section{Criticisms of Contingent Valuation Method.}

Despite its reception by the NOAA and other notable economists, CVM has received strong criticisms across the economics discipline. Primarily, economists question the use of CVM mostly due to its hypothetical nature (Diamond \& Hausman, 1994). Economic research typically relies on observed behaviors; therefore, the dependence of hypothetical situations reduces CV survey reliability (Niewik, 1992).

Typically, CV surveys provide respondents with background information on the situation along with information about the hypothetical change in the situation (e.g., the team relocating if it is unable to secure a new stadium locally) and how the payment will be collected (Bate, 1994). With this information, respondents are then asked to provide their maximum willingness to pay toward the hypothetical situation (Bate). Much of the criticism stems from the hypothetical nature of the survey question, but a number of other criticisms also exist. 
Hypothetical bias. The hypothetical nature of CV surveys suggests that hypothetical bias exists as the tendency for respondents to overstate their WTP since the issue at hand is more than likely improbable. The WTP value requested in CV surveys may merely represent numbers the respondent somehow developed to address the hypothetical situation presented in the survey (Niewik, 1992). Because CV surveys are implemented to measure public goods not available on the market, respondents are obligated to develop a numeric value based on the hypothetical information provided. In addition, because of the hypothetical nature of CV surveys and the potential unfamiliarity of the subject, respondents rely heavily on the information provided, and can be potentially affected by the mode of the survey (e.g., telephone, email, mail, in-person), question wording, the question format (e.g., open-ended, closed-ended, dichotomous), among other things (Niewik).

Another consequence of the hypothetical nature of $\mathrm{CV}$ surveys is its reliance on cognitive functions to express economic preferences (Diamond \& Hausman, 1994). Responses to CVM surveys can be viewed as expressions of attitudes toward the good in question where the respondents are required to state in dollar terms (Diamond \& Hausman). Simply stated, the value respondents are asked to put toward the good in question can be seen as a representation of their attitude toward the good. For example, if a respondent is domiciled near the proposed stadium site and foresees impending traffic issues due to the construction of a new facility, they may choose a lower WTP to deter the construction, despite their feelings towards the team. CVM results can potentially be "uncertain, subjective, and speculative" (Bate, 1994, p. 16). Diamond and Hausman stated, "expressed preferences are not an expression of true economic preferences" 
(p. 48), therefore undermining the valuations developed from CV surveys as not true economic expressions. When applied to sport stadium research, respondents may construe their true economic preference with their preference to support the team, and rely more on how they identify with a team more than whether or not they truly are willing to pay additional taxes to keep the team from leaving the city. Diamond and Hausman were adamant about CVM simply representing an opinion poll instead of true economic value, and proposed that CVM results be used in conjunction with expert opinion when dealing with public policy. Beyond the issues with the hypothetical nature of CVM, there are a number of methodological issues that are worrisome to economists.

Question formats. Question format has remained inconsistent over CV research, mainly with the use of open-ended questions versus dichotomous ones. Open-ended questions allow the respondents to list their own value of the good in question, while dichotomous options provide the respondents with specific choices.

Freeman (2003) proposed open-ended questions were the easiest to interpret as respondents are asked to state their maximum WTP for an environmental improvement or to avoid a loss. Open-ended questioning suffers, though, due to the higher chance of presenting respondents with an unfamiliar scenario, leading to higher rates of nonresponse to the valuation question or high proportions of implausibly high or low stated values (Freeman). Professional sport teams in a municipality are potentially a salient issue for residents, though not everyone gets use value from them. Although open-ended questions allow respondents to place a true monetary value on how much they would be willing to pay for a good, this route leaves room for a significant amount of nonresponse zeros or "protest zeros." 
On the other hand, dichotomous questions "force" respondents to accept a specific value to represent their WTP value. Although it only poses a "yes or no" question, it provides a simple decision for respondents and places them in relatively familiar social context (Freeman, 2003). This format provides respondents with a "take-it-or-leave-it" option, making it statistically inefficient and requires a large sample (Walker \& Mondello, 2007). Freeman recommends randomly assigning WTP values to subsamples in order to minimize bias. Dichotomous questions are also subject to a high response of protest zeros. Protest zeros have been seen to be an issue within CVM research and will be covered more in depth in the following section along with issues related to scope, temporal embedding, and warm glow.

Protest zeros. Protest zeros occur when respondents reject some aspect of the hypothetical scenario presented by reporting a zero value even though they may place a positive value on the amenity (Freeman, 2003). Protest zeros can also occur when a respondent chooses not to give a value to the good by not answering the valuation prompt.

While Diamond and Hausman (1994) suggested when managing protest zeros to "consider this zero not to be an accurate measure of preferences, on the assumption that people care about the resource" (p. 57), others have suggested other, more meaningful ways of managing these occurrences within the data. Freeman (2003) suggested the inclusion of a follow-up question asking respondents who choose to assign a zero value to the good to provide reasoning. Freeman also pointed out that the deletion of protest zeros can lead to item nonresponse bias if those who protest are systematically different in some respect from those who give nonzero responses. The management of protest 
zeros has been inconsistent across CVM research, as some studies delete these responses while others include them, or replace nonresponse with a mean imputation. Either way, protest zeros are a serious concern that can also bring about statistical bias as the results tend to be bimodal (Bate, 1994).

Scope issues. Scope refers to the sensitivity of the respondent to the hypothetical situation presented in the survey, and whether the respondents are willing to pay more for a good larger in scope, either in a quantity or quality sense (Carson, Flores, \& Meade, 2001). While CVM critics have claimed that evidence of scope insensitivity reveals respondents' unresponsiveness to the theoretical differences for the good in question, therefore essentially negating the method as invalid, supporters argue that scope sensitivity findings are an anomaly resulting from poor survey design (Walker \& Mondello, 2007). After a review of significant CVM research, Walker and Mondello concluded that a "familiarity with the resource and the hypothetical scenario surrounding the policy contributes more to the reduction of scope effects than any survey method" (p. 158). Survey design is crucial in CVM research because of its reliance on respondents' interpretation.

Temporal embedding. The embedding effect occurs when there is a tendency with WTP responses to be highly similar across different surveys, even when "theory suggests and sometimes requires the responses to be very different" (Walker \& Mondello, 2007, p. 155). The embedding effect usually comes from respondents' failure to consider the effect of their budget due to the nonexistence of individual preference for the public good and the hypothetical nature of the survey (Diamond \& Hausman, 1994). 
Warm glow. Respondents may choose a higher WTP value due to a sense of happiness experienced from choosing a larger WTP for a good cause. Within environmental studies involving CVM, respondents may experience a "warm glow" bias, where respondents experience elevated feelings of happiness due to supporting environmental causes (Diamond \& Hausman, 1994). Someone who is a season ticket holder or has a high level of fan identification for a team presented with a CV survey may choose to state a high WTP, without consideration of an actual budget, and may experience a sense of happiness because of higher support towards the team. The NOAA report suggested that when "warm glow" is suspected, responses should not be taken as reliable estimates of true WTP (Arrow et al., 1993).

Summary. Despite the criticisms of CVM and its methodology, all of which contribute to issues of internal consistency (Diamond \& Hausman, 1994; Walker \& Mondello, 2007), it has remained widely used in environmental research and has been introduced in the sport management field as a valuation method to measure the public good sport teams and facilities provide to a local constituent. Portney (1994) suggested CVM could be applied to other policies as "individuals may have existence values for many different goods, and the inclusion of such values in a regulatory analysis could markedly alter decision-making calculus" (p. 12). As previously mentioned, sport economists suggested focusing on measuring and promoting the noneconomic benefits of sport teams and facilities to the local voting population. Baade and Dye (1988a) suggested that "measurable economic benefits to area residents are not large enough to justify stadium subsides and the debate must turn to immeasurable benefits like fan identification and civic pride" (p. 37). Similarly, Noll and Zimbalist (1997) stated, 
"immeasurable benefits may be important: whether the value of the external benefits of a major league team to consumers really does exceed stadium subsidies is uncertain, but by no means implausible" (p. 58). Therefore, CVM can be an avenue to add value to the noneconomic benefits that a professional sports team brings to a municipality.

\section{Contingent Valuation Method in Professional Sport Stadium Financing Research}

CVM has been applied in sport facility research to attach a value to the noneconomic benefits of sport teams to further gauge how much residents would be willing to pay to keep their team from relocating, or to attract a new team or major sport event (Atkinson et al., 2008; Castellanos et al., 2011; Fenn \& Crooker, 2009; Groothuis et al., 2004; Johnson \& Whitehead, 2000; Johnson et al., 2001; Johnson et al., 2006, 2007; Owen, 2006; Santo, 2007). These studies have focused on developing a consumer value to attach to sport teams through use (e.g., attending games) and nonuse (e.g., talking about the team with friends) measures. The primary goal of many of these studies is to attempt to place a value on the public good the teams provide to the residents in order to justify subsidies for facility construction.

CVM is a technique based upon either observed behavior (revealed preferences) toward some marketed good (in this case, a sport team) with a connection to the nonmarketed good of interest (stadium) or stated preferences in surveys with respect to the nonmarket good (Freeman, 2003). Though there have been a number of CVM-based studies in professional sport facility research, there have been inconsistencies with the types of variables included (hypothetical versus actual), types of questions asked (open- 
ended versus dichotomous), type of funding requested (tax or voluntary), payment period (e.g., 1 year, 5 years, 10 years), and payment amount (e.g., $\$ 0, \$ 5, \$ 10, \$ 15$, and so on). Despite these inconsistencies and criticisms, particularly within its methodological approaches, CVM has provided sport economists and others the opportunity to measure use versus nonuse and add value to noneconomic benefits, such as civic pride.

The sport-focused CVM literature asks participants, hypothetically, how much they would be willing to pay to keep a sports team from relocating, whether financing a stadium construction project or purchasing the team as a municipality. The WTP values are usually posed in the form of additional taxes. Empirically, an attempt to measure noneconomic benefits, or public good a local sport team may bring to a community has been assessed through CVM by inquiring about how much a person may read about the team, discuss the team with others, watch the team on television as well as how the existence of a local team may increase the quality of life and the value of living in a major league city (Castellanos et al., 2011; Fenn \& Crooker, 2009; Johnson \& Whitehead, 2000; Johnson et al., 2001; Santo, 2007). Sport stadium CVM research has been applied to real circumstances such as the London Olympics bid (Atkinson et al., 2008) and the NFL's Minnesota Vikings threat to relocate (Fenn \& Crooker, 2009), while most other studies presented hypothetical situations. CV surveys have also been employed prior to a referendum in order to gauge residents' views and WTP contributions to better grasp what level of subsidies might be approved (Groothuis et al., 2004; Santo, 2007). The following section provides an overview of CVM research in stadium financing. 
Johnson and Whitehead (2000) conducted the first sport-based CVM study in relation to local residents' willingness to pay for a new arena for the University of Kentucky (UK) basketball team and a new baseball stadium to attract a minor league baseball team to the area. A mail survey utilizing a dichotomous question format was implemented with a total of 230 usable surveys (51.1\% response rate). Nonrespondents were assumed to have a zero WTP value in this study. The public good variable in this study included: reading about the team, talking about the team, level of fan loyalty (UK basketball only), and quality of life improvement. The nonuse values for both UK basketball and the minor league team were positive and statistically significant and were found to represent a small percentage of the total WTP for both scenarios. Ultimately, the proposed construction costs for both projects far outweighed what the residents were willing to pay based on the use and nonuse values found. The inclusion of UK as a hypothetical situation was a bit misleading, as the university would find it impossible to relocate in the case that the residents refused to provide a subsidy for a new arena. CVM would be best applied to a situation where an actual threat of absence exists, as recommended by Diamond \& Hausman (1994). Regardless of a new arena or not, UK basketball will always be in Lexington, Kentucky; therefore, residents would feel less apt to pay taxes to fund a new arena, feeding into the hypothetical bias issue of $\mathrm{CV}$ responses.

Next, Johnson et al. (2001) conducted a CVM study on the NHL Pittsburgh Penguins as the team faced potential bankruptcy and possible relocation in the late 1990s. The survey presented two scenarios--the Penguins potentially leaving the city, or the team being purchased by the city and becoming publicly owned at the cost to the 
taxpayers. Unlike the previous study, residents were asked to purchase the team as a municipal, instead of building the team a new arena. This study was more credible than Johnson and Whitehead (2000) as it focused on the potential relocation of the Penguins, something the team was struggling with publicly, reducing the hypothetical bias. Unfortunately, the survey for this study was disseminated after a judge issued a permanent injunction against ownership relocating the Penguins; therefore, the threat to relocate was reduced.

The survey for this study was mailed to 900 randomly chosen homes in the Pittsburgh MSA with a 35.6\% return rate (293 usable surveys). The researchers also distributed 200 surveys on cars parked at the hockey arena during a home Penguins game (.08\% response rate). This survey utilized a dichotomous question format in addition to double bound questioning, where respondents were asked if they would be willing to pay extra taxes and how much they would be willing to pay. Similar to Johnson and Whitehead (2000), respondents who did not return the survey were assumed to have a zero WTP value. The public good variable included: reading about the team, talking about the team, level of fan identification with the team, and quality of life improvement. The researchers also included a measure of whether or not the respondent watched and/or attended the Stanley Cup finals in which the Penguins competed. The WTP value for the Penguins was $\$ 5.57$, where nonuse value was found to be $\$ 4.08$ and use value was significantly lower at $\$ 1.49$, showing that consumption of public goods affected WTP more than attendance did. The public good variable was positive and statistically significant on the WTP value, as it raised the WTP by a total of $\$ 9.24$ per year strengthening the case of public good as a plausible argument towards subsidizing a team 
or stadium construction. In this case, residents seem to get more value from the existence of the Penguins in Pittsburgh rather than attending the games. Other positive and statistically significant variables in this CVM model included whether or not the respondent attended a Penguins game during the previous season, the number of Penguin games attended, and whether or not the respondent attended/watched the Stanley Cup when the Penguins competed.

Groothuis et al. (2004) extended the research on the Pittsburgh Penguins relocation situation by considering the use and nonuse benefits of the other two professional teams in Pittsburgh, Pennsylvania-the NFL Steelers and MLB Pirates-both of which were requesting new facilities, as well as other local civic assets such as museums, universities, and zoos. This study concentrated on measuring the civic pride these amenities provide a resident as well as if the respondent supports the use of state funds for stadiums. This study also used mail surveys with dichotomous question formats to collect data. There were 199 usable surveys for this study due to lack of full survey completion. Respondents valued Carnegie Museum, Pittsburgh Zoo, and Carnegie Science Center highest among institutions that provided civic pride (an average of $.92, .91, .91$, respectively) while the Steelers, Pirates, and Penguins were ranked at .78, .73 , and .67 , respectively. Opponents of public funding for baseball and football stadiums were unwilling to pay to keep the Penguins in Pittsburgh. The WTP value was positive and significant for supporters of public funds for stadiums. Only a minority of respondents supported public funding for football and baseball stadiums or efforts to keep the Penguins in town. Civic pride benefit of a sports team was primarily found in citizens who attended games and who felt that sports generated civic pride for the community. 
Interestingly enough, it was found that only about $40 \%$ of the sample in this study supported public funding of the new stadium, and the same proportion of individuals voted for the sales tax referendum to allow for the stadium construction (Walker \& Mondello, 2007), which supports the CVM referendum approach recommended by Arrow et al. (1993). This research also extends the work done by Swindell and Rosentraub (1998) that compared Indianapolis sport products to other civic assets in the area.

Owen (2006) expanded sport-based CVM research by examining residents' WTP statewide, instead of city or countywide as in the previous research. Seven professional sport teams in the states of Michigan and Minnesota were included (i.e., Michigan: MLB Tigers, NFL Lions, NHL Red Wings, NBA Pistons; Minnesota: MLB Twins, NFL Vikings, NBA Timberwolves). The sample in each state was divided into three regions: the MSA where the team(s) was located, within 100 miles from the home MSA, and beyond 100 miles of the MSA. There were 250 surveys mailed out to two randomly chosen counties in each region for a total of 3,000 surveys. There were 962 usable surveys included in the analysis. This study was one of the first sport-based CVM studies to utilize an open-ended survey approach, allowing the respondents to choose any dollar value to represent their individual WTP. Interestingly, the majority of respondents (between 54\% and 70\%) answered "zero" for their willingness to pay for any of the seven teams. The analysis found that with the exception of the Detroit Pistons, willingness to pay steadily decreased as the distance from the team increased. The public good variable in this study was based on the interest level in the teams and it was found that both interest in the team(s) and attendance were statistically significant in relation to the WTP 
value for every team. With this said, Walker and Mondello (2007) suggested using team identification as a potential moderator to gauge affective responses towards the sport organization in order to assess referendum support from fans and nonfans alike.

Johnson et al. (2006, 2007) utilized a sample from Jacksonville, Florida to examine the willingness to pay to keep the NFL Jaguars in town and to recruit an NBA team. First, Johnson et al. (2006) examined how the order of the information presented would affect the amount the participants were willing to pay for the teams in addition to how much they would be willing to pay over a specific period of time. Johnson et al. (2006) was the first sport-based CVM study to test ordering and temporal embedding effect. The mail survey utilized a dichotomous question format. The survey was sent to 1,200 households in Duval County in Florida and 367 surveys were usable $(30.1 \%$ response rate). More than half of the WTP responses were zero, and discussion of the management of the protest zeros was not included. Respondents were found to be more willing to pay if they attended games, and the magnitude of WTP was greater for those who attended games and for those who had higher incomes. Respondents preferred to pay higher annual WTP amounts if the number of payment years was lower, a finding that was inconsistent with previous literature. No ordering effect was found on the NFL scenario but there was an ordering effect for the NBA scenario when presented first (i.e., WTP was higher), which could have been due to the respondents' lack of experience with an NBA team. Johnson et al. (2006) suggested that CVM studies should explicitly state the length of the payment period, which would provide a more accurate aggregate WTP and avoid aggregating WTP estimates over a longer period of time than the respondents actually receive. 
Further, Johnson et al. (2007) directly addressed the value of public goods generated by the Jacksonville Jaguars and a potential NBA team. A dichotomous choice survey was presented to the respondents to determine their individual WTP value in conjunction with a payment card of 10 or 20 years of added taxes. The public good variable included measures for how often people read about the Jaguars, discuss the team with others, listen to sports talk radio surrounding the team, and wear Jaguar team merchandise. This was the only sport-based CVM study to include the act of wearing team merchandise as a form of public good. This study also considered the participant's thoughts on whether the Jaguars improved race relations among the city's population, and if the Jaguars put Jacksonville on the map as a major league city. Both these variables had a positive (and statistically significant) influence on the WTP value for both the Jaguars and the NBA team. Income was also found to have a positive statistically significant relationship with the WTP value while age has a negative statistically significant relationship. The aggregate WTP value for the Jaguars was between $\$ 19$ million and \$52 million, and the aggregate value for the NBA team was between $\$ 11$ million and \$31 million.

Santo (2007) applied CVM to quantify the potential noneconomic benefits associated with the potential relocation of a MLB team to Portland, Oregon. This study varied from the aforementioned research because it used a telephone survey, included a referendum-based question, and also inquired about respondents' thoughts regarding the potential economic impact of an MLB team. Of the 2,583 eligible phone numbers, data from 310 respondents were used due to nonresponse with the household income question (12\% response rate). Double-bound questioning was also implemented in this study as 
respondents were presented with a randomly selected price to pay towards building a stadium in addition to being followed up with asking respondents what the maximum amount they would be willing to pay in taxes for the new stadium. Results showed that most respondents did not receive substantial use or existence benefits from the Portland sports scene, but their attitudes about the potential MLB team were more positive than their attitudes about the city's existing teams. Although their attitudes about MLB in Portland were more positive, respondents had overall negative feelings about supporting the public funding of an MLB stadium in Portland due to other pressing social issues, opportunity costs, and diverted public resources. About $54 \%$ of respondents indicated that they would not be willing to pay any additional taxes to build a new stadium. Consumption of the public good variable (i.e., reading about team, talking about team, improving Portland's national reputation, and the potential for the MLB team to improve the quality of life in Portland) was statistically significant and increased WTP by about \$4.41. Respondents were also asked about their attitude towards the current state of taxes in Portland, which was also statistically significant. Tax-averse respondents were willing to pay $\$ 6.44$ less per year in comparison to people who did not oppose these taxes. Respondents who felt like Portland had more important things to spend its money on were negative and statistically significant, where respondents were willing to pay $\$ 7.10$ less. A positive and statistically significant relationship was found between the WTP value and the economic development stadium construction brings $(\$ 4.67$ per person aggregated to $\$ 35.68$ million). The variables for the number of games a respondent would attend and their household income level were also positive and statistically significant. Santo revealed that residents believed in the economic 
development benefits of stadium construction, which was a significant determinant of WTP. In addition, Santo's study showed that noneconomic benefits may be more important to those who support public investment.

Atkinson et al. (2008) applied CVM to examine the willingness to pay for London's bid to host the 2012 Olympics. Unlike the other CVM studies, Atkinson et al. was the first empirical study to measure the noneconomic benefits from hosting a megasports event on cost-benefits grounds. This study also was highly credible, as it was executed before London won the bid but after the bid became public knowledge. Diamond and Hausman (1994) indicated that one of the biggest criticisms of CVM surveys is that if respondents do not find the scenario to be credible, then the responses lack meaningful information about the resource being studied. Therefore, the condition of this situation worked well for CVM as Atkinson et al. were able to avoid this criticism. Respondents were asked about the events' perceived costs (i.e., operating, event-related, infrastructure, and noneconomic costs such traffic congestion, crowding, and safety and security) and perceived benefits (i.e., income generated by event-related investments and event-related consumption, and noneconomic benefits such as national pride, legacy of sport facilities, and promoting healthy living) to examine their WTP value. A number of variables were also included in the model such as: if the respondent wanted to attend London 2012 events, if the recent Athens 2004 Olympics influenced the WTP response, and if the respondent believed London 2012 would be better than recent Games. Similar to Owen (2006), the study was executed in three different areas-London, Glasgow, and Manchester-to examine if there would be a decline in WTP value based on the households' approximate distance from London. The final instrument was executed via 
interviews in London, Glasgow, and Manchester with a sample of 602, 152, and 151, respectively. Forty-four protest zeros were given in response to the WTP question, which were removed from the dataset. The payment method options for the three area subsamples were different, since the Games were held primarily in London. The London sample was given the option to pay additional taxes for the Games for 10 years for an unspecified amount. The Glasgow and Manchester samples were given the option to pay to support the Games voluntarily. Ultimately, the aggregate value for Londoners was $£ 480$ million. The aggregate value from Glasgow and Manchester was applied to the rest of the United Kingdom at $£ 1,472$ million, for a total WTP for noneconomic benefits of $£ 1,952$ million. Results from the entire sample (i.e., London, Glasgow, and Manchester combined) found that income, city, if the respondent thought that London 2012 would be better organized as most of the recent host cities, the level of support for the London 2012 bid, if the respondent planned on attending any of the London 2012 events, if the respondent thought the London 2012 bid would be successful, and the noneconomic benefits of hosting the event were all positive and statistically significant on the WTP value. The length of payment was found to be negative and statistically significant on the WTP value, which showed that respondents were sensitive to the length of time their WTP value would be paid.

Fenn and Crooker (2009) used CVM to explore residents' willingness to pay under the threat of relocation, allowing the credibility of CVM to be studied and focus on the "realism" of the situation, using the NFL Minnesota Vikings as the case study. There were 1,200 surveys which utilized a dichotomous question format, and 565 were returned (42\% response rate). The study found that $47 \%$ of the respondents were willing to pay a 
predetermined amount for a new stadium for the Vikings. Fifty-five percent of the respondents felt that the team would leave if it did not receive a new stadium. The bid amount had a significant and negative effect on the respondents' WTP, while the public good variable (i.e., read about the team, discuss the team with others, level of fan identification, and quality of life improvement) was positive and significant. It was also found that respondents seemed more willing to pay because the stadium would bring more prestige to the area, lower the threat of the team relocating, potentially would be shared with the local university football team, and increase the chance of winning the Super Bowl. Consumption of the public good variable strongly affected WTP as regularly talking about or reading about the team each increased WTP by $\$ 41.15$. People who thought a new stadium would enhance the local area's prestige were willing to pay $\$ 83.90$ more. The researchers noted the bid options $(\$ 5, \$ 15, \$ 25$, or $\$ 100)$ may have been too high or too low based on the high WTP response rate (47\% of the respondents).

Lastly, Castellanos et al. (2011) applied CVM to analyze the WTP to keep a First Division football club (R.C. Deportivo de A Coruña) in the city of A Coruña, Spain. This study differed from previous research because the management of protest zero responses was determined prior to study dissemination, and the WTP question was executed through use of personal interviews and open-ended questions. The survey used in this study was duplicated from Johnson and Whitehead (2000) and Johnson et al. (2001) with one key difference-respondents were asked if they were willing to voluntarily pay. A total of 739 respondents were included in the data set (73.5\% response rate). Users, or those who went to games, represented $36.1 \%$ of the sample and were willing to pay more than twice the amount reported by nonusers. Both groups showed high levels 
of consumption of public goods generated by the team, but more with the user group. Thirty-nine percent of respondents reported a WTP equal to zero but an anchor question was added as a follow-up to the zero response. About $54 \%$ of the respondents who chose zero WTP stated that the team should be able to generate enough resources to keep themselves in the top division (132 of 292 responses). The estimated WTP was $11.78 €$ for the total sample, with an average of $9.63 €$ from nonusers and $2.14 €$ from users, mostly due to the high number of nonusers represented in the sample ( $\mathrm{n}=472)$. Household income, number of games attended or watched on TV, being a male, and the consumption of public good variable (i.e., talking about the team, reading about the team, concerned about the team, and quality of life improvement) had a positive effect on WTP. Interestingly, living within the city limits (A Coruña) had a negative effect on the WTP, which is inconsistent with the findings from Owen (2006), where the further a respondent lived from the main city, the lower their WTP value. Additionally, the higher the interest in the team and the higher the prestige value for A Coruña, the lower the probability of having a protest zero, while having a degree and being male had the opposite effect. The estimated nonuse value of the football team represented $81.8 \%$ of the average WTP for the whole sample, emphasizing the fact that residents get more value from the team through the sheer fact of having the team in the city, similar to Johnson et al. (2001).

Given the irregularity of the variables in the aforementioned CVM studies on sport stadiums, it is imperative to determine some sort of consistency so this research can be more applicable to stadium construction and development. Ultimately, the NOAA Panel considered the closed-ended question format combined with a referendum context the most desirable for contingent valuation. "The simplest way to approach the valuation 
problem is to consider a contingent valuation survey as essentially a self-contained referendum in which respondents vote to tax themselves for a particular purpose" (Arrow et al., 1993, p. 20). Hanemann (1994) also maintained the use of a closed-ended question in order to frame the valuation as voting in a referendum. Fort (1997) stated voting enables people to express their preference but not their level, or intensity of this preference. In a market, consumers are able to demonstrate their intensity of their preferences by demonstrating their WTP such as making a higher bid or buying a larger amount of the product (Fort).

Arrow et al. (1993) recommended the use of a referendum format where respondents should be asked how they would vote if faced with the issue at hand. Santo (2007) was the only study that employed a referendum format to examine how the residents would vote if faced with a referendum on the stadium proposal. The saliency and frequency of stadium referendums coincides with the CVM referendum recommendations (Arrow et al., 1993; Hanemann, 1994; Portney, 1994).

Summary. CVM research within sport facilities can potentially aid politicians with gaining support for facility subsidy referendum from local constituents due to its ability to allow residents to put a value on their local team. Noneconomic benefits may add to the justification of stadium subsidies, in addition to the measureable benefits (Baade \& Dye, 1988b; Noll \& Zimbalist, 1997). CVM also allows for ex ante studies, providing a different approach to the ex post research sport economists have relied upon thus far with economic impact studies. Unfortunately, CVM bears many criticisms, inconsistencies, and general issues to continue to be applied to sport stadium research. In addition, sport-based CVM studies has shown that aggregate willingness to pay value is 
typically well below the subsidy level requested for stadium construction projects far (Johnson, 2008). There also are other external variables that have not been accounted for in the sport stadium $\mathrm{CV}$ research. For example, research has suggested that an increased level of unity amongst politicians, media, and/or key members of the community can be related to the levels of public support for stadium construction projects (Delaney \& Eckstein, 2007, 2008; Duquette \& Mason, 2008; Mason \& Buist, 2013; Paul \& Brown, 2001, 2006). Therefore, it would be beneficial to further examine the role these influential stakeholders may have on constituents with stadium construction projects.

\section{Stakeholder Influence}

Stadium construction projects can affect or be affected by many people in a local community. Depending on the stadium location, tax financing proposal, opportunity costs, or potential ancillary revenues and expenses that may come with a stadium construction, various stakeholders can potentially affect the outcome, or be affected by the outcome, of these projects.

Notwithstanding, stadium construction projects are often left in the hands of the local constituents for approval in specific stadium referendums. Twenty-six professional stadium referendums were held between 1990 and 2000 in the United States, where 20 passed and six failed (Mondello \& Anderson, 2004). Additionally, there were at least six stadium referendums held between 2005 and 2014, where all but one passed (Kellison \& Mondello, 2014). Despite the inconsistency surrounding the support or rejection of a sport stadium subsidy, these referendums often see record voter turnouts. There was a $41 \%$ average voter turnout across 37 stadium referendums held between 1984 to 2000

(Paul \& Brown, 2001). Stadium construction projects often maintain saliency throughout 
a municipality due to the project's massive nature, its visibility, and potential affective connection with the local residents.

Fort (1997) posited that citizens are generally ignorant regarding ballot measures and are more susceptible to being influenced by external factors such as proponent groups. Additionally, politicians, the media, and key members of the business community, though they may have divergent interests, have shown success in swaying voters in supporting a stadium referendum (Brown \& Paul, 1999; Sage, 1993). Beyond these groups, there may be a number of stakeholders that can affect or are affected by a stadium construction project. For example, proponent groups are created to support and promote the stadium measure, while opponent groups almost instinctively appear as conversations of stadium projects arise (Fort, 1997; Freidman \& Mason, 2005; Sage, 1993). Additionally, neighborhood groups have been key factors in the ultimate decision of stadium location (Euchner, 1993; Pelissero, Henschen, \& Sidlow, 1991). These stakeholders, among others, are affected by or can affect the outcome of a stadium construction project. Therefore, it is imperative to further examine who the relevant stakeholders are in stadium construction projects and how they may affect or influence a voter's support of a stadium referendum.

\section{The Urban Regime}

In relation to local municipal growth and governance, urban regime theory suggests the existence of an elite group of stakeholders who represent informal coalitions of political and corporate elites who make key policy decisions for the local community (Duquette \& Mason, 2008; Stoker \& Mossberger, 1995; Stone, 1989). Stakeholders in the urban regime are those "who use their time and money to participate in local affairs 
... the ones who, in vast disproportion to their representation in the population, have the most to gain or lose in land-use decisions" (Logan \& Molotch, 1987, p. 62). The urban regime thrives in the behind-the-scenes world of politics, where deals are often crafted but influenced by threats and promise between stakeholders (Delaney \& Eckstein, 2007).

Stone (1989) suggested systemic power lives at the core of urban regime theory, where local governments are more concerned with the preferences of business leaders over other groups in the polity (Davis, 2002). Businesses may be able to exercise influence on urban policy agenda due to their control of productive resources in the community (Davis, 2002). This influence then provides businesses with pre-emptive power or "the capacity to occupy, hold, and make use of a strategic position" (Stone, 1988, p. 83). Pre-emptive power feeds into systemic power as it creates conditions favorable for businesses over other groups, tactically positioning them in relation to public policy development such as a stadium construction project (Davis, 2002). Stone (1989) also argued that local public officials make policy decisions based on the market and the economy, and not solely on the demands of the local business community. Despite the conflicting viewpoints, the urban regime of a polity shapes the city's politics, public policy, and strategy as regimes are often built and maintained on the power to potentially exercise pre-emptive power over another group, influence policy agenda, and exclude other groups from the policy process (Stone, 1980), eventually shifting to power over (Stone, 1993) other stakeholders. Additionally, the urban regime has better access and control of civic resources necessary for local development (Duquette \& Mason, 2008), strengthening its power over other stakeholders and policy development. 
Urban regime coalitions may differ from city to city, are often based on member makeup and their agendas (Pelissero et al., 1991), and are not necessarily entirely made up of only businesses. Two examples of urban regime coalitions are the corporate regime and the progressive regime. A corporate regime may consist of corporations located in the downtown area of a city (Elkin, 1987), while a progressive regime focuses on neighborhood groups and their specific agendas (Body-Gendrot, 1987). Depending on the city and case, corporate regimes may promote public stadiums and the public financial support of such ventures as a public good that provides entertainment to local citizens, a competitive edge for attracting businesses to the area, and prestige to the city (Pelissero et al.). In a similar fashion, a progressive regime may focus on how sport stadium construction sparks revitalization and redevelopment in certain areas and neighborhoods in a city (Whelan, 1987).

In their examination of stadium construction public policy, Duquette and Mason (2008) discussed how and why cities have shifted to an entrepreneurial-based strategy, how the partnerships among businesses and politicians have operated, and why sport has become a prominent part of this strategy. The urban regime in an entrepreneurial city is mostly concerned with developing the area as an attractive place and has done so utilizing a sport-based strategy that provides the city with an increased media profile and increased tourism (Duquette \& Mason). The urban regime in many cities has shifted to a sportbased strategy for community development, including the presence of sport franchises, major sport events, and sport facilities (Duquette \& Mason). The presence of a team allows the urban regime the ability to promote its city as "having more status than one without a team," specifically in relation to a city's perceived competition (Duquette \& 
Mason, p. 226). This idea of status focuses on growth, economic stability, and additional amenities to the area to attract businesses and improve quality of life for the citizens, supporting the urban regime local growth agenda (Duquette \& Mason). The urban regime focuses on pro-growth strategies that brand the local community as an attractive place to work and live (Duquette \& Mason).

One of the valuable qualities of applying urban regime theory is the ability to identify the public and private stakeholders and organizations with interests in local development (Duquette \& Mason, 2008). A critical quality of the being a part of the urban regime is that despite their various positions within a city, each stakeholder in the regime shares the unified interest of promoting the city (Duquette \& Mason). Stoker and Mossberger (1995) presented five general categories of stakeholders in the urban regime: business leaders, locally elected politicians, trade unions, local technocrats (e.g., government, development corporations), and members of community organizations. Public sector (e.g., mayors, city councilors, commissioners, bureaucrats, state legislatures) and private sector (e.g., corporate CEOs, local developers, local franchise owners, and media) are also included in the urban regime. More specifically, in their examination of the urban regime surrounding the stadium development projects for the MLB White Sox and NFL Bears in Chicago, Illinois, Pelissero et al. (1991) suggested that city government officials, team owners, large downtown corporations, developers, financial institutions, urban planners, fans, spectators, and those reliant on sport teams and stadiums for work were considered a part of the sport stadium urban regime.

Urban regime theory provides a macro level review of policy development in a municipality. A review of an urban regime in a city can provide insight into which 
stakeholders exist in relation to a sport stadium project. Both the public and private sectors are heavily involved with the development of stadium construction projects. Local business interests may lie with development and redevelopment of an area, while construction companies vie to build the project. The media may benefit in content and advertising with the addition of a new stadium and team. Due to the financial implications of stadium construction projects where the teams often request the use of public funds to support the projects, the public sector such as mayor, council people, and governors may be involved. The existence of the urban regime shows the nature of the decision making within a city, those who influence it and those who may be excluded. Once an urban regime has been recognized, more insight into the stakeholders involved with stadium construction projects may help in understanding their influence over voter outcome.

\section{Stakeholder Theory}

A micro level review of an urban regime involves a further examination of specific individuals and groups connected to the stadium construction project within the municipality. Stakeholder theory provides a framework of acknowledging and addressing these specific groups, or stakeholders.

Freeman (1984) presented seminal work on stakeholder management and aided in establishing it as a construct worthy of deeper examination. Stakeholders are "any group or individual who can affect or is affected by the achievement of an organization's purpose" (p. 46). The term "stakeholder" was first seen in management literature in 1963 in an internal memorandum at the Stanford Research Institute, bearing the definition of "those groups without whose support the organization would cease to exist" (Freeman, 
p. 31). Since Freeman's seminal presentation of stakeholder theory, it has become a broadly practiced and examined topic in academic disciplines such as organizational theory, marketing, organizational management, and sport management (Friedman, Parent, \& Mason, 2004). Within sport management research, stakeholder theory has been applied in the last 20 years to college athletics (Covell, 2005; Putler \& Wolfe, 1999; Trail \& Chelladurai, 2002; Wolfe \& Putler, 2002), mega events (Parent, 2008; Parent \& Deephouse, 2007), franchise relocation (Mason \& Slack, 1997), stadium financing (Friedman \& Mason, 2004, 2005; Mason \& Buist, 2013), and sport research with issues management (Friedman et al., 2004).

Some researchers have expanded on Freeman's (1984) seminal work on stakeholder theory, which has aided in its development as a well-rounded theory. Clarkson (1995b) further defined stakeholders as having "some form of capital, either financial or human, at risk and, therefore, has something to lose or gain depending on an organization's behavior" (as cited by Rowley, 1997, p. 889). Clarkson's (1994) riskbased stakeholder model focused on risk as the defining property of a stakeholder, where their position as stakeholders could be voluntary or involuntary (as cited by Phillips, 1999). Phillips further supported the risk-based stakeholder approach by suggesting that not all risks have the same degree or level. Clarkson proposed the existence of two stakeholder groups-primary and secondary. Primary stakeholders are pertinent to the organization's success, as the organization would fail to exist without the continued involvement of this group (Clarkson, 1995b, as cited by Rowley). Secondary stakeholders are people who affect or influence the organization (or are affected or influenced by the organization) but are not essential to the organization's survival 
(Clarkson, 1995b, as cited by Rowley). In relation to issues management, Friedman et al. (2004) further defined stakeholders as "a person or group of similarly oriented people who, with respect to the issue, possess at least one attribute of power, legitimacy, and urgency" (p. 22).

Donaldson and Preston (1995) discussed the application of stakeholder theory in management literature, primarily with how it has been advanced and justified. Stakeholder theory has been justified in management literature on the basis of its descriptive accuracy, instrumental power, and normative validity. The descriptive nature of stakeholder theory has provided empirical support for the theory, and has been used to describe and explain specific characteristics and behaviors of corporations and firms. This aspect of stakeholder theory has focused on reflecting and explaining the state of affairs for a corporation and its stakeholders, taking into account the past, present, and future. The instrumental application of stakeholder theory has been used to identify the connections (or lack thereof) between stakeholder management and the organization's ability to achieve its objectives such as profitability. Finally, the normative approach, the dominant approach, is used to interpret the management of a corporation by identifying its moral or philosophical guidelines. Unlike the descriptive and instrumental application of stakeholder theory, the normative approach "attempts to interpret the function of, and offer guidance about, the investor-owned corporation on the basis of some underlying moral or philosophical principle" (p. 72).

Donaldson and Preston (1995) suggested that stakeholder theory is normative at its core because it "appeals to underlying concepts such as individual or group 'rights,' 'social contract,' or utilitarianism" (p. 74). Critics have argued that these approaches are 
too simplistic based on the complex realities that organizations face (Wolfe \& Putler, 2002). Despite this criticism, the normative approach will be applied in this study to further examine the pertinent stakeholders' civic duties in relation to public policy, local residents, and the interests of the polity

Donaldson and Preston (1995) suggested the "ultimate managerial implication of stakeholder theory is that managers should acknowledge the validity of diverse stakeholder interests and should attempt to respond to them within a mutually supportive framework. ..." (p. 87). Because of the number of stakeholders involved with a stadium construction project, voluntary or involuntary, it is important for a focal stakeholder such as the professional team or politician to recognize these groups and their needs in order to garner support to induce the success of a stadium construction project. Involuntary stakeholders, though they are not invested in the organization, may still be at risk regardless (Clarkson, 1995b). For this reason, it is important to examine how influential these stakeholders may be on the voters' outcome. Stakeholder analysis provides an outlet to assess these various stakeholders involved and determine their level of influence.

Stakeholder development is centered on defining the stakeholder concept and classifying stakeholders into categories that can provide a better understanding of the various relationships (Rowley, 1997). Understanding who the key stakeholders are is vital to organizational success, as these stakeholders may maintain attributes that can hinder the organization from achieving its objectives. Friedman et al. (2004) proposed qualifications to address when determining who is a stakeholder. First, there must be a connection between the stakeholder and the organization. Second, the stakeholder must 
experience some level of self-interest in relation to the organization. Self-interest can play an important role when considering the makeup of stakeholder groups and how individuals form their opinions on political and public policy issues (Wolfe \& Putler, 2002). Donaldson and Preston (1995) posited that a stakeholder develops this salience in the organization's environment by their own interest in the specific organization.

Third, a stakeholder exists in an organization's environment due to the interest in the organization. In other words, a stakeholder relationship does not exist without some type of connection to the organization and some level of self-interest in relation to the organization. Further, Mahon and Waddock (1992) proposed that various stakeholders will perceive and act on an issue differently as they participate with an organization to protect and/or advance their interest. Friedman et al. (2004) also stated that one of the qualifications of stakeholders is that they may show variability in the way they are configured (e.g., individuals, groups, divergent interests).

Stakeholders often have a "stake," or a claim on the organization based on their bearing of risk (Phillips, 1999). A stake can be "an investment of money, time, or other resource in something that offers an opportunity for a profitable return in terms of achievement of the constituent's purpose and/or potential to suffer harm or bear costs from the actions of another" (Clarkson, 1995b, as cited by Friedman et al., 2004, p. 11). Stakes are an important aspect of stakeholder analysis because they may motivate stakeholder groups and potentially determine the group's priorities (Wolfe \& Pulter, 2002). Also, the degree to which members of the stakeholder groups are invested in these stakes is also a potential factor in discovering common priorities with a given issue (Wolfe \& Putler). Clarkson's (1995b) point regarding stakeholders holding some form of 
capital at risk, whether it is financial or human, builds upon the idea that without the element of risk, there is no stake (Clarkson, 1994 as cited by Mitchell, Agle, \& Wood, 1997). The larger the risk at hand, the more the stakeholder has to gain or lose; therefore, it is imperative to understand the type of stake involved to understand the level of investment from the stakeholder. Similarly, Friedman et al. (2004) posited that a stakeholder will make judgment on an issue based on whether or not the level of interests matches the organization and whether the issues is morally right or wrong.

Freeman (1984) suggested three broad categories of stakes: equity, economic (market), and influencer. Equity stakes are held by those stakeholders who have a vested interest in an organization, such as stockholders (Wolfe \& Putler, 2002). Economic or market stakes are held by those stakeholders invested in a company through economic interests and include employees, suppliers, and competitors (Wolfe \& Putler). Finally, influencer stakes are held by stakeholders who have interest in the company such as advocates, trade organizations, and government agencies (Wolfe \& Putler). Wolfe and Putler argued that stakeholders invested in equity or economic stakes are motivated by self-interest. Self-interest may only become a dominant factor in specific situations when potential repercussions to an individual are large, when the costs and benefits of obvious alternatives are certain, when the cons outweigh the pros, and when the individual can attribute responsibility for the issue to someone other than themselves (Wolfe \& Putler). For example, stadium construction projects are attractive to politicians and local political elites because they can generate opportunities for economic and political gain with little risk to those individuals (Danielson, 1997). The level of stakeholder involvement has a direct relationship with an individual or group's stake in the organization. Once the stake 
has been determined, the analysis moves toward determining which group is more salient, and therefore more influential in achieving the goals of the organization.

Stakeholder salience. Both Clarkson (1994, as cited by Phillips, 1999) and Phillips (1999) recognized that Freeman's (1984) definition of stakeholders was both broad and dual purpose, as it highlighted two very different groups-those who can affect the organization and those who are affected by it. This definition can be troublesome when determining what stakeholders exist and how invested are they in the organization as it potentially dilutes or disturbs the focus of the focal organization to the inclusion of various and numerous stakeholders that may or may not be vital its success. To clarify the stakeholder approach, Mitchell et al.'s (1997) stakeholder salience model will be applied.

Mitchell et al. (1997) proposed a theory of stakeholder salience through a dynamic model based on a group typology that recognizes situational uniqueness and managerial perception in order to explain how managers prioritize stakeholder relationships. Stakeholder salience is the degree to which managers give priority to competing stakeholder claims and is developed with the presence of one or more attributes in a stakeholder-power, legitimacy, and/or urgency (Mitchell et al.). Alone, each attribute separately affords stakeholders low salience. As stakeholders gain additional attributes, their position becomes more salient and more influential in managements' ability to achieve their goals. Notably, each attribute is a variable, not a steady state, and can change for any particular entity or stakeholder-manager relationship (Mitchell et al.). 
Mitchell et al.'s (1997) stakeholder typology is a useful tool for prioritizing stakeholders in relation to the focal organization. Friedman and Mason (2004) applied this typology to further prioritize stakeholders and to determine their saliency in relation to stadium construction projects, which will be further examined in the current study. Friedman and Mason developed a model specifically to assess and understand the sport stadium subsidy policy environment across the United States through a review of the various stakeholders highlighted in the literature. This stakeholder framework explored the changing roles of different stakeholder groups and individuals involved in the intricate process of stadium construction policy decision making and development (Friedman \& Mason). In relation to stadium construction projects, the higher the saliency of a stakeholder, the more influence they will have over other less salient stakeholders. Each attribute-power, legitimacy, and urgency-play an important role in building stakeholder saliency.

Power. Power is the probability that one actor within a social relationship would be in a position to carry out his or her own will despite resistance (Weber, 1947 as cited by Mitchell et al., 1997). Mitchell et al. also relied on Etzioni's (1964) seminal work on power, where three types of power were identified based on the type of resource used to employ power: coercive, utilitarian, and normative. Coercive power involves the use of physical means such as the use of a firearm or some level of physical force. Utilitarian power comes from the use of material means, such as goods and services, for control purposes. Normative power involves the use of symbols such as prestige, esteem, love, and acceptance. In relation to this study, normative power is mostly applicable as the existence of a local professional sports team can represent civic pride and give a city a 
“major league" status (Euchner, 1993), providing normative power to salient stakeholders.

Power is the most important attribute when building salience (Parent \& Deephouse, 2007), but without the other two attributes, stakeholders lack authority and exercise (Mitchell et al., 1997). In relation to stadium development projects, Friedman and Mason (2004) defined the attainment of the power attribute when stakeholders are able to affect governments' subsidization decision. More specifically, power is the ultimate ability to grant or reject the stadium subsidization (Friedman \& Mason). Various stakeholders involved with stadium development projects may naturally maintain the power attribute, while others may gain it through some unique avenue. Politicians, team owners, and sport leagues are examples of stakeholders who maintain the power attribute in stadium construction projects.

Legitimacy. Legitimacy is "a generalized perception or assumption that the actions of an entity are desirable, proper, or appropriate within some socially constructed system of norms, values, beliefs, and definitions" (Suchman, 1995, p. 574). Legitimacy is a desirable social good that may be defined and negotiated differently at various levels of social organizations (Mitchell et al., 1997). People may perceive legitimate organizations as more worthy, meaningful, predictable, and trustworthy (Suchman). Suchman also noted three different types of legitimacy: pragmatic, moral, and cognitive. Pragmatic legitimacy is based on the audience's self-interest and relies on an exchange legitimacy where the support for an organizational policy is based on the expected value to a group of constituents. Pragmatic legitimacy is practiced in stadium construction projects amongst team owners, politicians, the local media, and the business community, 
as each stakeholder group supports the stadium construction project to achieve its level of self-interest, whether it is an increase in sales, tax revenue, or other ancillary benefits. Moral legitimacy is based on the normative approach to stakeholder theory and relies on judgments about whether the activity is the right thing to do. For example, opponent groups may exercise moral legitimacy as they often organize due to the proposed use of taxes toward the stadium construction project, or to push for direct democracy actions through a referendum. Cognitive legitimacy is based on comprehensibility and taken-forgrantedness rather than relying on interest or evaluation. For example, the general public stakeholder may ignore a team's threat to relocate until it may be too late.

While this attribute has value, legitimacy could potentially be the most unstable attribute due to its subjective nature (Friedman \& Mason, 2004). To become highly salient, those with legitimacy will gain rights through the power attribute and a voice through urgency (Mitchell et al., 1997). Within stadium construction projects, legitimacy has existed with stakeholders whose claims or participation were recognized as socially acceptable from the perspective of a local government's economic development decision makers (Friedman \& Mason). Examples of stakeholders who bear legitimacy within a stadium construction project may be the general public, the federal government, and advocacy groups.

Urgency. Finally, urgency is the degree to which stakeholder claims call for immediate attention (Mitchell et al., 1997). Mahon and Waddock (1992) argued that urgency comes into practice when 'public policy makers' attention is drawn to an issue as public awareness increases and demands for action are initiated by pressure groups" (p. 26). In addition, issues become more salient to managers as pressure or interest 
groups attempt to affect the issue and ultimately affect the corporation (Mahon \& Waddock). When stakeholders have a higher interest in the issue, substantive actions may be taken such as using or risking resources such as time, money, and political capital (Friedman \& Mason, 2004). Stakeholders involved with a stadium construction project who hold the urgency attribute and a high interest in the issue may invest in an advertising and public relations campaign to build support for or against the project. Contrastingly, when stakeholders have a lower interest in the issue, they may act in a more symbolic nature such as issuing statements of support (Friedman \& Mason). For example, a governor may issue a statement of support for a stadium construction project within the state, despite not providing any statewide financial support toward the project, but still maintaining interest in the team remaining local.

Mitchell et al. (1997) proposed that urgency exists "when two conditions are met: 1) when a relationship or claim has a time-sensitive nature, and 2) when that relationship or claim is critical to the stakeholder" (p. 867). When applied to stadium construction projects, urgency represents the actions taken by the stakeholders assessed on the basis of importance (Friedman \& Mason, 2004). Examples of stakeholders who hold urgency within stadium construction projects include opponent groups and sport fans.

As previously stated, stakeholder salience is developed through the addition of one or more of the power, legitimacy, and/or urgency attributes. The more salient a stakeholder, the more influential they are in the stadium construction project. Mitchell et al. (1997) proposed a classification typology based on the number of each attributes attained as definitive, expectant, or latent. Definitive stakeholders are those who possess all three attributes-power, legitimacy, and urgency-and hold the highest level of saliency. 
Expectant stakeholders possess any combination of two of the three attributes. Expectant stakeholders can either be dominant (power and legitimacy), dependent (urgency and legitimacy), or dangerous (power and urgency). Finally, latent stakeholders are those who possess only one of the three attributes. Latent stakeholders can either be dormant (power), discretionary (legitimacy), or demanding (urgency). Nonstakeholders or potential stakeholders are those who possess no attributes. This typology was applied to stadium construction projects by Friedman and Mason (2004) and will be examined in the next section.

Stakeholders and stadium construction projects. Stadium construction projects are affected by or can affect a number of different stakeholders in a municipality. Friedman and Mason (2004) proposed five encompassing stakeholder group segments based on their involvement with stadium construction and development decision making. Within each of these segments exists a more specific collection of stakeholders who either affect or are affected by stadium construction projects, all with various levels of saliency. These five stakeholder segments involved with stadium construction projects are: (a) the sports industry (team owners, professional leagues), (b) local business community (local media, local business community), (c) government actors (politicians, the federal government, competing cities), (d) local citizens (sport fans, general public, lower income residents), and (e) advocacy groups (neighborhood groups, proponents, opponents) (Friedman \& Mason). The following sections will explore each of these stakeholder segments in further detail.

Sports industry. Team owners and sport leagues make up the sports industry stakeholder segment. Team owners have the largest stake in getting a new stadium built 
and hold the power, legitimacy, and urgency to affect a stadium construction project as seen through threats of relocation and power of an unregulated monopoly. Team owners have an equity stake in the development of a new stadium due to the potential revenue generation opportunities such as the addition of luxury suites and sponsorship inventory toward the overall financial success of the organization. Team owners are financially dependent on the local market, and utilize the threat of relocation to strengthen their negotiating power. For example, Fenn and Crooker (2009) found that respondents who felt that the NFL Minnesota Vikings would relocate without a new stadium were willing to pay an average of $\$ 73.26$ per household to build the team a new stadium. In addition, the definitive stakeholder status maintained by team owners may have the power to influence a voter's support or rejection of a stadium construction project, as the more realistic voters' beliefs are about a team relocating, the higher the spending level that a pivotal voter will support (Fort, 1997). For example, in 1995, the NFL Cincinnati Bengals owner presented the city of Cincinnati with an ultimatum: a new stadium deal had to be reached by a certain date or he would open negotiations with competing city Baltimore (Brown \& Paul, 1999). The Cincinnati stadium referendum passed with a $61 \%$ approval (Brown \& Paul).

Friedman and Mason (2004) proposed professional leagues as definitive stakeholders holding all three attributes; however, leagues sometimes lack the urgency to promote relocation, primarily for the stability of the league. Friedman and Mason held that professional leagues' urgency lie with the leagues' discretion to choose the timing, conditions, and cities for expansion. Often times, though, the league generally wishes for teams to remain in their home city, as seen with MLB Oakland Athletics. MLB blocked 
the potential Athletics move from Oakland to San Jose, California. In response, the city of San Jose filed a lawsuit against Major League Baseball to allow the Athletics to relocate to the city. Another example of relocation issues between teams and leagues occurred when the NFL Oakland Raiders sued the NFL in the 1990's for blocking its move to Los Angeles. Relocation is a league-wide issue that typically requires a majority vote for approval, also diminishing the sense of urgency due to the long timeframe between seeking relocation and being granted relocation. For example, the NFL St. Louis Rams declared its intent to relocate in January 2015 and was granted approval by owners over a year later. These examples do not support Mitchell et al.'s (1997) two conditions of urgency; therefore, professional leagues are demoted from definitive to dominant stakeholders in the current study, maintaining only the power and legitimacy attributes.

Professional leagues have power and legitimacy with their ability to maintain an unregulated monopoly through the control of team supply, locations, and establishing standards for new facilities (Baade, 2003; Siegfried \& Zimbalist, 2000; Vrooman, 1997). Leagues maintain an equity stake in how teams perform in order to maintain the profitability of the league as a whole, but are generally hands-off when dealing with dayto-day team operations. MLB's power and legitimacy was displayed during the early 1990's when the league insisted that to be granted an expansion team, stadiums had to have natural grass and the MLB team had to have first priority in scheduling, requiring the group in Denver to build a new stadium as the NFL Broncos maintained priority scheduling (Sage, 1993). 
Local business community. The local business community stakeholder segment includes the business community and the media as definitive stakeholders. In a traditional urban regime coalition, business owners and groups maintain a level of power with the ability to convince local government officials to invest in development projects such as stadiums which can prompt increased rents and profits (Molotch, 1976; Stone, 1988, 1989). Local businesses such as construction, real estate, banking companies, and the media have economic stakes in the success of a stadium construction project, as it may help develop and grow their own business ventures (Delaney \& Eckstein, 2007; Friedman \& Mason, 2004; Mason \& Buist, 2013). For example, business interests were the driving force behind the recruitment of professional teams in Phoenix, Arizona, Jacksonville, Florida, and Milwaukee, Wisconsin (Danielson, 1997).

The business community displays both urgency and legitimacy through the investment in the team such as the purchase of tickets, suites, sponsorships, and advertising (Duquette \& Mason, 2008; Eitzen, 1999), and monetary contributions to promoting the stadium subsidization projects (Sage, 1993). Businesses are also the primary source of support for the professional teams through this financial funding (Danielson, 1997). The local business community played a vital role in getting publicly funded stadiums built for the MLB Cincinnati Reds and NFL Cincinnati Bengals through the assistance of the city's unique CEO-only Cincinnati Business Chamber (Delaney \& Eckstein, 2007). During Denver's venture to obtain a MLB expansion team, Coors Brewing Company launched the "Great Baseball Starts Here" campaign in Denver that included marketing materials inviting consumers to support the Colorado Baseball Commission, while companies such as McDonalds, Oscar Meyer \& Co., and Prime 
Sports Network each supported the movement through advertising or financial support (Sage, 1993).

The media holds a unique place in the stadium construction scenario. The local media's involvement with a stadium construction project can be seen as twofold. In one aspect, as businesses, the media has to produce and deliver content. The existence of local professional sport teams provides additional content for the local viewership and readership. On the other hand, the media has significant influence in a local community. As a source of reference, the media has the power to frame or shape the public agenda, perceptions, and the outcome of the project (Brown \& Paul, 1999; Buist \& Mason, 2010; Delaney \& Eckstein, 2007, 2008; Turner \& Marichal, 1998). Local newspapers are included in the urban regime, as they have tended to support pro-growth urban development projects such as professional sport stadiums. A pro-growth agenda tends to increase circulation and advertising revenues (Logan \& Molotch, 1987). Media participation is both legitimate and urgent, due to its ability to influence the masses through particular frames. The power of media was demonstrated in the Denver, Colorado's venture to recruit a MLB team to the city (Sage, 1993). The Rocky Mountain News, Denver's largest newspaper, was a major proponent for the stadium construction project for the new MLB expansion team, running editorials up until the referendum that called residents to:

Get out and vote YES, baseball fans ... if you don't come out of the woodwork to pass the stadium tax on Tuesday, you have only yourselves to blame when you have to drive or fly at least 600 miles for the rest of your lives to see Major League Baseball. (Dressman, 1990 as cited by Sage, 1993, p. 116) 
Further, Buist and Mason (2010) examined the Plain Dealer, the local daily newspaper for Cleveland, Ohio during the 1984 and 1990 stadium construction projects proposals. The 1984 Domed Stadium project ultimately failed, but the 1990 Gateway Project passed. Results from the content analysis found the Plain Dealer was a proponent of the stadium subsidy in both project proposals through the amount of positive coverage and overall editorial position taken by the newspaper (Buist \& Mason). Another example of media influence was in Pittsburgh, Pennsylvania where the TribuneReview, one of two major daily newspapers in the city, outwardly opposed the stadium construction proposals for the MLB Pirates and NFL Steelers, which was found to be a major factor in the referendum defeat (Delaney \& Eckstein, 2008).

Government actors. The government actors' stakeholder segment contains the federal government, competing cities, and politicians. Though the federal government maintains power and legitimacy when considering its relation to stadium construction projects, specifically with how it relates to federal taxes, it lacks urgency with local governmental issues. Historically, the federal government has taken a backseat when it comes to stadium construction projects, as these are matters of the local polity, and therefore would be considered an involuntary stakeholder based on this stake (Clarkson, 1994, as cited by Phillips, 1999). The federal government has not remained wholly docile, though, maintaining an influencer stake in stadium construction projects. After the NFL Cleveland Browns left for Baltimore in 1995, congressional delegates from Ohio introduced three separate bills to protect the community and to ensure a replacement expansion team for the one Cleveland had recently lost, none of which passed (Friedman \& Mason, 2005). A Congressional Baseball Expansion Task Force was created in the 
early 1990s and led by senators from Colorado and Florida who threatened to abolish baseball's longstanding antitrust exemption if the league did not expand (Sage, 1993). Interestingly enough, MLB awarded expansion teams to Colorado and South Florida after the formation of this taskforce (Sage).

Competing cities were presented as dangerous stakeholders, based on their potential position to undercut and recruit the team in question (Friedman \& Mason, 2004). Though lacking legitimacy in their claims on a local stadium construction project, competing cities are seen as a dangerous stakeholder due to their power and urgency in offering a more lucrative and appealing stadium deal. This stakeholder group has an economic stake in stadium construction projects as the competition (Wolfe \& Putler, 2002). The city of Nashville, Tennessee, experienced municipal competition with Memphis, Tennessee in its venture to recruit the NFL Houston Oilers to Nashville (Friedman \& Mason, 2005). Memphis had a long-standing pursuit of an NFL franchise in addition to its fight for municipal superiority over Nashville in the state of Tennessee (Friedman \& Mason). The mayor of Nashville was able to secure support from the governor of Tennessee, thwarting any further competition from Memphis.

Politicians are the definitive stakeholders in this segment, holding the highest salience. According to Kalich (1998), maximizing votes, winning reelection, and gaining a higher office are the primary objectives of a politician. Stadium construction projects have a large enough magnitude, and the association with such projects have been perceived to help advance political careers (Pelissero et al., 1991). The visibility of such projects also allow for a more palatable form of public policy, comparatively. Politicians have an economic stake in the success of a stadium construction project, as they may lead 
the charge in rallying public support to fund these projects with public tax dollars. Mayors and governors are typically the main boosters for their cities and states, and typically lead the charge in recruiting an expansion team as seen in a number of political leader-led coalitions in Denver, Colorado, Los Angeles, California, and St. Louis, Missouri (Danielson, 1997). Politicians have the power and legitimacy due to their position invoked by the local electorate. Through representative democracy, politicians are enabled to develop public policy reform including government projects and spending on behalf of the electorate, depending on the polity (Friedman \& Mason, 2004). Urgency comes with politicians' association with stadium construction projects (Friedman \& Mason). A Colorado senator, the governor of Colorado, and the Denver mayor each injected themselves in the stadium construction project process by lobbying in support, and were successful in obtaining an MLB expansion team in the early 1990's (Sage, 1993).

The saliency of stadium construction projects in a community, as seen by the high average turnout rates, offers a unique outlook on how these measures are supported. A strong positive relationship was found between the degree of local elite unity in favor of a stadium referendum and the electoral support to pass the measure (Paul \& Brown, 2001). Elites were considered to be individuals who were actively engaged in local decisionmaking process such as appointed officials, corporate CEO's, and community leaders. The researchers also found that a shift from a very low local elite unity to a very high elite unity could result in a $19.4 \%$ change in the referendum final vote (Paul \& Brown, 2001). Paul and Brown (2006) examined 41 professional sport stadium referendums between 1984 and 2001 and found that elected officials who spoke out against the 
stadium construction project had a significant influence on public support. This finding also supports the conclusion that elected official opposition is exogenous to public opinion (Paul \& Brown). This evidence supports the potential influence this stakeholder group may have on a voter's support or opposition of a stadium construction project.

Local citizens. The local citizens' stakeholder segment consists of sports fans, the general public, and lower income residents. Though these stakeholder groups have the potential to represent a large number of constituents in a polity, each group lacks key attributes and therefore fails to meet the highest level of saliency. Ultimately, the per capita costs of a stadium are low, thus local citizens have little at stake and invest little time and effort into stadium construction projects (Fort, 1997).

Sport fans maintain no real power in a stadium construction project, besides claims by politicians that their decision to support stadium construction projects has been influenced by sports fans (Friedman \& Mason, 2004). Sport fans do maintain legitimacy and urgency in their claims to support their local professional sports team financially through purchase of season tickets and personal seat licenses, and expressively through their involvement with proponent groups (Brown \& Paul, 1999; Friedman \& Mason, 2005). Because of this financial support, sport fans can be seen as having an equity stake in the construction project, due to their investment in the team through season tickets. Sport fans came to the rescue in Nashville, Tennessee by providing manpower to support the proponent group, Yes for Nashville, to convince the public to support the project (Friedman \& Mason, 2005). 
The general public and lower income residents carry only one attribute, legitimacy. Both groups maintain legitimacy due to their position as taxpayers. Both these groups are involuntary stakeholders based on their lack of risk associated with stadium construction projects (Clarkson, 1994, as cited by Phillips, 1999). These stakeholder groups lack direct risk in stadium construction projects until the project somehow directly affects them (i.e., the imposition of taxes on the larger population). These two stakeholder groups maintain an influencer stake in the stadium construction situation as they are more likely to be motivated by symbolic predispositions such as civic pride when supporting this type of project (Wolfe \& Putler, 2002). Though the general public can reach the definitive stakeholder level through exercising their voice in a referendum, it relies on opponent groups or other vested groups of people to force the referendum, as seen in Nashville, Tennessee (Friedman \& Mason, 2005) and Cincinnati, Ohio (Brown \& Paul 1999). Additionally, the general public's opinion is often overshadowed or negated through representative democracy. Failed sport stadium referendums in Seattle, Washington and Milwaukee, Wisconsin were eventually passed through another democratic avenue and eventually provided the local professional teams new local homes through public funds (Brown \& Paul, 2002; Fort, 1997). Phoenix, Arizona and Pittsburgh, Pennsylvania also passed stadium construction plans through the state, despite the failed referendums in each city (Brown \& Paul, 2002). These examples emphasize the ability for stakeholders, specifically the general public, to shift saliency in a stadium construction project at the hand of other stakeholders.

Despite the similarity to the general public, lower income residents may have "a lack mobility, concerns of equity, and a greater reliance on public services," which 
separates them from the general public stakeholder group (Friedman \& Mason, 2004, p. 348). Further, stadium construction projects are typically funded through some tax mechanism such as general sales tax or sin taxes on alcohol or cigarettes, which affect the general public. Due to the regressive nature of some of these tax mechanisms, lower income residents may be affected even more (Spirou, 2010).

Lower income residents often lack resources to speak out against a stadium construction project, as seen in Chicago, Illinois with the MLB White Sox. The team was successful in obtaining public funds for a new stadium, which would be placed across the street from the team's old ballpark. This area, called South Armour Square, was a predominantly African-American community that housed about 1,500 citizens and was not considered an economically thriving community (Spirou, 2010). The stadium project plans included removing 178 privately owned homes and 12 community businesses (Spirou). Citizens attempted to garner city wide attention regarding the issue but were unable to gain support from their alderman due to his political base deriving mainly from the predominately white community of Bridgeport (Spirou).

Advocacy groups. The last stakeholder segment consists of advocacy groups such as neighborhood groups, opponent groups, and proponent groups. Both neighborhood groups and opponent groups have legitimacy and urgency but lack power. Each of these stakeholder groups maintains an influencer stake in the stadium construction situation as they are motivated by symbolic predispositions such as civic pride and living in a major league city (Wolfe \& Putler, 2002). 
There have been examples in Chicago, Illinois and Los Angeles, California where politically weak neighborhoods have been chosen as stadium construction sites to avoid neighborhoods with more substantial political power (Euchner, 1993). Additionally, it was found that voters in Munich, Germany widely supported the development of the professional soccer stadium, but voters in close proximity of the proposed stadium construction site generally opposed the project (Ahlfeldt \& Maennig, 2012). The benefits of a stadium located in a particular area are also up for debate. Many of the neighborhood businesses surrounding the Kingdome in Seattle, Washington stated their revenues either remained constant or decreased as a consequence of the Kingdome (Baade, 2000). Neighborhood groups have the potential to shift a stadium construction project but, due to their general lack of power, are often unsuccessful. Similar to the general public and lower income residents' stakeholder groups, neighborhood groups are often involuntary stakeholders as they have minimal at stake in regards to a stadium construction project until the project directly affects the neighborhood by choosing the area to develop, for example.

Opponent groups also lack power due to a lack of organization and resources, and often have to rely on stakeholders with power such as politicians or the media in order to influence stadium construction projects (Friedman \& Mason, 2004). For example, No Jones Tax, the opponent group in Dallas, formed in response to the NFL Dallas Cowboys stadium project in downtown Dallas. This opponent group was legitimized through its media exposure, as the local newspaper announced and reported on the group's meetings (Delaney \& Eckstein, 2008). Opponent groups have shown some success in forcing referendums through petitions (Brown \& Paul, 1999, 2002; Sage, 1993) but typically 
have been less than successful due to the lack of organization and resources. Brown and Paul (2002) found that seven of the 40 referendums held between 1984 and 2000 involved citizen initiatives, or referendums that are forced after a specific number of voter signatures have been collected. Both neighborhood groups and opponent groups maintain legitimacy and urgency in their stake on stadium construction projects due to their position in the community and how a stadium may affect their livelihoods.

Of the three advocacy groups, proponent groups are the only definitive stakeholder. Proponent groups have historically been highly funded and use highly visible campaigns in order to sway the support of the general public and voting citizens (Paul \& Brown, 2001). These efforts help maintain this stakeholder's saliency, and they can affect the outcome of stadium construction project. Proponent groups have been successful through the use of various tactics, as found by Brown and Paul (2002). First, proponents managed to not allow the referendum to be pigeonholed as just a professional sport stadium issues, but promoted as "downtown redevelopment" or "neighborhood renewal" instead, as seen in Arizona where the campaign focused on the funding that would become available for local youth programs (Brown \& Paul). Second, proponents often focused on the idea that the projects would have little to no effect on the local taxpayers, as taxes targeted tourists (e.g., hotel/motel, car rental) or the economic impact would be substantial enough to cover the costs. For instance, representatives in San Diego, California claimed that the overall increased economic activity spurred by the project would pay for the new MLB stadium (Brown \& Paul). Third, proponent groups often promoted the project as a necessity to make the city "major league" in cities like Pittsburgh, Pennsylvania, Cincinnati, Ohio, St. Louis, Missouri, and Denver, Colorado 
(Brown \& Paul). Finally, proponent groups would directly or indirectly communicate that the team would relocate if a stadium project was not approved, even if the team made no such threats. For example, though the MLB Texas Rangers did not threaten to leave Arlington, Texas in the early 1990s, stadium supporters asserted that a referendum defeat would lead to the team relocating (Brown \& Paul).

Proponent groups typically comprise other stakeholders such as sport fans, teams, leagues, the media, the business community, and politicians (Brown \& Paul, 1999), enabling them to gain power through resources and support from other stakeholders (Friedman \& Mason, 2004). These stakeholders typically develop after the emergence of opponent groups, prompting their legitimacy and urgency to build coalitions to garner support for the stadium construction measure (Friedman \& Mason). Proponent groups were found to be successful $60 \%$ of the time in getting stadium referendums approved by the voting population, mostly due to the amount of resources they have over opponents (Brown \& Paul, 2002).

Summary. The definitive stakeholders-professional team owners, the business community, politicians, the media, and proponent groups-are the most salient of the stakeholder groups and have the potential ability to affect the outcome of a stadium construction project. These stakeholder groups have historically been proponents of facility subsidization (Friedman \& Mason, 2004), and have had success in framing the issue as an overall development issue, instead of pigeonholing it as just a stadium issue, one that was needed to make it a "major league" city (Brown \& Paul, 2002). 
Each of these stakeholder groups also bears some level of self-interest in this matter, whether financially, commercially, or through some level of growth. The business community and local politicians have a shared interest in developing a city's status, competitive position, economic health, and downtown vitality (Danielson, 1997), while team owners look for additional revenue opportunities. The local media is interested in additional revenue opportunities as well as content for their outlets, and proponent groups look to keep city status as a "major league city."

Because of their saliency, these stakeholders have the potential to affect the outcome of stadium construction projects through their power, legitimacy, and urgency in relation to the matter. When these definitive stakeholders work together, their success rate is even further defined. For example, proponent groups for the stadium financing for the Cincinnati Reds and Cincinnati Bengals were able to feed the media with appeals for citizens to come to the defense of their city (Brown \& Paul, 1999). In addition, there was visible support from the governor, mayor, and county commissioner to add to the credibility of the plea, all of which ultimately brought success to the Cincinnati stadium referendum, with a record $49.5 \%$ voter turnout and a $61 \%$ approval (Brown \& Paul). Further, post-election survey results showed that civic pride was an important element respondents considered when placing their vote for the stadium referendum (Wilkerson, 1996, as cited by Brown \& Paul, 1999). In this case, a number of definitive stakeholders promoted the idea of living in a "major league city" to sway voters to support a stadium referendum to its success.

Stakeholders hold some level of influence when it comes to stadium construction projects. Team owners, the business community, politicians, the media, and proponent 
groups all hold the highest stake in the matter and therefore have the most to lose if the stadium construction project does not come to fruition. While other stakeholder groups may exist, the primary focus of this study was to examine the how influential the most salient stakeholders are on a stadium construction project, largely on their influence on the voting population. It is vital to include them as a potential influencing variable as the exploration of voter outcome continues.

\section{Team Identification}

As previously covered, various salient stakeholders have the potential to influence if a voter supports or rejects a stadium construction project. But the sport fan and general public stakeholder groups warrant further examination. Though sport fans can be considered a part of the general public, they only make up a portion. Sport fans, who carry legitimacy and urgency due to their relationship with the sport team, are more salient than the general public, who only bear legitimacy. Because of this additional attribute, sport fans are somehow considered more salient, given their position within the general public. The main quality that sets a sports fan apart from the general public is the sports fan's relationship with the team. Therefore, this relationship between the team and the public should be further examined, as it potentially can have a significant shift on how a constituent may feel about supporting a stadium construction project.

Additionally, the application of stakeholder management provides an organization with a route of developing organizational identity. Scott and Lane (2000) proposed that “individual stakeholders perceive and interpret presented organizational images and, from these data, construct a cognitive image of an organization" (p. 48). When stakeholders are able to recognize some overlap between the cognitive image of the organization and 
their own identity, they are able to identify with the organization (Scott \& Lane).

Professional sport teams, which can be seen as one of the focal organizations of stadium construction projects, have the ability to hold definitive positions within a local market and connect with local residents on a cognitive level through their ability to develop a connection to individuals in the development of a fan base. This cognitive connection may influence a resident's willingness to support a stadium project.

The inclusion of team identification along with noneconomic benefits has been promoted by notable sport economists Baade and Dye (1988a) who asserted, “... . measurable economic benefits to area residents are not large enough to justify stadium subsidies and the debate must turn to immeasurable benefits like (team) identification and civic pride" (p. 37). Notably, in Walker and Mondello’s (2007) assessment of CV application in sport stadium research, the researchers suggested using team identification as a moderator to gauge affective responses towards the organization in order to assess referendum support from fans and nonfans alike. Team identification may influence the relationship concerning how a constituent may vote towards a stadium referendum.

The role of team identification was discussed almost in passing in a few sport stadiums CV studies (Fenn \& Crooker, 2009; Johnson \& Whitehead, 2000; Johnson et al., 2001; Owen, 2006). Team identification is the level of psychological connection a person has with a team (Wann, 1997), and could potentially affect a constituents' willingness to support a stadium construction project. This connection also highlights the difference between a sport fan (presence of a psychological connection) and a sport spectator (mere observer) (Dietz-Uhler \& Lanter, 2008). Team identification can also produce two beneficial outcomes: a decreased price sensitivity and decreased 
performance-outcome sensitivity (Sutton, McDonald, Milne, \& Cimperman, 1997).

Team identification can serve to potentially build an unwavering connection to the local professional team. This connection can then influence how a resident supports a stadium referendum, when faced with this circumstance in the local polity. On the other hand, the lack of psychological connection with the local team may cause the resident to further consider the costs behind such projects, while a resident with a moderate to high level of team identification may ignore these details.

The psychological connection to a team may spur a special bond for fans beyond attendance or watching games. An example of this phenomenon occurs when fans and citizens alike include themselves as a part of the team through the use of "we" in reference to a team's performance (Cialdini, Borden, Thorne, Walker, Freeman, \& Sloan, 1976). This bond is further evidence of the connection that can be made between a fan and the local sport team. It emphasizes the importance and value of considering team identification when examining influencing factors on voter support or rejection of stadium referendums.

The relationship of team identification on referendum support, though, should be approached with care. Fenn and Crooker (2009), Johnson and Whitehead (2000), and Johnson et al. (2001) included some measure of fan identification as a part of the public good variable (which also included other noneconomic benefits such as reading about the team and talking about the team). Fenn and Crooker's (2009) study on the NFL Minnesota Vikings, Johnson and Whitehead's (2000) study on a University of Kentucky basketball arena and new minor league baseball team, and Johnson et al.'s (2001) study on the NHL Pittsburgh Penguins yielded very different levels of fan identification. The 
portion of respondents in these three $\mathrm{CV}$ studies who identified as fans of the teams in question were $18 \%, 33 \%, 72 \%$, respectively. The role of fan identification in sport stadium CV research has been sporadic and inconsistent. In addition, the statistical significance of team identification on respondents' level of WTP is unknown in the latter studies due to its inclusion in the public good variable. Therefore, it is pertinent to consider this variable as its own function, as team identification may in fact influence the relationship between noneconomic factors and willingness to support the stadium project.

Further evidence to support the potential role of team identification in a resident's decision to support or reject a stadium construction project was in Owen's (2006) study on the professional teams in Minnesota and Michigan. Owen held team interest (identification) as its own variable, unlike Fenn and Crooker (2009), Johnson and Whitehead (2000), and Johnson et al. (2001). Team interest was found to be statistically significant in determining a respondent's level of WTP. Owen (2006) found that team interest is a critical element in the general public's willingness to pay for a sports stadium, supporting further exploration of this variable.

Depken (2000) endeavored to measure fan loyalty in professional baseball as it related to the outcomes of public funding proposals in MLB host cities. Using attendance data from 26 MLB teams (excluding the two teams in Canada) from 1990 to 1996, Depken based the team loyalty measure on attendance, holding price constant, hypothesizing that attendance would increase only when an improvement in team quality occurs. Using stochastic frontier method, an economic theory that posits efficiency conditions defining a frontier between the attainable and unattainable (see Greene, 1995), Depken found four of the seven teams that were granted public funding existed in the 
upper half of relative fan loyalty. Three exceptions existed-Cincinnati, Ohio Houston, Texas, and Detroit, Michigan-each of which received public funding for new ball parks, were on the lower half of the fan loyalty ranking. This study further illustrates how a connection with a team may or may not influence a person' willingness to support a stadium project.

Team identification warrants further examination in regards to the variable's potential influence on a resident. This variable may potentially influence a constituent's willingness to support a stadium project. Team identification is the level of psychological connection a person has with a team (Wann, 1997), and this connection, despite the details of the referendum, may sway a resident towards supporting a stadium referendum.

\section{Summary}

Stadium construction projects have continued to be prevalent in cities across the United States. A number of stadium referendums have been held over the past 25 years with mixed results. Some of the voting public approve these measures and others are easily rejected, despite the existence of a strong fan base. The voting population has questioned the logic of these stadium projects and has recognized the cost-benefit imbalance (i.e., increase in local jobs and spending, increased tourism, opportunity costs, additional targeted taxes).

Despite the inconsistent stadium referendum results, local governments continue to spend tax dollars on stadium construction projects to keep professional teams from leaving the area. Economic impact reports have been commissioned to measure the 
financial return on investment for stadium construction projects, ensuring the public that their tax dollars are well used. Unfortunately, many economic impact studies have concluded that sport teams and facilities do not provide enough economic impact to cover the costs of the facility (Baade, 1994, 1996; Baade \& Dye, 1988a, 1990; Baade et al., 2008; Coates \& Humphreys, 1999, 2002; Zipp, 1996). This has caused some sport economists to suggest shifting the focus from measureable economic impact to the noneconomic benefits such as civic pride and living in a major league city in order to justify the public's investment in these large scale projects (Baade \& Dye, 1988a, 1990; Coates \& Humphreys, 1999; Noll \& Zimbalist, 1997; Sanderson, 2000; Zipp, 1996).

CVM has been utilized in the attempt to measure these noneconomic benefits. An economics-based approach, CVM is concerned with attaching value to a good not placed on the market. In the case of stadium construction projects, respondents are asked how much they would be willing to pay (usually in taxes) to build a new stadium for their local professional team to keep it from relocating. This willingness to pay (WTP) value is not something that can be purchased in the market and can vary widely across individuals, depending on a number of factors.

Primarily, sport-based CVM research has grounded the WTP value in the public good a sports team can provide to a respondent. This public good variable has a variation of: reading about the team, talking about the team with others, watching the team on television, and how the existence of the teams increases the quality of life in the city (Atkinson et al., 2008; Castellanos et al., 2011; Fenn \& Crooker, 2009; Groothuis et al., 2004; Johnson \& Whitehead, 2000; Johnson et al., 2001; Johnson et al., 2006, 2007; Owen, 2006; Santo, 2007). In some cases, fan, or team identification, was utilized as a 
measure of public good (Fenn \& Crooker, 2009; Johnson et al., 2001; Johnson \& Whitehead, 2000; Owen, 2006). Other significant factors that influenced respondent's willingness to pay values also included: attendance (Atkinson el al., 2008; Castellanos et al., 2011; Groothius et al., 2004; Johnson et al., 2001; Johnson et al., 2006, 2007; Santo, 2007); household income (Atkinson et al., 2008; Castellanos et al., 2011; Johnson et al., 2006, 2007; Santo, 2007); length of payment (Atkinson et al., 2008; Johnson et al., 2006); tax amount (Fenn \& Crooker, 2009; Groothuis et al., 2004; Johnson et al., 2006); economic impact (Santo, 2007); prestige/national reputation (Fenn \& Crooker, 2009; Johnson et al., 2007; Santo, 2007); and the location of the stadium in relation to the respondent's home (Atkinson et al., 2008; Castellanos et al., 2011; Owen, 2006).

While CVM has been the primary approach to measuring public goods, it comes with many methodological inconsistencies and criticisms, deeming it an inappropriate channel to utilize in sport stadium financing research. In addition to these criticisms, some sport stadium CVM research has excluded potentially key variables from its models such as stakeholder influence and team identification. These additional variables should not be dismissed, in combination with the public good variables, and deserve adequate attention as potential influential variables when considering a constituent's willingness to support a stadium construction project.

Stakeholder influence should be considered as a potential influential variable in examining a constituent's willingness to support a stadium construction project. Based on the typology proposed by Mitchell et al. (1991), Friedman and Mason (2004) proposed a number of stakeholders who either affect or are affected by stadium construction projects, all with various levels of saliency-team owners, professional 
leagues, the media, the business community, politicians, the federal government, competing cities, sport fans, general public, lower income residents, and neighborhood groups, proponents, and opponents. The most salient stakeholders-team owners, the business community, politicians, the media, and proponent groups-many of which belong to the urban regime, all hold the highest stake in the matter and therefore have the most to lose if the stadium construction project does not come to fruition. Each of these salient stakeholders bears some form of self-interest in stadium construction projects, and ultimately aims to contribute to the urban regime of the local city, promoting growth and development to potentially attract new residents, businesses, and tourism. The collective goal of the urban regime in stadium construction projects is to obtain or retain a professional team by way of financing a new stadium or renovating an existing stadium to meet the requests of the professional team and league requirements. Through their own accord, each stakeholder may influence the outcome of stadium construction projects, whether through representative democracy, framing the project to promote growth and revitalization, and threatening to relocate in the instance that demands are not met, for example. These various actions potentially may influence or impact how a constituent may vote when presented with a stadium referendum.

In addition to the potential influence stakeholders may have on the constituents, the level of identification with a team should be considered as a potential influential variable in examining how a constituent may vote when confronted with a stadium referendum. As previously defined, team identification is the level of psychological connection a person has with a team (Wann, 1997). This psychological connection may provide local citizens with unwavering support for the local professional team. In 
contrast, the lack of identification may influence a constituent to reject a stadium referendum for various reasons. Considering the extant literature, there has not been a streamlined approach of measuring the influential variables that may impact a constituents support or rejection of a stadium referendum. Therefore, the purpose of this research was to examine what variables may influence a voter to support or reject a stadium construction project. 


\section{CHAPTER III}

\section{METHOD}

This chapter outlines the methodological approach for the current study. First, the research purpose will be addressed, followed by the research questions and hypotheses. The research design will outline the conceptual framework of the current study. Data collection procedures follow along with sampling strategy. Finally, the data analysis will be presented.

\section{Research Purpose}

The purpose of this study was to examine how Stakeholder Influence, Perceived Noneconomic Benefits, Perceived Economic Benefits, and Team Identification may influence a constituent's willingness to support a professional sport stadium referendum.

\section{Research Questions and Hypotheses}

In order to examine what influences constituents' willingness to support a stadium referendum, a number of research questions and hypotheses were presented. RQ1-What effect does Stakeholder Influence, Perceived Economic Benefits, Perceived Noneconomic Benefits, and Team Identification have on constituents' willingness to support a stadium referendum?

H1: Stakeholder Influence has a direct positive effect on Stadium Support. H2: Perceived Noneconomic Benefits has a direct positive effect on Stadium Support 
H3: Perceived Economic Benefits has a direct positive effect on Stadium Support.

H4: Team Identification has a direct positive effect on Stadium Support.

H5: Team Identification has an indirect positive effect on Stadium Support

through Stakeholder Influence.

H6: Team Identification has an indirect positive effect on Stadium Support

through Perceived Noneconomic Benefits.

H7: Team Identification has an indirect positive effect on Stadium Support

through Perceived Economic Benefits.

RQ2-Which stakeholder groups do voters believe are campaigning for or against the stadium referendum?

\section{Research Design}

To further delve into what influences a person's willingness to support a stadium referendum, the current study focused on the case presented in Chapter I-San Diego, California. The city of San Diego was faced with sport stadium referendum for the NFL San Diego Chargers in the November 2016 election cycle.

The case approach was used for a number of reasons. Primarily, stadium referendums are held on a local or state level, making each situation unique. For example, stadium referendums may vary in the stadium proposal, tax plan, voting mechanism, and policy approach. Additionally, the current study relied on sport-based contingent valuation method (CVM) research as the conceptual framework, which focused on a specific team or teams (Castellanos et al., 2011; Fenn \& Crooker, 2009; Groothuis et al., 2004; Johnson \& Whitehead, 2000; Johnson et al., 2001; Johnson et al., 2006, 2007; Santo, 2007), event (Atkinson et al., 2008), or region (Owen, 2006). The 
focus has also been on specific cities, states, or regions such as Lexington, Kentucky (Johnson \& Whitehead, 2000); Pittsburgh, Pennsylvania (Groothuis et al., 2004; Johnson et al., 2001); Jacksonville, Florida (Johnson et al., 2006, 2007); Portland, Oregon (Santo, 2007), London, United Kingdom (Atkinson et al., 2008); A Coruña, Spain (Castellanos et al., 2011); the state of Minnesota (Fenn \& Crooker, 2009); and the states of Minnesota and Michigan (Owen, 2006).

In addition to the case-based CVM literature, research in the general area of stadium financing has focused on specific cases, uncovering the nuances of municipalities, their unique policies and laws, and the individual stakeholder involvement, as outlined in the literature review (Brown \& Paul, 1999, 2002; Buist \& Mason, 2010; Friedman \& Mason, 2005; Mason \& Buist, 2013; Paul \& Brown, 2001, 2006; Sage, 1993). These cases, though singular, offer a broader lens into understanding policy approaches to stadium financing in the United States, mostly through the lens of salient stakeholders. Though the current study focuses on a specific case similar to much of the literature in this area, it can fill a gap due to the focus on voters' perceptions of stadium construction projects rather than relying solely on the perceptions of the salient stakeholders, or economic impact studies that rely on economic indicators instead of survey methods.

\section{Data Collection and Sampling Procedure}

\section{Sampling Procedure}

The sampling frame for the current study consisted of registered voters who reside in San Diego, California. Voter email data was purchased from L2, a data processing company that specializes in voter data. L2 provides "high quality enhanced voter data 
and customized data processing" (“About us,” 2016, para. 1). The company also offers data randomization (T. Teehan, email communication, July 31, 2016). As of August 2016, LN had email data for 565,862 voters in San Diego (T. Teehan, personal communication, August 1, 2016).

To reduce sampling error, Dillman, Smyth, and Christian (2009) recommended a sample size of at least 384 . This sample recommendation is based on a population of 1,000,000 and a 95\% confidence interval (Dillman et al.). Per these recommendations, the researcher aimed to obtain at least 384 useable questionnaires at the minimum. While these recommendations are standard for survey research, others have posited lower standards for various statistical analyses. The current study utilized structural equation modeling (SEM) to conduct the data analysis. Kline (2015) recommended a sample size

of at least 200 to conduct a sound SEM analysis, while Nunnally (1967) recommended 10 cases per variable. Further, Bentler and Chou (1987) recommended 5-10 cases per model parameter. Due to the variation surrounding adequate sample size, the researcher aimed to obtain 450 usable surveys.

\section{Study Participants}

The sample frame for this study was registered voters of San Diego, California. The number of registered voters as of June 2016 was 660,471 registered voters in San Diego as of July 2016 (G. Gutierrez, personal communication, July 14, 2016). In California, individuals must be a U.S. citizen, at least 18 years of age, a California resident, not declared mentally incompetent by the court, and not in prison or on parole for a felony conviction (“Check your registrations status," n.d.). 
This sample frame was selected for this study because the stadium project proposal was voted on in the November 2016 election. The San Diego stadium proposal presented voters with a $4 \%$ increase to the hotel tax. Most importantly, the residents of the city of San Diego were able to voice their opinion through vote in the election, providing an opportunity to examine what factors may have influenced their vote. A brief recap of the San Diego NFL Chargers stadium proposal is outlined in Table 3.

\section{$\underline{\text { Table } 3}$}

\section{Breakdown of San Diego Chargers Stadium Proposal.}

\begin{tabular}{lllll}
\hline Tax proposal & $\begin{array}{l}\text { Total proposed cost of stadium } \\
\text { project }\end{array}$ & $\begin{array}{l}\text { Age of } \\
\text { current } \\
\text { stadium }\end{array}$ & $\begin{array}{l}\text { Number } \\
\text { of } \\
\text { registered } \\
\text { voters }\end{array}$ & $\begin{array}{l}\text { Population } \\
(2010 \\
\text { census })\end{array}$ \\
\hline $\begin{array}{l}\text { Increase the } \\
\text { hotel tax from }\end{array}$ & $\begin{array}{l}\text { \$1.8 billion total. Chargers and } \\
\text { the NFL will contribute a total }\end{array}$ & & $\begin{array}{l}600,471 \\
\text { as of July } \\
\text { of } \$ 650 \text { million to the overall } \\
\text { project. The city will pay } \$ 1.15 \\
\text { billion from the increased hotel } \\
\text { room tax which will cover } \\
\text { costs for the stadium, adjoining } \\
\text { convention center, and land. }\end{array}$ & \\
\hline
\end{tabular}

\section{Instrument}

The current study aimed to address what variables may influence a constituent's willingness to support professional stadium referendum. Therefore, the study included a collection of variables that may influence how the respondent may vote when faced with a stadium project referendum. These variables were discussed in Chapter II and will be further addressed in the following section.

There was not an existing scale to accommodate the current study; therefore, a number of different subscales and items were adopted from previous literature (Atkinson et al., 2008; Castellanos et al., 2011; Fenn \& Crooker, 2009; Groothuis et al., 2004; 
Kellison, 2013; Johnson \& Whitehead, 2000; Johnson et al., 2001; Johnson et al., 2006, 2007; Owen, 2006; Santo, 2007). Further, a number of these items were adapted to the context of the current study. In addition, a number of these items were not supported with reliability scores, which is another underlying issue of the sport-based CVM research. Though this was the case, the items chosen for the current study were statistically significant predictors of willingness to pay (Atkinson et al., 2008; Castellanos et al., 2011; Fenn \& Crooker, 2009; Groothuis et al., 2004; Johnson \& Whitehead, 2000; Johnson et al., 2001; Johnson et al., 2006, 2007; Owen, 2006; Santo, 2007) as outlined in the following section. As such, these items align with the purpose of the current study. The researcher was aware of the potential issues that come with unreliable items and instruments and addressed the instrument's readability, reliability, and validity in a series of preliminary steps (i.e., panel of experts, field test, and pilot test). Further details are discussed later in this chapter.

The instrument included seven sections: (a) Stakeholder Influence, (b) Perceived Noneconomic Benefits, (c) Perceived Economic Benefits, (d) Team Identification and Passion, (e) Stadium Support (the dependent variable), (f) Additional Influential Variables, and (h) Demographics. There were 48 total items in the instrument, and unless otherwise noted, the items utilized a 7-point Likert scale from strongly disagree to strongly agree.

The survey began with a brief introduction to the proposed stadium project, which provided the respondent with details about the situation. The statement read:

On November 8, 2016, voters in the city of San Diego will be able to vote on the $4 \%$ hotel room tax increase for the new Chargers Stadium. This plan, called the Citizen's Initiative, proposes a hotel room tax from $12.5 \%$ to $16.5 \%$ to help fund the $\$ 1.8$ billion downtown Chargers stadium and convention center expansion 
project. The Chargers and the NFL will contribute a combined total of $\$ 650$ million to the overall project, while the city is slated to raise $\$ 1.15$ billion that will cover the stadium, convention center, and land costs through the increased tax. Please answer the following survey based on the San Diego Chargers stadium project proposal that will be up for vote in November.

Stakeholder influence. The Stakeholder Influence construct evaluated to what level community leaders may influence voter's perceptions of the stadium construction project (Friedman \& Mason, 2004; Paul \& Brown, 2001, 2006). This construct was measured by four original items based on the work of Lupia and McCubbins (1998) and Paul and Brown (2006). Lupia and McCubbins theorized that voters must perceive a local elite or community leader (e.g., local elected officials, business groups, community groups, minority leaders) to be both trustworthy and knowledgeable in order for the voter to be influenced in a certain way. Lupia and McCubbins also suggested that a voter can come to trust an elite if they perceive themselves to share common interests. Paul and Brown (2006) built on this theory suggesting that common interest between voters and elites comes in the form of shared political beliefs as well as more discernable commonalities such as race.

One of the criticisms of stakeholder research is the lack of empirical research (Friedman et al., 2004). As such, there was no relevant preexisting scale or subscale to address this specific construct; therefore, four original items were developed to address voters' perceptions of community leaders' trustworthiness, knowledge, common interests, and approval based on the research conducted by Lupia and McCubbins (1998) and Paul and Brown (2006). 


\section{$\underline{\text { Table } 4}$}

\section{$\underline{\text { Stakeholder Influence Item List }}$}

\begin{tabular}{ll}
\hline Code & Construct/Item \\
\hline Influence1 & $\begin{array}{l}\text { Stakeholder Influence } \\
\text { I trust the community leaders who are associated with the proposed } \\
\text { stadium project. }\end{array}$ \\
Influence2 & $\begin{array}{l}\text { I believe the community leaders who are associated with the proposed } \\
\text { stadium project are knowledgeable. }\end{array}$ \\
Influence3 & $\begin{array}{l}\text { I agree with the community leaders who are associated with the proposed } \\
\text { stadium project. }\end{array}$ \\
Influence4 & $\begin{array}{l}\text { I have common interests with the community leaders who are associated } \\
\text { with the proposed stadium project. }\end{array}$
\end{tabular}

Perceived noneconomic benefits. Perceived Noneconomic benefits are those benefits a respondent may associate with a professional sports team as important or valuable, but do not have a tangible price attached with them (Baade \& Dye, 1988a, 1990; Crompton, 2004; Johnson, 1986; Noll \& Zimbalist, 1997; Sanderson 2000; Zipp, 1996). This construct was measured by a number of items utilized in sport-based CVM studies surrounding the public good variable (i.e., reading about the team, watching the team on television, talking about the team with friends, family, and/or co-workers, and quality of life improvement) (Castellanos et al., 2011; Johnson et al., 2001; Santo, 2007).

Four items were adopted from Johnson et al. (2001), Santo (2007), and Castellanos et al. (2011). The items were slightly modified for the current study by including details on the current case and including the term "value" as the action since the focus of this study is on perceptions. The quality of life item, which was adopted from Santo (2007), was not modified. Johnson et al. (2001), Santo (2007), and Castellanos et al. (2011) included the four items in their study to determine willingness to pay. Of the aforementioned studies, the only study to report psychometric values for the 
scale was Johnson et al. (2001). Cronbach's alpha for the Johnson et al. (2001) scale was .74 , yielding internal consistency per standards established by Nunnally and Bernstein (1994). Further, the other aforementioned studies found the public good variable was a positive and statistically significant predictor of willingness to pay.

Additionally, other Noneconomic Benefit items that focus on the city's national reputation, prestige, and elevated status due to the team were adopted from CVM research for the current study. Three additional items addressed respondents' perceptions of the city's national reputation, prestige, and elevated status in relation to the professional team in this construct. The national reputation item was adopted from Santo’s (2007) study on potential MLB expansion Portland, Oregon. The researcher adapted this item to remove the references to Portland and to include the details of the case in the current study. Though the reliability coefficient was not reported, this item was found to be a positive and statistically significant predictor of the dependent variable (willingness to pay) in the Santo study. The item addressing prestige was directly adopted from Fenn and Crooker (2009) with no modifications. Similarly, the reliability coefficient was not reported but the item was a positive and statistically significant predictor of the dependent variable (willingness to pay) in the Fenn and Crooker study. The elevated status item was adapted from Kellison's (2013) Columbus Arena Survey, which aimed to measure the support of the specific financing details of the NHL Columbus Blue Jackets arena in Columbus, Ohio. The item was pulled from the 7-item Perceived Arena Impact subscale. This subscale yielded a Cronbach's alpha of .90, confirming the scale's internal consistency, per the threshold established by Nunnally and 
Bernstein (1994). The item was modified to include the specific details of the case, replacing any reference to the city of Columbus.

The various items for this construct were pulled from a number of different studies (Castellanos et al., 2011; Fenn \& Crooker, 2009; Kellison, 2013; Johnson et al., 2001; Santo, 2007) due to their relevance and previous findings (e.g., statistically significant predictors of willingness to pay). Because of the unconventional method, the researcher closely examined the construct's validity and reliability in the pilot test.

\section{Table 5}

$\underline{\text { Perceived Noneconomic Benefits Item List }}$

\begin{tabular}{|c|c|}
\hline Code & Construct/Item \\
\hline & Perceived Noneconomic Benefits \\
\hline NonEconomic1 & $\begin{array}{l}\text { I value reading about the [local professional team] in the local } \\
\text { newspapers. }\end{array}$ \\
\hline NonEconomic2 & $\begin{array}{l}\text { I value watching the [local professional sports team] games on } \\
\text { television. }\end{array}$ \\
\hline NonEconomic3 & $\begin{array}{l}\text { I value talking about the [local professional sports team] with friends, } \\
\text { family, and/or co-workers. }\end{array}$ \\
\hline NonEconomic4 & The [professional team] makes the city a better place to live. \\
\hline NonEconomic5 & The proposed new stadium will improve the city's national reputation. \\
\hline NonEconomic6 & $\begin{array}{l}\text { The proposed new stadium will elevate the city's status compared to } \\
\text { other cities. }\end{array}$ \\
\hline NonEconomic7 & The proposed new stadium will bring more prestige to the city. \\
\hline
\end{tabular}

Perceived economic benefits. Perceived Economic Benefits are those benefits a respondent may consider to bring measureable improvement to the city (Crompton, 1995; Danielson, 1997). These benefits can range from the new stadium project providing additional jobs to the area or improving the city's economy. This area of interest is often a focal point in discourse presented by the definitive stakeholders when presenting a stadium project to the public. 
This variable was measured with four items. First, three items were adapted from Kellison's (2013) Columbus Arena Survey from the 7-item Perceived Arena Impact subscale. These three items were selected for the current study due to their relevance. One other item from this subscale was used in the Perceived Noneconomic Benefits construct, while the other three items were not included because they were not relevant to the case or the purpose of the study. For example, one of the excluded items refers to "more energy in downtown Columbus because of Nationwide Arena," which is not the focus for the current study. Because Kellison's scale was built specifically for the Columbus market, the items required modification to fit the context of the current study. The full 7-item subscale yielded acceptable internal consistency as seen by its Cronbach's alpha statistic of 90 (Nunnally \& Bernstein, 1994).

Further, one item from Santo's (2007) CVM survey on MLB potential expansion to Portland, Oregon was adapted, which addressed the respondent's perception of how the new stadium will affect the local economy. Research has shown that economic impact is one of the key positions stakeholders promote to gain support for stadium construction projects (Crompton, 1995; Danielson, 1997); therefore, the inclusion of this item further aided in the examination of respondent's perception of the economic impact of a stadium project. The item originally mentioned the MLB stadium and the city of Portland; therefore, modifications were made to fit the details of the cases. Santo's scale did not report the scale's psychometric properties, but the item was found to be a positive and statistically significant predictor of the dependent variable in that study (i.e., willingness to pay). 


\section{Table 6}

$\underline{\text { Perceived Economic Benefits Item List }}$

\begin{tabular}{ll}
\hline Code & Construct/Item \\
\hline & Perceived Economic Benefits \\
Economic1 & The proposed new stadium will improve the city's economy. \\
Economic2 & The proposed new stadium will create jobs for the community. \\
Economic3 & The city's economic success depends on the proposed new stadium. \\
Economic4 & The proposed new stadium will bring business to the city.
\end{tabular}

Team identification. Team identification is the level of psychological connection a person has with a team (Wann, 1997). This construct was measured by three items from the Motivation Scale for Sport Consumption developed by Trail and James (2001). This scale was created to help differentiate between those respondents who watch the local sports teams and respondents who consider the local sports teams as an important part of their life (Trail \& James). The subscale proved to have acceptable internal consistency as it yielded a Cronbach's alpha of .85 (Nunnally \& Bernstein, 1994) in the Trail and James study.

Further, a comparable four-item scale developed by Wakefield (2016) was included in the current study. Wakefield argued that passion is more reliable when predicting sport consumption. Wakefield developed a scale based on the work of Vallerand et al. (2003; 2010). This scale was added to the current study as a comparison between the team identification scale and the passion scale in relation to the dependent variable. Vallerand et al. $(2003 ; 2010)$ operationally defined passion as focusing on how it relates to one's heart, mind, body, and spirit (Vallerand et al., 2003; 2010). Wakefield then applied the aforementioned criteria to a sport setting to develop the four-item scale. In its initial testing, the internal consistency was acceptable as the Cronbach's alpha 
exceeded .90 , well above the .70 standard recommended by Nunnally and Bernstien (1994). These four items were measured on a 7-point Likert scale, but response options varied by question (see Table 7). No modifications were made to either scale besides inserting the name of the team in question.

\section{$\underline{\text { Table } 7}$}

Team Identification and Passion Item List

\begin{tabular}{|c|c|}
\hline Code & Construct/Item \\
\hline & Team Identification \\
\hline ID1 & I consider myself to be a "real" fan of the [professional sports team]. \\
\hline ID2 & $\begin{array}{l}\text { I would experience a loss if I had to stop being a fan of the [professional } \\
\text { sports team]. }\end{array}$ \\
\hline ID3 & Being a fan of the [professional sports team] is very important to me. \\
\hline Passi & $\begin{array}{l}\text { How passionate are you about the [professional sports team]? (no passion- } \\
\text { ultimate passion) }\end{array}$ \\
\hline Passion2 & $\begin{array}{l}\text { During the season, to what degree does the [professional sports team] } \\
\text { occupy your mind? (never on my mind-always on my mind) }\end{array}$ \\
\hline Passion3 & $\begin{array}{l}\text { During the season, how much do you prioritize your time so that you can } \\
\text { follow the [professional sports team]? (not at all-completely) }\end{array}$ \\
\hline Passion4 & $\begin{array}{l}\text { When it comes to the [professional sports team] in your life, how do you } \\
\text { feel? (disagree-agree) }\end{array}$ \\
\hline
\end{tabular}

Stadium project support. The dependent variable, Stadium Project Support, measured the respondent's willingness to support the stadium construction project. Ultimately, respondents in San Diego were presented with the option to vote for or against the local professional stadium referendum. The items asked the respondents to consider their support for the specific project. The dependent variable was measured using the 4-item Support of Financing Plan subscale created by Kellison (2013) in his Columbus Arena Survey. This subscale addressed the specifics of the Columbus Nationwide Arena public funding plan and specifically address respondent's perception of the stadium construction plan in their respective city. It yielded a Cronbach's alpha of 
.98 , well over the .70 acceptable thresholds (Nunnally \& Bernstein, 1994) and confirming the scale's internal consistency. Though this was above Nunnally and Bernstien's threshold, the reliability coefficient is very high, which may lead to issues with multicollinearity. The items were adapted to the current study by replacing the Columbus-specific references to reflect the details of the current study.

Further, two additional items were included to address the Stadium Project Support. In the current study, both dichotomous and scale responses were used to measure the dependent variable to allow for a number of outcomes and for validation purposes. The first item was dichotomous and was created specifically for this study to provide a referendum-style question that would allow the respondents to state how they would vote if the election was held in that moment. Researchers suggested the use of referendum-style questions to reduce potential hypothetical bias (Arrow et al., 1994; Fort, 1997; Hanemann, 1994). The wording was adapted from Dillman et al. (2009) who recommended this language as a clarification when posing dichotomous yes/no questions in a voting situation. The item was modified to fit the specific case referendum details. This item has not been previously tested in a scale; therefore, has no psychometric properties to report.

The second item was adapted from Santo's (2007) CVM study on the MLB expansion to Portland. The item also addressed how the respondent would vote in the stadium referendum. This item was modified to fit the details of the current study, and removed any reference to requesting a willingness to pay value. The item was also modified to be a nominal variable, scaled to a 7-point Likert scale to provide more statistical information about the item, as it was previously a dichotomous variable (i.e., 
"how would you vote on a referendum that would provide public funding for the stadium, if it would increase the amount of taxes you pay each year by \$X”, Santo, p. 462).

Santo's scale did not report the scale's psychometric properties for the outcome variable.

\section{$\underline{\text { Table } 8}$}

Proposed Stadium Support Item List

\begin{tabular}{|c|c|}
\hline Code & Construct/Item \\
\hline & Stadium Support - Dependent Variable \\
\hline Support1 & I support the proposed tax plan to build the new stadium. \\
\hline Support2 & I am in favor of the proposed tax plan to build the new stadium. \\
\hline Support3 & $\begin{array}{l}\text { Using [specific tax mechanism] to build the new stadium is an idea I can } \\
\text { endorse. }\end{array}$ \\
\hline Support4 & $\begin{array}{l}\text { Building the new stadium with funds from the proposed tax plan is a } \\
\text { favorable plan. }\end{array}$ \\
\hline VoteYN & $\begin{array}{l}\text { In the November election, you will be asked to vote on this referendum: } \\
\text { "INCLUDE EXACT REFERENDUM LANGUAGE." If the election were } \\
\text { held today, would you vote for or against the measure? }\end{array}$ \\
\hline Vote & $\begin{array}{l}\text { I am likely to vote in support of a referendum that would provide public } \\
\text { funding for a new stadium for the [local professional team]. }\end{array}$ \\
\hline
\end{tabular}

Additional variables. A number of items were included in the instrument to assess other potential factors that may influence a respondent's willingness to support a stadium referendum.

Opportunity costs. Opportunity costs refer to the alternative areas where public funds may be better applied such as the local public school system, the police force, or any other public utility in need of additional financial support from the public (Lansing \& Casper, 2000). This item was adapted from Santo (2007) and modified to remove the details from the original study (i.e., references to Portland and MLB). No psychometric data was reported for this scale, but this item was found to have a negative and statistically significant effect on the dependent variable (willingness to pay) in the Santo 
study. In other words, respondents who felt the city had other, more pressing issues to invest in were less willing to pay for the MLB stadium project.

Potential relocation. Fenn and Crooker (2009) examined how the threat of relocation affected respondents' willingness to pay. This may be an important variable because the respondent may believe the team may relocate if a new local stadium is not financed and built. The Chargers openly discussed relocation opportunities prior to the referendum, which also had merit as the NFL granted the team one year (until January 2017) to determine if it would move to Los Angeles. The item was adapted from Fenn and Crooker and modified to remove the details from the original study (i.e., references to Minnesota Vikings). Cronbach's alpha was not reported for this scale, but this item was a positive and statistically significant predictor of the dependent variable (willingness to pay). In other words, respondents were willing to pay more when they considered the team's relocation coming to fruition. It should also be noted that the Chargers did opt to relocate to Los Angeles, California in January 2017, two months after the failed San Diego referendum.

Knowledge of the proposed stadium plan. Many of the sport-based CVM studies were based on hypothetical situations (Castellanos et al., 2011; Groothuis et al., 2004; Johnson \& Whitehead, 2000; Johnson et al., 2001; Johnson et al., 2006, 2007; Owen, 2006; Santo, 2007), where a hypothetical bias may exist because the respondent tends to overstate their willingness to pay since the issue is unlikely to occur in reality. The two items were included to assess the respondent's preexisting knowledge of the referendum. The researcher created the original item, as it is a variable that has not been directly measured in previous research. 
Details of proposed stadium plan. The specific details of each proposed stadium funding plan may impact a respondent's willingness to support a new project. Details such as how long the additional taxes will be in place or how much the proposed taxes may be could be considered unique and potentially covariates in the model. Various CVM studies included items that addressed the details of the financing plans. The tax length item was adapted from Atkinson et al. (2008) and Johnson et al. (2006). This item was modified from an interval scale to remove the specific length of time included in the original study to ordinal, measured on a 7-point Likert scale (strongly agree to strongly disagree). The tax amount item was adopted from Fenn and Crooker (2009), Groothius et al. (2004), and Johnson et al. (2006) and was modified to remove the specific tax amount included in the original study. The tax amount item was an interval scale and assigned specific dollar figures to aggregate the market's willingness to pay threshold. Similarly, the tax length item used a similar approach, assigning specific years to the item. The tax

\section{$\underline{\text { Table } 9}$}

Additional Influencing Variable Item List

\begin{tabular}{ll}
\hline Code & Construct/Item \\
\hline OppCost & $\begin{array}{l}\text { Additional Influencing Variables } \\
\text { The city has other, more pressing social issues that should be addressed } \\
\text { before public money is spent on this proposed stadium project. } \\
\text { The [professional team] may relocate to another city if they do not get a } \\
\text { new stadium. }\end{array}$ \\
Relocation & $\begin{array}{l}\text { I consider myself to be knowledgeable of the proposed stadium project. } \\
\text { Knowledge length of time it will take to pay off the new stadium will influence } \\
\text { TaxLength }\end{array}$ \\
TaxAmount & $\begin{array}{l}\text { how I vote for the new stadium project. } \\
\text { The proposed tax plan will influence how I vote for the new stadium } \\
\text { project. }\end{array}$
\end{tabular}


amount item was also changed from interval to ordinal scale, measured on a 7-point Likert scale (strongly agree to strongly disagree).

Stakeholder presence. Expanding on the Stakeholder Influence construct, Stakeholder Presence is the evaluation of the specific stakeholder's involvement with the stadium construction project. More specifically, Stakeholder Presence was included to assess the definitive stakeholders in San Diego (i.e., the business community, politicians, the media, proponent groups, and team owners). This section of the instrument allowed the respondent to specify the stakeholders in the market whom they perceived were openly supporting and/or opposing the stadium measure. The definitive stakeholders as defined by extant research on the topic (see Freidman \& Mason, 2004, 2005) were addressed through descriptive items.

To assess the specific definitive stakeholders involved with the stadium project, four items were adapted from the American National Election Studies (ANES) 2012 Direct Democracy Study (ANES, n.d.). ANES examines election outcomes by nationally surveying the American electorate (ANES, 2016). The items and response options were modified to mention the stadium project proposal as the campaign in question, and to include the definitive stakeholders in the item's responses. Respondents were provided the option to choose "all that may apply" when indicating which stakeholders they perceived to be in favor and/or against the stadium project (for items Presence1 and Presence3). An open-ended option was provided in items Presence 2 and Presence 4 when respondents signified they were aware of other stakeholder in favor and/or against the stadium project. 


\section{Table 30}

Stakeholder Presence Item List

\begin{tabular}{ll}
\hline Code & Construct/Item \\
\hline Presence1 1 & $\begin{array}{l}\text { Stakeholder Presence } \\
\text { From the list below, please choose which individuals or groups who you } \\
\text { are aware of campaigning IN FAVOR OF the stadium project proposal. } \\
\text { Choose all that apply. If you aren't aware any individuals or groups } \\
\text { campaigning IN FAVOR OF the stadium project proposal, please select } \\
\text { "Not aware of other person or group." }\end{array}$ \\
Presence2 & $\begin{array}{l}\text { Are there any other individuals or groups who you are aware of } \\
\text { campaigning IN FAVOR OF the stadium project proposal? Please list. If } \\
\text { you aren't aware of any other individuals or groups campaigning IN }\end{array}$ \\
FAVOR OF the stadium project proposal, please select "Not aware of other \\
Person or group".
\end{tabular}

Demographics. The instrument included items to address the demographic makeup of each participant. The nine demographic variables included: participant's age, household income, gender, confirmation of voter registration status, confirmation of resident of city in question, race, tenure in city, education level, and residence in relation to the new stadium location. Participants were given the option to select "I choose not to respond" to sensitive questions regarding race, household income, and gender. Other demographic variables included were general future voting intentions and future game attendance intentions. 


\section{Table 11}

\section{Demographics Item List}

\begin{tabular}{ll}
\hline Code & Construct/Item \\
\hline & Demographics \\
Age & How old are you (in years)? \\
HHIncome & What was your annual household income in 2015 (in dollars)? \\
Gender & What is your gender? \\
Registered & Are you registered to vote in [specific city/county]? \\
Resident & I am a resident of [specific city]. \\
Race & What is your race? \\
Tenure & How many years have you lived in [specific city]? \\
Education & What is your highest level of education? \\
VoteIntentions & I intend to vote in the upcoming election on November 8, 2016. \\
Attendance & I intend to go to home games in the proposed new stadium. \\
Location & How many miles do you live from the new proposed stadium site?
\end{tabular}

\section{Field and Pilot Test}

The instrument was built for the purpose of this study and utilized various items from previous studies in addition to original items; therefore, it was vital to ensure validity and reliability of the measure before launching the study. First, a panel of experts assessed the instrument to examine and identify whether the items were valid. After this assessment, the instrument was field tested to further examine content validity and readability. Finally, the instrument was pilot tested using a small portion of the sample population to test for construct validity.

Panel of experts. The first step of instrument testing was to have a number of experts review the items for content validity and readability. The instrument was reviewed by a number of professors and doctoral students in the sport management and education field at two research institutions in the Midwest. A number of modifications were suggested during this preliminary stage, primarily with ordering. Another edit was 
to an item in the Perceived Noneconomic Benefits sub-scale that addressed if participants read about the professional sports team in the newspaper. It was suggested to add a reference to reading about the team either in the newspaper or online. Another suggestion was to add "and other events" to the item that address attendance intentions (i.e., "I intend to go to home games and other events in the proposed new stadium.").

Two new items were also suggested by the panel of experts. One expert suggested the inclusion of an item to address previous voting patterns. In addition, it was suggested to add an item that addressed participant's knowledge of the referendum itself. There was an item that addressed participants' knowledge of the project, but the experts felt that this item focused primarily on the project, and not of the mechanics surrounding the financing of the project.

Field test. The next step in checking the readability of the instrument was to test it through a field test. The instrument was field tested through ten cognitive interviews with various participants not connected to the study, based on a convenience sample of proximity and availability (Dillman et al., 2009). Dillman et al. suggested fewer than 20 interviews are adequate for examining the instrument in the field test stage. Respondents were asked to complete the instrument in a "think out loud" format in the presence of the researcher, where they were prompted to tell the interviewer everything they are thinking as they developed and recorded their responses (Dillman et al.).

Eight interviews were conducted in person, and two were conducted over the phone. The participants were not involved with the main research project, and were not provided information about the study's purpose. Each interviewee was asked to complete the online survey with the researcher present. Interviewees were asked to provide 
feedback and notes regarding the items and the overall instrument as they completed the survey. After the interviews were conducted, the researcher reexamined the feedback for any patterns and common points of issue and made adjustments to the instrument. The edits were minor in nature, and mostly included adjustments to the wording and organization of some of the items.

First, a few of the interviewees suggested replacing any reference to "proposed new stadium" or "the city" with the specific city and professional sport team name to make the survey more applicable to the participant. Another modification came from the Stadium Support sub-scale. Many of the interviewees commented about the similar wording of the items in this subscale. As this subscale was adopted from Kellison (2013), the wording remained the same, but the items were re-arranged so they were not presented one after the other. Another modification to the instrument was the order. The interviewees suggested the initial subscale presented (Stakeholder Influence) was complex, and perhaps belonged further into the survey. This subscale was moved to be the third page of items presented (Noneconomic Benefits subscale was presented across the first two pages of the instrument).

Finally, the items that addressed Tax Length and Tax Amount were removed as they were found to be repetitive (i.e., similar wording to the Stadium Support items).

Pilot test. Pilot studies are necessary when a new survey questionnaire is developed (Dillman et al., 2009); therefore, a pilot test was conducted in the current study. The pilot test was executed to test the instrument for any problems or implementation issues after the field test has been completed and adjustments to the instrument have been made. 
Additionally, many of the scales used for the instrument did not report its psychometric properties. Because of this, one of the goals of this study was to establish scale reliability. The pilot study allowed the researcher to assess the internal consistency of the instrument's items and constructs. Per Nunnally and Bernstein (1994), Cronbach's alpha estimates above .70 are acceptable for the proposed constructs.

A separate random sample of 500 email addresses of residents who live in the city of San Diego and who are of voting age was purchased specifically for the pilot study from L2, a voter data provider. As discussed earlier, L2 claims to provide "high quality enhanced voter data and customized data processing” (“About us,” 2016, para. 1).

Three contact attempts were made via an email invitation during the first two weeks of October 2016 from the researcher's university email account. The information provided to the participants was brief, as they were presented with context of the study and a request to participate by following the link embedded in the email. The email also contained contact information of the primary researcher in case participants had further questions. The first email attempt introduced the study and requested participation. The second email was sent a few days later as a reminder to fill out the survey. The final email was sent a week after the first as a last attempt to garner participation. A total of fifty-one surveys (41 usable surveys) were collected for the pilot study after the three contacts $(10 \%$ response rate).

Once the pilot study data collection was complete, the researcher analyzed the collected data to review the psychometric properties of the scale, specifically focusing on the reliability of the constructs to be included in the measurement model (i.e., Stakeholder Influence, Perceived Noneconomic Benefits, Perceived Economic Benefits, 
and Team Identification).

\section{Data Collection}

Once the pilot study was complete, the main study was launched. Because of the low response rate from the pilot study, the researcher made adjustments to the Institutional Review Board documents to add an incentive to encourage additional participation for the main study. The incentive was a \$25 Visa gift card to be given to a randomly chosen participant who opts into the gift card lottery. Participants in the main study were asked to provide their name and email addresses at the end of the survey if they wanted to be included in the lottery.

The main study was distributed to the email list in October 2016. A random sample of 1,500 emails was chosen and questionnaires were disseminated. The instrument was distributed via email utilizing Qualtrics as the data collection platform. It was important to execute the full study prior to November 8, 2016 as this study aimed to examine participant's perceptions, and not action (i.e., if and how they actually voted). The data collection for the main study began in late October 2016 and continued until November 7, 2016. Four different email contacts were launched over a two-week period starting in October 2016. After the first two initial contacts and a span of a week, only 73 surveys were completed ( $4 \%$ response rate). Due to the low response rate, a separate round of data collection commenced. The researcher posted the survey link on websites related to the City of San Diego, the San Diego Chargers, and news media websites located in San Diego. Websites included blogs, fan pages, news articles, and social media pages. See Appendix $\mathrm{C}$ for the list of websites.

The initial data collection method through email was sent another two times 
before the election on November 8, 2016 for a total of four email contacts. A total of 105 responses were collected from the email campaign (7\% response rate), and 62 responses were collected from the secondary data collection method, for a total of 167 responses. After reviewing the data for completion, there were a total of 88 useable surveys from the email campaign and 53 useable surveys from the secondary data collection method (141 total surveys, $9 \%$ response rate based on initial email campaign). Due to concerns with low sample size, particularly with how it would relate to the data analysis, the researcher included the data from the pilot study as a part of the main study. There were no changes to the items after the pilot study except the addition of an incentive, and the reliability of the subscales was acceptable based on the cutoff points established by Nunnally and Bernstein (1994); therefore, it was appropriate to include the pilot data with the data from the main study. The final sample size total was 182 useable surveys (9\% response rate based on 2,000 email campaign including the pilot study and main study).

\section{Data Analysis}

Research question 1. To address the first research question and hypotheses, structural equation modeling (SEM) was utilized. SEM is a statistical approach that "hypothesizes how sets of variables define constructs and how these constructs are related to each other" (Schumacker \& Lomax, 2016, p. 1). SEM examines the relationship between the indicators, or items, and the latent variables, or factors (Brown, 2015). In the current study, Stakeholder Influence, Perceived Noneconomic Benefits, Perceived Economic Benefits, and Team Identification were the exogenous variables, and Stadium Project Support was the endogenous variable. 
Although multiple regression (MR) could be considered an adequate statistical technique for predicting willingness to support a stadium referendum, SEM allows for the use of multiple indicators of a construct (or multiple constructs) and accounts for measurement error in each of them (Adelson, 2012). The measurement error assumption in MR is one that rarely holds true in social and behavioral sciences (Brown, 2015). Other advantages of SEM include the ability (and availability) to examine complex relationships through simultaneous tests and the ability to test construct level hypothesis at the appropriate level (Ullman, 2006). Further, SEM allows for the systematic examination of direct and indirect effects between the latent variables.

SEM requires a number of assumptions to be met. The data must have multivariate normality, the correct model specification, meet sampling assumptions such as simple random sample and independent observations, and meet a sufficient sample size of at least 200 (Kline, 2011).

AMOS version 22, statistical computer software for SEM, was utilized to test the research question 1. AMOS is an add-on program with SPSS capable of specifying the model by drawing it on the screen with the ability to "drag and drop" variable names into the model (Kline, 2011; Schumacker \& Lomax, 2016). It also provides the ability to test alternative models through free-form path drawings. AMOS also offers a special maximum likelihood method for raw data to manage data missing at random and special estimation methods for ordinal outcome variables (Kline, 2011).

The SEM analysis involved hypothesizing a model, collecting sample data, and testing the data to see how it fits with the model (Schumacker \& Lomax, 2016). SEM was utilized to test theory and the hypotheses presented. First, the measurement model, 
which included both the latent variables and the indicators to examine relationship among the indicator errors (Brown, 2015). After the measurement model was established, the structural model was built and examined, allowing for an examination of the relationship between the specified paths and the latent variables (i.e., direct effects, indirect effects).

Measurement model. The measurement model portion of the analysis included an examination the factor structure of the model to address scale reliability, convergent and divergent validity, and the relationship between the latent variables (Brown, 2015). Expected results would show that items on a specific construct would have a relatively high standardized factor loading (e.g. > |.70|) for convergent validity. To assess discriminant validity, the correlations between factors should not be excessively high (e.g. $<|.90|)($ Kline, 2011). Internal consistency was also assessed by examining the instrument's Cronbach's alpha, where an acceptable value should be above .7 (Nunnally \& Bernstein, 1994). Once the psychometric properties of the scale were addressed, the statistical analysis began. Kline outlined a six step process to SEM analysis: (a) model specification, (b) model identification, (c) selecting the measures, collect and screen the data, (d) model estimation, (e) respecification, and (f) reporting the results.

Specification. The first step of the SEM analysis is model specification. Model specification refers to drawing the measurement model diagram between Stakeholder Influence, Perceived Noneconomic Benefits, Perceived Economic Benefits, Team Identification, and Stadium Project Support. The measurement model included correlations across each latent variable.

Identification. The second step of SEM analysis is to fit the model with the data through identification. In general, there should be at least three indicators per latent 
variable, as recommended by Brown (2015) and Kline (2011). In addition, all measured variables should be free to load on only one construct, and error terms should be fixed to zero and not estimated.

Select the measures. Prior to estimating the model, the raw data was examined. Case screening and variable screening was utilized to examine the raw data. The researcher may run into analysis issues in AMOS if data is missing; therefore, it was imperative that the data be screened before it is estimated in the proposed mode. Thirtysix cases were removed from the current study due to incomplete surveys and/or nonnormality.

Estimation. Model estimation involved completing the initial analysis, including an assessment of model fit. Model fit was assessed by reviewing a number of modification indices recommended by Kline (2011). Chi-square test of significance helps determine if the model is overall a good fit. Ultimately, the researcher would want a nonsignificant chi-square statistic to accept the model fit null hypothesis which states the specified model fit is true. The chi-square value is highly sensitive to sample size and data normality; therefore, other approximate fit indices must be assessed. The root mean square error of approximation (RMSEA) was assessed, which is a "badness of fit" index. Ideally, this index should be zero. Kline also suggests assessing the comparative fit index (CFI), which would be ideal fit if the statistic is close to one. Finally, Kline suggests including the standardized root mean square residual (SRMR), which would indicate a good model fit if the statistic is less than .06.

Respecification. If the model fit is poor, respecification is needed. This iterative process must consider theory when making respecifications to the model to achieve 
acceptable model fit. Respecification includes an examination of areas of concern (e.g., chi-square test for significance, correlation residuals, factor loadings, error variances, modification indices, cross loadings, etc.), bearing in mind theoretical implications before making any model adjustments. Once the specific issues were addressed, and an acceptable model fit is obtained, the results and conclusions were reported and the structural model analysis began.

Structural model. The structural model examined the structural relationship between the latent variables. Path models allow the researcher to specify direct, indirect, and correlated effects between the latent variables (Schumacker \& Lomax, 2016). In this case, the direct effects between the Stakeholder Influence, Perceived Noneconomic Benefits, Perceived Economic Benefits, and Team Identification exogenous variables will be examined in relation to the Stadium Project Support endogenous variable. This step established the relationship (or lack thereof) with the exogenous variables and the endogenous variable (i.e., hypotheses 1-5). 


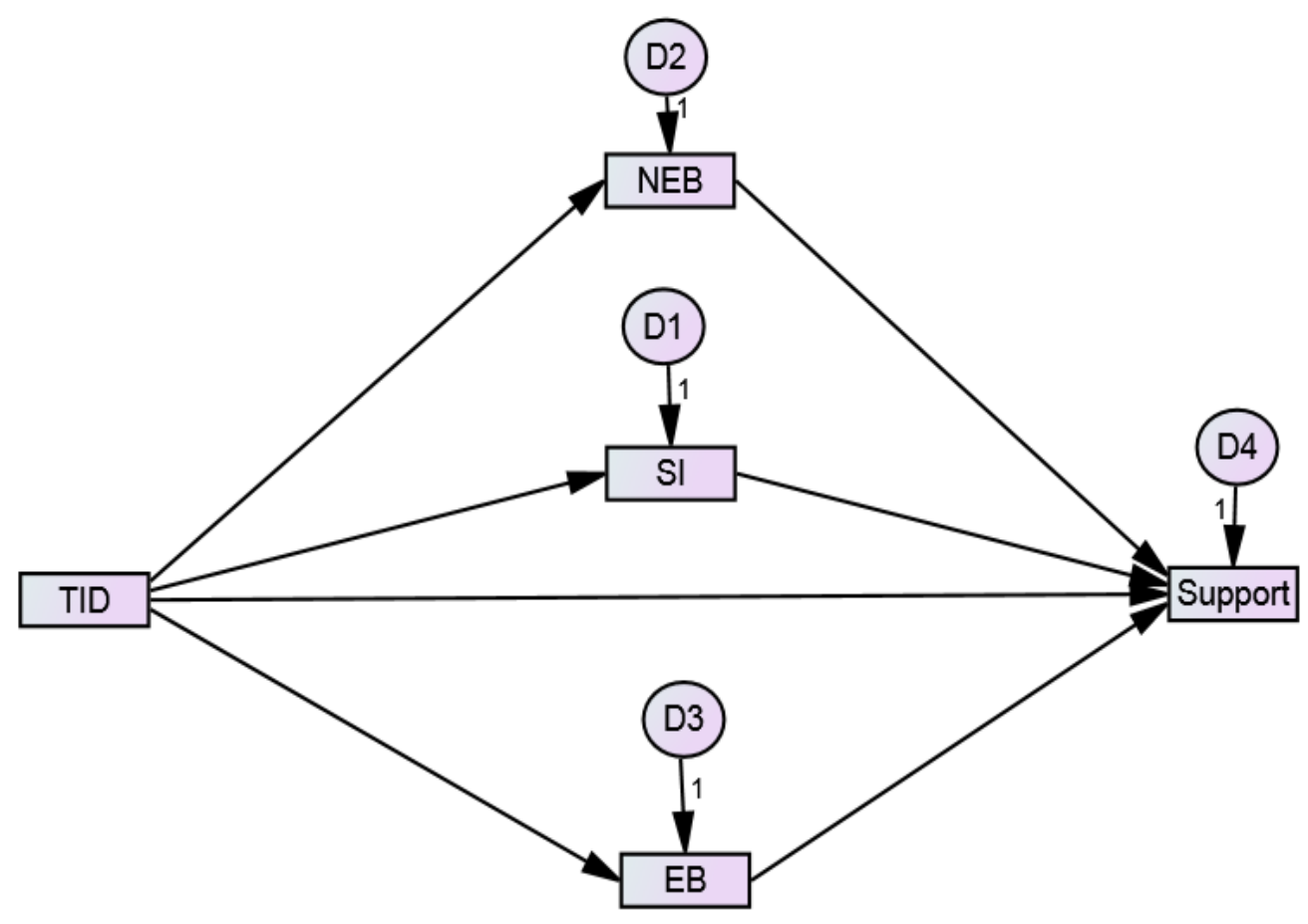

Figure 1. Hypothesized structural model.

Mediation analysis. Once model fit has been established for both the measurement model and structural model, the relationship between the exogenous variable, the mediator variable(s), and the endogenous variable will be examined separately in a mediation analysis. This analysis addresses hypotheses 5-7, where Team Identification remains the exogenous variable and Stadium Support is the endogenous variable. The other latent variables (i.e., Stakeholder Influence, Perceived Noneconomic Benefits, Perceived Economic Benefits) are tested as mediators.

Due to the existence of multiple mediators in the model and the researcher's hypotheses, the phantom model approach was applied, as recommended by Kenny (2016). The inclusion of multiple latent variables and paths potentially influence the relationship between the hypothesized relationship between the variables in question. 
The phantom model approach allows for a more flexible approach for estimating and testing models with multiple latent variables (Macho \& Ledermann, 2011), as it has the ability to isolate each mediating relationship. The logic behind the phantom model approach is respecifying the indirect effect of the relationship in question to a total effect in an independent model (Macho \& Ledermann, 2011). The phantom model approach addresses the limitations of AMOS, by modeling "the specific indirect effects of interest in the parent model as the total effects in dependent phantom model" (Perera, 2013, p. 48).

Phantom models are functional only, serving as additional latent variables with fixed paths "to force SEM programs to provide estimates and tests of specific effects and of their contrasts" (Macho \& Ledermann, p. 35). The authors also recommended the use of a phantom model when using AMOS, specifically. Macho and Ledermann recommend building a phantom model where the researcher: (1) identifies the specific variables and paths to be tested, (2) adds a new latent variable and path to replicate each identified variable in step 1, (3) restrict the path coefficients for the paths of the main and replicated variables, and (4) equally constrain the variance of the exogenous phantom variable and its counterpart in the main parent model. This is repeated for every latent variable relationship the researcher is interested in examining (i.e., the hypothesis to be tested).

As recommended by Macho and Ledermann (2011), the researcher created a separate phantom model with three latent variables (i.e., the exogenous variable, the mediator, and the endogenous variable). Two paths were drawn in the phantom model: one from the exogenous variable to the mediator, and another path from the mediator to 
the endogenous variable. The paths were labeled $a$ and $b$ in the phantom model and in the parent model between the specific variables in question. The variance of the exogenous variable in both the parent model and phantom model were constrained to be the same (i.e., labeled var_a). Finally, the variables in the phantom model were labeled similarly to the parent model (e.g., phantom_TID, phantom_EB, phantom_Support, etc.). This process was repeated for each of the hypotheses by changing the names of the variables, and shifting the constrained paths in the parent model.

As recommended by Kenny (2016), Bollen and Stine (1990), Shrout and Bolger (2002), and Preacher and Hayes (2008), bootstrapping was utilized to test for the significance of the indirect effect of Team Identification on Stadium Support, addressing hypotheses 5-7. Bootstrapping is a way to estimate statistical estimates based on resampling from original observations (Bollen \& Stine). Further, the bootstrap procedure along with the phantom model approach generates the unstandardized beta weights, standard errors, and confidence intervals for the specific indirect effect in question (Perera, 2013). A 90\% confidence interval and bootstrapping sample of 2000 was employed to test the significance of the individual effects for each hypothesized relationship. The researcher should review the confidence interval yielded from the bootstrapping analysis to determine statistical significance. The researcher can be confident that the indirect effect is statistically significant if zero is not in the confidence interval (Kenny). The Sobel method was not recommended for this study as it assumes the hypothesized relationship between the latent variable(s) are not correlated (Kenny), which is not the case in the current study. 
Research question 2. To address the second research question, the researcher examined Stakeholder Presence items descriptive statistics. The Stakeholder Presence items asked the respondent to identify the definitive stakeholders they perceive to be in favor and/or against the stadium construction project. Because this was categorical data, frequencies were examined, as it provided insight as to which stakeholder is most frequently chosen in each of the cases.

In addition, there was an opportunity for respondents to provide additional stakeholders associated with the stadium project with an open-ended response with the Stakeholder Presence items. The data from the open-ended responses was reviewed and categorized based on the definitive stakeholder group (i.e., politicians, the media, stadium proponent groups, team owners, businesses). Responses that did not belong to a definitive stakeholder group were placed in an "other" category to be further examined qualitatively for patterns and trends based on the literature (see Friedman \& Mason, 2004, 2005). 


\section{CHAPTER IV}

\section{RESULTS}

The purpose of the current study was to examine how Stakeholder Influence, Perceived Noneconomic Benefits, Perceived Economic Benefits, and Team Identification may influence a constituent's willingness to support a professional sport stadium project.

Data were collected from citizens of San Diego, California who were of voting age (18 years or older) and responded to the online-based survey in October 2016. Structural equation modeling (SEM) was utilized to analyze the data for research question 1. Frequencies were examined to address research question 2. The results of the statistical analysis are presented in the following section.

\section{Scale Validation}

Scale validation is an essential part of quantitative research. To ensure the instrument was sound in readability and validity, the instrument was tested in three stages of validation--panel of experts, field test, and a pilot test--as suggested by Dillman et al. (2009). The results of the pilot test are reported in the following section.

\section{Pilot Test}

Modifications were made to the survey instrument based on feedback received from the panel of experts and the field test, which helped to assess readability and content validity. The final instrument was put together and executed via a pilot test to assess reliability. 
Once the data were collected for the pilot study, the researcher assessed the internal consistency of the subscales. As recommended by Nunnally and Bernstein (1994), a Cronbach's alpha statistic equal to or exceeding .70 is acceptable for internal consistency for the subscales. A review of Table 12 shows that each of the subscales was above the recommended .70 cutoff point. No additional adjustments were made to the instrument. Further, the data from the pilot study were combined with the data from the main study to address the low sample size. The Cronbach's alpha statistic for the main study is reported in Table 14.

\section{$\underline{\text { Table } 42}$}

$\underline{\text { Cronbach's Alpha Statistics from the Pilot Study }}$

\begin{tabular}{lcc}
\hline Subscale & Number of Items & Alpha \\
\hline Noneconomic Benefits & 7 & .934 \\
Stakeholder Influence & 4 & .864 \\
Economic Benefits & 4 & .923 \\
Team Identification & 3 & .919 \\
Stadium Support & 4 & .962 \\
\hline
\end{tabular}

\section{Data Analysis}

\section{Demographic Information}

The final sample consisted of 182 total responses. Fifty-six percent of the respondents were male and closely resembled the population, residents in the city of San Diego, as reported by the U.S. Census (see Table 3 for more information), which consisted of $50.5 \%$ of males, according to the U.S. Census (2010). Overall, the sample was more educated than the population, as $63.8 \%$ of the respondents indicated they have 
a four-year degree or higher. Comparatively, $42 \%$ of the population had a Bachelor's degree or higher (U.S. Census). In terms of race, the sample had a higher percentage of White participants $(68.9 \%)$ when compared to the population $(58.9 \%)$. The sample was underrepresented in all other ethnic categories compared to the population. Lastly, the sample was wealthier than the population, as the U.S. Census reported the median household income in 2014 was less than $\$ 70,000$. More than $60 \%$ of the participants in the current study had an annual household income of over $\$ 70,000$. Other demographic variables collected were also reported in Table 13.

\section{$\underline{\text { Table } 13}$}

\section{Demographic Frequencies}

\begin{tabular}{|c|c|c|}
\hline Variables & Percentage & $N$ \\
\hline \multicolumn{3}{|l|}{ Gender } \\
\hline Male & 54.9 & 100 \\
\hline Female & 36.8 & 67 \\
\hline Chose not to respond & 8.2 & 15 \\
\hline \multicolumn{3}{|l|}{ Age } \\
\hline Under 18 & 0 & 0 \\
\hline $18-24$ & 9.3 & 17 \\
\hline $25-34$ & 19.8 & 36 \\
\hline $35-44$ & 18.1 & 33 \\
\hline $45-54$ & 13.1 & 24 \\
\hline $55-64$ & 18.6 & 34 \\
\hline $65-74$ & 12.6 & 23 \\
\hline $75-84$ & 2.7 & 5 \\
\hline 85 or older & 1.0 & 2 \\
\hline Chose not to respond & 4.4 & 8 \\
\hline \multicolumn{3}{|c|}{ Annual Household Income } \\
\hline Less than $\$ 10,000$ & 1.6 & 3 \\
\hline$\$ 10,001-\$ 19,999$ & 5.5 & 10 \\
\hline$\$ 20,000-\$ 29,999$ & 2.7 & 5 \\
\hline$\$ 30,000-\$ 39,999$ & 3.8 & 7 \\
\hline$\$ 40,000-\$ 49,999$ & 7.1 & 13 \\
\hline$\$ 50,000-\$ 59,999$ & 3.3 & 6 \\
\hline$\$ 60,000-\$ 69,999$ & 4.9 & 9 \\
\hline$\$ 70,000-\$ 79,999$ & 4.9 & 9 \\
\hline
\end{tabular}




\begin{tabular}{lll}
\hline Variables & Percentage & $N$ \\
\hline \$80,000-\$89,999 & 6.6 & 12 \\
\$90,000-\$99,999 & 5.5 & 10 \\
\$100,000-\$149,999 & 19.2 & 35 \\
More than \$150,000 & 24.2 & 44 \\
Chose not to respond & 10.4 & 19 \\
\hline Highest Level of Education Completed & & \\
High school & 1.6 & 3 \\
Some college & 13.7 & 25 \\
Two year degree & 4.9 & 9 \\
Four year degree & 30.2 & 55 \\
Graduate degree & 33.5 & 61 \\
Doctorate & 11.5 & 21 \\
Chose not to respond & 10.4 & 19 \\
\hline Race* & & \\
White & 68.2 & 126 \\
Black & .5 & 1 \\
Native American & 1.1 & 2 \\
Asian & 2.7 & 5 \\
Pacific Islander & 1.1 & 2 \\
Hispanic & 11.0 & 20 \\
Other & 4.4 & 8 \\
Chose not to respond & 9.9 & 18 \\
\hline Tenure in City & & \\
Less than 1 year & 1.6 & 3 \\
1-2 years & 2.7 & 5 \\
2-5 years & 11.5 & 21 \\
5-10 years & 8.8 & 16 \\
More than 10 years & 70.9 & 129 \\
Chose not to respond & 4.4 & 8 \\
\hline Voter Registration Status & & \\
Registered & 92.3 & 169 \\
Not registered & 2.7 & 1 \\
Planned on registering before the election & .5 & 7 \\
Chose not to respond & 3.8 & 7 \\
\hline Voting Intentions & 95.6 & \\
Plan on voting & .5 & \\
Won't be voting & 3.8 & \\
Chose not to respond & 90.7 & 5.5 \\
\hline Past Voting Behavior & 3.8 & \\
Voted in previous elections & & \\
Has not voted in previous elections & & \\
Chose not to respond & & \\
\hline & & \\
& & \\
\hline
\end{tabular}




\begin{tabular}{lll}
\hline Variables & Percentage & $N$ \\
\hline Future Attendance Habits & & \\
Attend games/events & 34.6 & 63 \\
Do not plan on attending games/events & 61.5 & 112 \\
Chose not to respond & 3.8 & 7 \\
\hline Location of Stadium & & \\
Less than 10 miles & 51.6 & 94 \\
11-20 miles & 31.3 & 57 \\
21-30 miles & 9.3 & 17 \\
31-40 miles & 1.6 & 3 \\
More than 50 miles & 2.2 & 4 \\
Chose not to respond & 3.8 & 7 \\
\hline
\end{tabular}

Note. *Per the U.S. Census, persons who indicated Hispanic may be of any race, and may also be included in applicable race categories.

\section{Descriptive Statistics}

The descriptive statistics for each latent variable were examined. Each item was measured on a 7 -point Likert scale $(1=$ strongly disagree to $7=$ strongly agree $)$. In addition, the instrument reliability was examined. The alphas for the subscales ranged from .899 to .970 , well above the .70 recommended by Nunnally and Bernstein (1984). Mean scores, standard deviations, and reliability coefficients are reported in Table 14.

\section{Table 14}

$\underline{\text { Descriptive Statistics and Reliability Coefficients for Subscales }}$

\begin{tabular}{|c|c|c|c|}
\hline Item & $\alpha$ & $M$ & $S D$ \\
\hline Stakeholder Influence & .899 & & \\
\hline $\begin{array}{l}\text { I trust the community leaders who are associated with the } \\
\text { proposed stadium project. }\end{array}$ & & 2.81 & 1.681 \\
\hline $\begin{array}{l}\text { I believe the community leaders who are associated with the } \\
\text { proposed stadium project are knowledgeable. }\end{array}$ & & 3.74 & 1.718 \\
\hline $\begin{array}{l}\text { I agree with the community leaders who are associated with } \\
\text { the proposed stadium project. }\end{array}$ & & 2.86 & 1.709 \\
\hline $\begin{array}{l}\text { I have common interests with the community leaders who are } \\
\text { associated with the proposed stadium project. }\end{array}$ & & 2.81 & 1.712 \\
\hline
\end{tabular}




\begin{tabular}{|c|c|c|c|}
\hline Item & $\alpha$ & $M$ & $S D$ \\
\hline Noneconomic Benefits & .948 & & \\
\hline $\begin{array}{l}\text { I value reading about the San Diego Chargers in the local } \\
\text { newspapers or online. }\end{array}$ & & 3.68 & 2.041 \\
\hline I value watching the San Diego Chargers games on television. & & 3.97 & 2.238 \\
\hline I value talking about the San Diego Chargers with friends, & & 373 & 2146 \\
\hline The Chargers makes the San Diego a better place to live. & & 3.78 & 1.915 \\
\hline $\begin{array}{l}\text { The proposed new stadium will improve San Diego's national } \\
\text { reputation. }\end{array}$ & & 3.81 & 2.060 \\
\hline $\begin{array}{l}\text { The proposed new stadium will elevate San Diego's status } \\
\text { compared to other cities. } \\
\text { The proposed new stadium will bring more prestige to San }\end{array}$ & & 3.61 & 2.119 \\
\hline $\mathrm{m}$ will bring more prestige to San & & 3.63 & 2.126 \\
\hline Economic Benefits & .935 & & \\
\hline $\begin{array}{l}\text { The proposed new stadium will improve San Diego's } \\
\text { economy. }\end{array}$ & & 3.49 & 2.130 \\
\hline $\begin{array}{l}\text { The proposed new stadium will create jobs for the } \\
\text { community. }\end{array}$ & & 4.09 & 1.968 \\
\hline The proposed new stadium will bring business to San Diego. & & 3.68 & 2.143 \\
\hline $\begin{array}{l}\text { Team Identification } \\
\text { I consider myself to be a "real" fan of the San Diego }\end{array}$ & .950 & & \\
\hline $\begin{array}{l}\text { Chargers. } \\
\text {. }\end{array}$ & & 3.46 & 2.201 \\
\hline $\begin{array}{l}\text { I would experience a loss if I had to stop being a fan of the } \\
\text { San Diego Chargers. }\end{array}$ & & 2.92 & 2.144 \\
\hline $\begin{array}{l}\text { Being a fan of the San Diego Chargers is very important to } \\
\text { me. }\end{array}$ & & 2.84 & 2.131 \\
\hline Stadium Support (dependent variable) & .970 & & \\
\hline I support the proposed tax plan to build the new stadium. & & 2.85 & 2.236 \\
\hline $\begin{array}{l}\text { I am in favor of the proposed tax plan to build the new } \\
\text { stadium. }\end{array}$ & & 3.09 & 2.175 \\
\hline $\begin{array}{l}\text { Using hotel tax to build the new stadium is an idea I can } \\
\text { endorse. }\end{array}$ & & 3.48 & 2.112 \\
\hline $\begin{array}{l}\text { Building the new stadium with funds from the proposed tax } \\
\text { plan is a favorable plan. }\end{array}$ & & 3.08 & 2.218 \\
\hline
\end{tabular}

Note. All items are a 7-point Likert Scale (strongly disagree to strongly agree).

\section{Assumptions}

The main assumptions were checked prior to the analysis (i.e., sample size, normality, linearity, and homoscedasticity). There are a number of different perspectives on adequate sample size for structural equation modeling. There is a general sense, 
though, that there is not a "one size fits all" (Muthén \& Muthén, 2002; Wolf, Harrington, Clark, \& Miller, 2013). As such, a number of researchers have stated that a sample of 100 to 150 respondents can be considered an adequate minimum (Anderson \& Gerbing, 1988; Ding, Velicer, \& Harlow, 1995; Tabachnick \& Fidell, 2001; Tinsely \& Tinsely, 1987). Further, a sample size of at least 150 with 3 to 4 items per factor removes statistical bias and is typically sufficient for a convergent and proper solution (Anderson \& Gerbing, 1984; Iacobucci, 2009). The final sample size for the current study was 182 participants. Each latent variable contained at least three items; therefore, the sample size was adequate for the statistical analysis.

Multivariate normality was assessed through a review of skewness and kurtosis. Skewness that lies between -1 and 1 is acceptable. Anything outside of this range should be managed through transforming the data or removing the influential outliers (Gaskin, 2012). A kurtosis score of 2.20 or more is a cause for concern (Sposito, Hand, \& Skarpness, 1983). The item "Economic3” (i.e., "San Diego's economic success depends on the proposed new stadium") was the only item that displayed issues with skewness or kurtosis. This item had a skewness score of 1.389 and was positively skewed. It also had the lowest mean score (2.22). Because this item was heavily skewed, it was removed from the analysis.

Linearity and homoscedasticity were addressed by reviewing scatter plots. Both of these assumptions were met through an examination of the scatterplots. 


\section{Research Question 1}

RQ1: What effect does Stakeholder Influence, Perceived Economic Benefits, Perceived Noneconomic Benefits, and Team Identification have on constituents' willingness to support a stadium referendum?

Measurement model. The measurement model initially included 20 items and five latent constructs. Before model fit was addressed, convergent and divergent validity were assessed. An examination of the item factor loadings displayed convergent validity issues with item Influence2. The item yielded a factor loading less than the recommended $|.70|$ (Kline, 2011). Because of this, the item was removed from the analysis. After the removal of Influence2, the data displayed discriminant validity issues between the Perceived Noneconomic Benefits (NEB) and Perceived Economic Benefits (EB) factor. Utilizing the validity statistics tool developed by Gaskin (2016), the researcher determined the average variance extracted for NEB was larger than EB. Because of this issue, the NEB factor was split into two factors-Perceived Noneconomic Benefits-individual and Perceived Noneconomic Benefits-community. A number of the items in this factor (i.e., Noneconomic1, Noneconomic2, Noneconomic3, and Noneconomic4) were used as the public good variable in the contingent valuation method (CVM) studies. Further, the content of the items focused on the individual (e.g., "I value reading about the [local professional team] in the local newspapers or online") while the other three items focused on the community aspect of the team (e.g., "The proposed new stadium will improve the city's national reputation"). The factor split addressed the discriminant validity issue as well as remained consistent with theory. Convergent and discriminant validity issues no longer existed after the factor split. Additionally, while 
the correlations may seem high, Kline (2011) recommended the correlations between factors should not be excessively high (e.g., < $|.90|$ ); therefore, the analysis continued.

Due to the iterations completed to address discriminant and convergent validity, specifically with the factor split, the hypotheses were updated. Two additional hypotheses were added to address the Perceived Noneconomic Benefits factor split (i.e., hypothesis $2,3,7$, and 8 ).

H1: Stakeholder Influence has a direct positive effect on Stadium Support. H2: Perceived Noneconomic Benefits-individual has a direct positive effect on Stadium Support.

H3: Perceived Noneconomic Benefits-community has a direct positive effect on Stadium Support.

H4: Perceived Economic Benefits has a direct positive effect on Stadium Support. H5: Team Identification has a direct positive effect on Stadium Support. H6: Team Identification has an indirect positive effect on Stadium Support through Stakeholder Influence.

H7: Team Identification has an indirect positive effect on Stadium Support through Perceived Noneconomic Benefits-individual.

H8: Team Identification has an indirect positive effect on Stadium Support through Perceived Noneconomic Benefits-community.

H9: Team Identification has an indirect positive effect on Stadium Support through Perceived Economic Benefits.

As displayed in Table 15, all factor correlations were positive. Each of the six factors was positively correlated and statistically significant, given the critical ratio for 
each path was larger than 1.96 (Bryne, 2001). This finding shows that each of the variables is related the other variables. The size of the correlation coefficient $(r=.884$, $p<.001$ ) between Perceived Economic Benefits and Stadium Support was the largest, and could be expected given the perceived relationship between supporting the proposed stadium project and its potential impact on the local economy. Another expected high correlation coefficient $(r=.853, p<.001)$ was between Perceived Economic Benefits and Perceived Noneconomic Benefits-community, as both of these factors focused on the perception of the project's impact on the community. Stakeholder Influence yielded a high correlation coefficient $(r=.827, p<.001 ; r=.806, p<.001)$ with Perceived Economic Benefits and Support, respectively. Again, these factors each relate to the perception of the project on the community. The high correlations and relationship between factors will be further addressed in the structural model.

\section{$\underline{\text { Table } 15}$}

\section{$\underline{\text { Factor Correlations }}$}

\begin{tabular}{lcccccc}
\hline Variables & SI & NEBi & NEBc & EB & TID & Support \\
\hline SI & - & & & & & \\
NEBi & .545 & - & & & & \\
NEBc & .751 & .693 & - & & & \\
EB & .827 & .616 & .853 & - & & \\
TID & .551 & .859 & .683 & .597 & - & \\
Support & .806 & .636 & .799 & .884 & .616 & - \\
\hline
\end{tabular}

Note. SI, Stakeholder Influence; NEBi, Noneconomic Benefits-individual; NEBc, Noneconomic Benefits-community; EB, Economic Benefits; TID, Team Identification

Once convergent and discriminant validity were addressed, model fit was assessed by a number of approximate fit indices. Table 16 displays model fit statistics 
from the initial model (i.e., measurement model after convergent and divergent validity issues were addressed). One respecification was made to the measurement model after the adjustments from the convergent and discriminant validity issues. The modification index between e12 and e14 was the highest for the model. Because of this, a correlation path was added between the two errors, which improved model fit for most model fit indices $\left(\chi^{2}=270.426, d f=154, p<.001\right.$, root mean square error of approximation $[$ RMSEA $]=.065$, RMSEA confidence interval $=.052-.077$, standardized root mean square residual $[\mathrm{SRMR}]=.0351$, comparative fit index $[\mathrm{CFI}]=.977)$. Given the value for RMSEA is below .08 (Browne \& Cudeck, 1993), CFI is close to one and above .95 (Hu \& Bentler, 1999; Kline, 2011), and SRMR is close to zero (Kline), they have each met the thresholds established (Kline). Thus, the measurement model for this data was acceptable.

\section{$\underline{\text { Table } 16}$}

$\underline{\text { Values of Model Fit for Measurement Model }}$

\begin{tabular}{cccc}
\hline & & \multicolumn{2}{c}{ Model } \\
\cline { 3 - 4 } Index & Recommended & Initial & Final \\
\hline$\chi^{2}$ & Significant $p$-value & .000 & .000 \\
CFI & .90 or greater & .97 & .977 \\
SRMR & .06 or less & .0399 & .0351 \\
RMSEA & .10 or less & .073 & .065 \\
\hline
\end{tabular}

Note $\chi^{2}=$ Chi-square statistic. $\mathrm{CFI}=$ Comparative fit index. $\mathrm{SRMR}=$ Standardized root mean square residual. RMSEA = Root mean square error of approximation. Recommendations are from Kline (2011).

It is important to note that the $\chi^{2}$ statistic was significant, indicating poor model fit. There has been much debate regarding the value of the $\chi^{2}$ statistic with respect to other approximate fit indices. The $\chi^{2}$ statistic is sensitive to both large and small sample 
sizes (see Kenny \& McCoach, 2003; Jöreskog \& Sörbom, 1993). Bryne (2001) stated that the $\chi^{2}$ statistic has been shown to be unreliable across SEM studies. Brown (2015) suggested this statistic is typically reported but other fit indices are relied on more heavily to evaluate model fit. Further, Miles and Shevlin (2007) recommended against reliance on the $\chi^{2}$ statistic alone, considering the number of fit indices available to assess model fit. Miles and Shevlin recommended considering the fit indices as a whole, along with sample size, reliability, and model complexity. Hooper, Coughlan, and Mullen (2008) suggested that despite the problems associated with the $\chi^{2}$ statistic, it should continue to be reported along with the degrees of freedom and $p$-value. Though sample size may be considered an issue when working with the $\chi^{2}$ statistic, CFI has been found to be affected minimally by sample size (Fan, Thompson, \& Wang, 1999). While the $\chi^{2}$ statistic was significant for the current study, lending itself to poor model fit, the assessment of RMSEA, SRMR, and CFI, all which confirmed adequate model fit, provided enough evidence to deem the measurement model as acceptable.

The standardized factor loadings were all statistically significant $(p<.001)$ based on the critical ratios. The factor loadings ranged from .79 to .98: Stakeholder Influence (Influence $1=.88$, Influence $3=.96$, Influence $4=.79$ ); Noneconomic Benefits-individual $($ Noneconomic $1=.90$, Noneconomic $2=.97$, Noneconomic $3=.93) ;$ Noneconomic Benefits-community $($ Noneconomic $4=.82$, Noneconomic $5=.93$, Noneconomic6 $=.98$, Noneconomic7 $=.95)$; Support $($ Support $1=.96$, Support2 $=.96$, Support3 $=.88$, Support $4=.97) ;$ Economic Benefits $($ Economic $1=.97$, Economic $2=.88$, Economic4 $=$ $.90)$; and Team Identification $(\mathrm{ID} 1=.92, \mathrm{ID} 2=.95, \mathrm{ID} 3=.92)$. Each of these factor loadings was acceptable per the .40 cutoff criteria established by Stevens (2009). Hair, 
Tatham, Anderson, and Black (1998) also suggested a cutoff point of .45 based on a sample size of 150 . The data for this study comply with both recommendations. Refer to Figure 2 for the measurement model.

Further, an examination of the squared multiple correlations showed that over $90 \%$ of the variance in the indicators was accounted for by the respective latent variables. These indicators included Economic1, Support4, Support2, Support1, Noneconomic7, Noneconomic6, Influence3, and Noneconomic2. The multiple $R^{2}$ for two indicators were relatively low, compared to the other items in the study, accounting for $60 \%$ of the variance in their respective latent variables (i.e., Noneconomic4 and Influence4). 


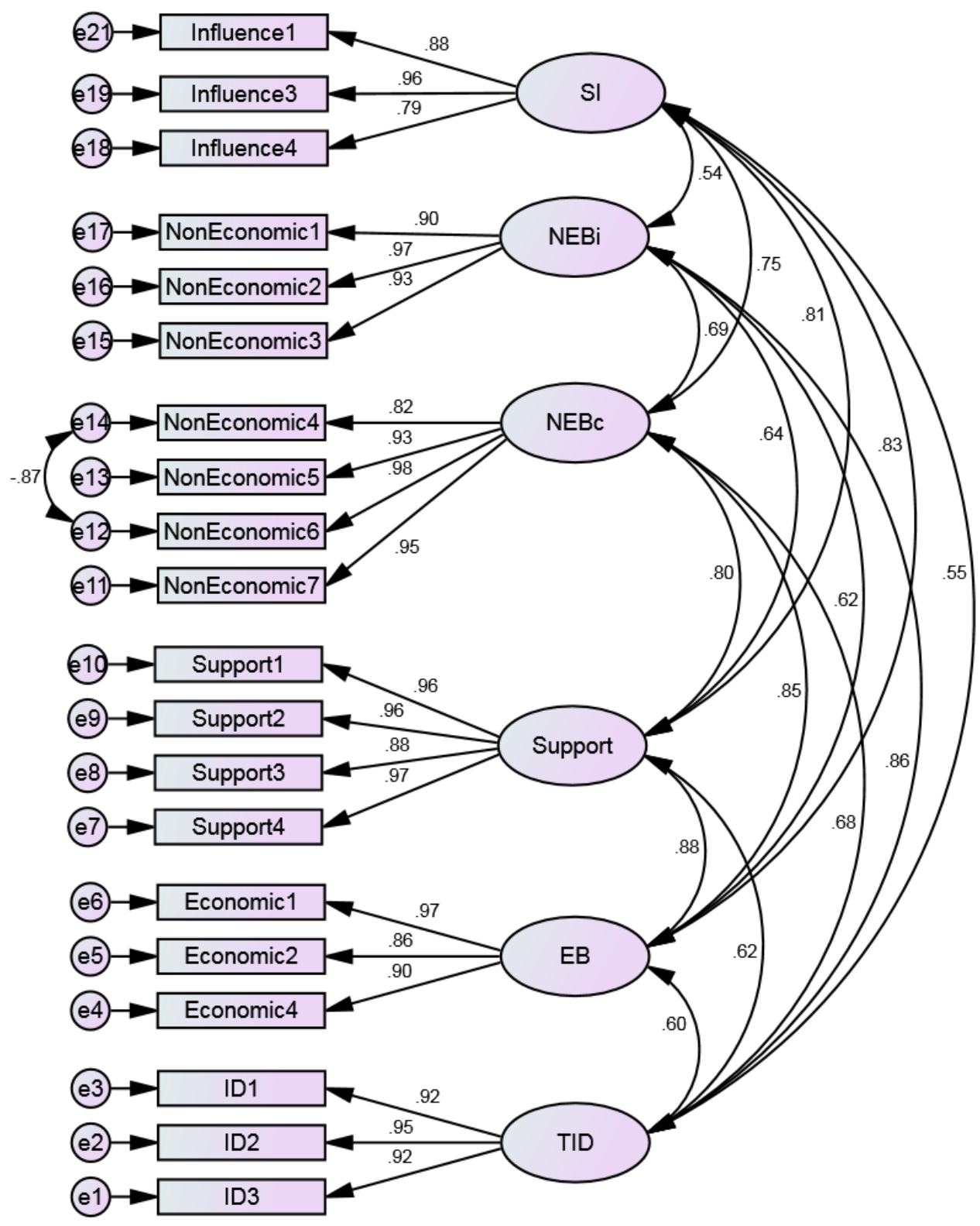

Figure 2. Measurement model.

Structural model. The statistical analysis from the structural model addressed hypotheses 1-5. Team Identification was the exogenous variable along with Stakeholder Influence, Perceived Noneconomic Benefits-individual, Perceived Noneconomic Benefits-community, and Perceived Economic Benefits, each of which was an 
endogenous variable. Stadium Support was also an endogenous variable. Approximate fit statistics showed that the initial model was not a good fit; therefore, respecification occurred. Table 17 outlines the model fit indices for each iteration. The removal of the correlation between e12 and e14 initially due to a Heywood case (Fit 1 in Table 17), plus the addition of correlations between D4 and D3 (Fit 2 in Table 17), D1 and D4 (Fit 3 in Table 17), e13 and e14 (Fit 4 in Table 17), D1 and D3 (Fit 5 in Table 17), and e12 and e14 (Final in Table 17), respectively, improved the model fit to be acceptable, per the standards outlined in the measurement model section $\left(\chi^{2}=271.071, d f=158, p<.001\right.$, $\mathrm{RMSEA}=.064, \mathrm{RMSEA}$ confidence interval $=.051-.076, \mathrm{SRMR}=.0537, \mathrm{CFI}=.977)$. The modifications to the model each remained consistent with theory. Further, an examination of the correlations of the disturbances for Stakeholder Influence and Perceived Noneconomic Benefits-community (.62), Stakeholder Influence and Perceived Economic Benefits (.74), and Perceived Noneconomic Benefits-community and Perceived Economic Benefits (.76) were relatively high, providing evidence of an underlying connection between these factors.

\section{$\underline{\text { Table } 17}$}

\section{$\underline{\text { Values of Model Fit for Structural Model }}$}

\begin{tabular}{ccccccccc}
\hline & & \multicolumn{7}{c}{ Model } \\
\cline { 3 - 9 } Index & Recommended & Initial & Fit 1 & Fit 2 & Fit 3 & Fit 4 & Fit 5 & Final \\
\hline & & & & & & & & \\
$\chi^{2}$ & Significant $p$-value & .000 & .000 & .000 & .000 & .000 & .000 & .973 \\
CFI & .90 or greater & .97 & .921 & .941 & .955 & .96 & .973 & .977 \\
SRMR & .06 or less & .0399 & .1473 & .1343 & .0947 & .0973 & .0582 & .0537 \\
RMSEA & .10 or less & .073 & .116 & .1 & .089 & .084 & .068 & .064 \\
\hline
\end{tabular}

Note $. \chi^{2}=$ Chi-square statistic. $\mathrm{CFI}=$ Comparative fit index. $\mathrm{SRMR}=$ Standardized root mean square residual. RMSEA = Root mean square error of approximation. Recommendations are from Kline (2011). 
A review of the structural model and the paths between each of the latent variables yielded interesting results. The standardized coefficients for the paths and correlations for all factors and disturbances (where applicable) were positive. The path between Team Identification and Perceived Noneconomic Benefits-individual $(\beta=0.87$ ), Team Identification and Noneconomic Benefits-community $(\beta=0.69)$, Team Identification and Perceived Economic Benefits $(\beta=0.61)$, and Team Identification and Stakeholder Influence $(\beta=0.56)$ were statistically significant. Respondents' perceptions of Noneconomic benefits, economic benefits, and stakeholder influence were influenced by their connection with the team.

In relation to the endogenous variable, the following direct paths were significant: Stakeholder Influence to Support $(\beta=0.22)$ and Perceived Economic Benefits to Support ( $\beta=0.60)$, supporting hypotheses 1 and 4 . Respondents' perceptions of Stakeholder Influence and Perceived Economic Benefits influenced their willingness to support a stadium project.

The structural model also displayed a few mediating relationships, when considering the full model. The structural model showed the relationship between Team Identification and Stadium Support was fully mediated through Perceived Economic Benefits and Stakeholder Influence, given the significant individual paths between Team Identification, Stakeholder Influence, and Perceived Economic Benefits as well as the nonsignificant path from Team Identification and Stadium Support. Though the structural model may support these mediating relationships, the hypotheses in question aimed to examine the mediating relationships separately, and not as part of the full structural model. The full mediation analysis was conducted utilizing the phantom model 
approach recommended by Macho and Ledermann (2011) in conjunction with bootstrapping.

There were also a number of nonsignificant paths. The path between Perceived Noneconomic Benefits-community and Support was nonsignificant $(p=.609, \beta=.04)$. Additionally, Perceived Noneconomic Benefits-individual to Support $(p=.204, \beta=0.10$ ) and the path between Team Identification and Support $(p=.770, \beta=.03)$ were not significant. Hypotheses 2, 3, and 5 were not supported, highlighting no relationship between respondents' perception of Perceived Noneconomic Benefits-individual, Perceived Noneconomic-community, and Team Identification and their willingness to support a stadium project. A primary bootstrap procedure was conducted to compare the results of the maximum likelihood estimates (Table 18). When resampled 2000 times, the same paths from the maximum likelihood estimates are not significant (Table 19). That

\section{$\underline{\text { Table } 18}$}

Maximum Likelihood Estimates of the Direct Effects

\begin{tabular}{ll}
\hline Hypothesized Path & Estimates \\
\hline TID $\rightarrow$ NEBi & $.87(.81)^{*}$ \\
TID $\rightarrow$ NEBc & $.69(.53)^{*}$ \\
TID $\rightarrow$ EB & $.61(.64)^{*}$ \\
TID $\rightarrow$ SI & $.56(.46)^{*}$ \\
TID $\rightarrow$ Support & $.03(.03)$ \\
NEBi $\rightarrow$ Support & $.10(.12)$ \\
NEBc $\rightarrow$ Support & $.04(.06)$ \\
EB $\rightarrow$ Support & $.60(.62)^{*}$ \\
SI $\rightarrow$ Support & $.22(.28)^{*}$ \\
\hline
\end{tabular}

Note. ${ }^{*} p<.01$, Unstandardized estimates in parentheses. SI, Stakeholder Influence; NEBi, Noneconomic Benefits-individual; NEBc, Noneconomic Benefits-community; EB, Economic Benefits; TID, Team Identification. 


\section{Table 19}

Bootstrap Estimates of the Direct Effects with Standard Errors and 90\% Confidence Bounds

\begin{tabular}{lcccc}
\hline \multirow{2}{*}{ Effect } & Unst. & $S E$ & \multicolumn{3}{c}{$90 \%$ CI } \\
\cline { 4 - 6 } & & & LB & UB \\
\hline Direct effect of TID on NEBi & .81 & .049 & .728 & .889 \\
Direct effect of TID on NEBc & .53 & .054 & .444 & .620 \\
Direct effect of TID on EB & .64 & .064 & .532 & .743 \\
Direct effect of TID on SI & .46 & .063 & .360 & .570 \\
Direct effect of TID on Support & .03 & .116 & -.152 & .217 \\
Direct effect of NEBi on Support & .12 & .110 & -.052 & .297 \\
Direct effect of NEBc on Support & .06 & .141 & -.153 & .306 \\
Direct effect of EB on Support & .62 & .127 & .444 & .857 \\
Direct effect of SI on Support & .28 & .119 & .093 & .480 \\
\hline
\end{tabular}

Note. Unst. $=$ unstandardized; $\mathrm{SE}=$ standard error. $\mathrm{CI}=$ confidence interval. $\mathrm{LB}=$ lower bound. UB = upper bound. SI = Stakeholder Influence; NEBi = Noneconomic Benefitsindividual; $\mathrm{NEBc}=$ Noneconomic Benefits-community; $\mathrm{EB}=$ Economic Benefits; $\mathrm{TID}=$ Team Identification.

is, the confidence intervals for the direct effect between Team Identification and Stadium Support ( $C I=-.152$ to .217$)$, Noneconomic Benefits-community and Stadium Support $(C I=-.153$ to .306$)$, and Noneconomic Benefits-individual and Stadium Support $(C I=-.052$ to .297$)$ cross zero; therefore, were not statistically significant different from the population. These results show that when the data are resampled 2000 times, the statistically significant paths remained the same. 


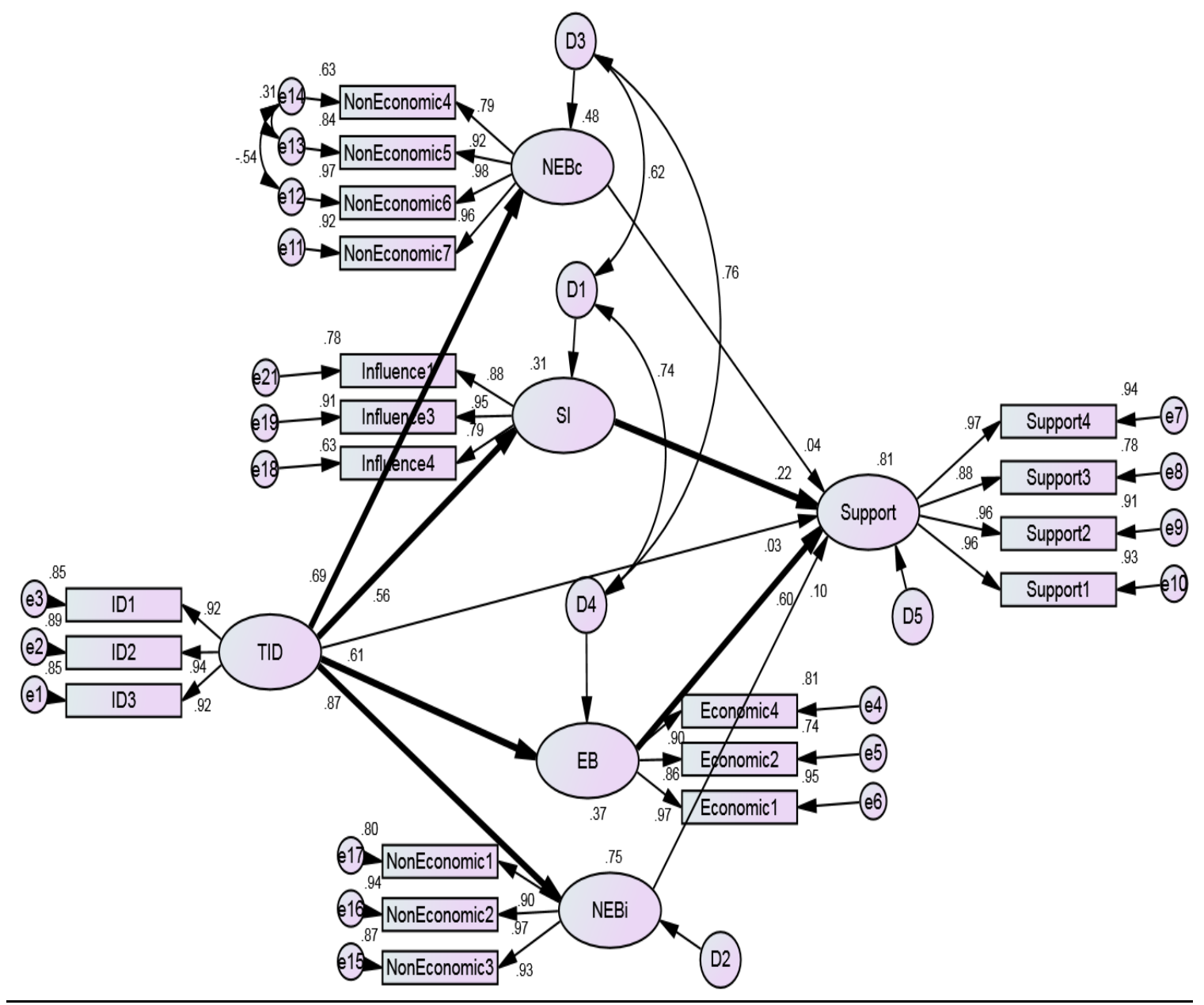

Figure 3. Structural model.

Note. Standardized beta weights are shown. The weighted solid lines represent significant paths $(p<.01)$, and the thin lines represent nonsignificant paths.

Mediation analysis. To address the mediating relationships outlined in hypotheses 6-9, the phantom model approach recommended by Macho and Ledermann (2011) was utilized. This approach allowed the testing of specific effects within the structural model. Stakeholder Influence, Perceived Noneconomic Benefits-individual, Perceived Noneconomic Benefits-community, and Perceived Economic Benefits were 
held as mediator variables in each individual analysis utilizing the phantom model, where Team Identification was held as the exogenous variable, and Stadium Support was held as the endogenous variable. The unstandardized estimates of the indirect effects with bootstrap standard errors and $90 \%$ confidence intervals for the indirect effects are shown in Table 19.

Table 20 shows the bootstrap estimates of the four specific indirect effects of Team Identification on Stadium Support through Noneconomic Benefits-individual, Noneconomic Benefits-community, Economic Benefits, and Stakeholder Influence based on a bootstrap resample of 2000 . The bootstrap procedure showed no mediation effect, as none of the confidence intervals cross over zero. These findings do not support hypotheses 6-9.

\section{Table 50}

Bootstrap Estimates of the Indirect Effects of Team Identification on Stadium Support with Standard Errors and 90\% Confidence Bounds

\begin{tabular}{lcccc}
\hline \multirow{2}{*}{ Effect } & Unst. & $S E$ & \multicolumn{2}{c}{$90 \%$ CI } \\
\cline { 4 - 5 } & & & LB & UB \\
\hline Indirect effect of TID on Support through NEBi & .000 & .000 & .000 & .000 \\
Indirect effect of TID on Support through NEBc & .000 & .000 & .000 & .000 \\
Indirect effect of TID on Support through SI & .000 & .000 & .000 & .000 \\
Indirect effect of TID on Support through EB & .000 & .000 & .000 & .000 \\
\hline
\end{tabular}

Note. Unst. $=$ unstandardized; $\mathrm{SE}=$ standard error. $\mathrm{CI}=$ confidence interval. $\mathrm{LB}=$ lower bound. UB = upper bound. SI = Stakeholder Influence; NEBi = Noneconomic Benefitsindividual; $\mathrm{NEBc}=$ Noneconomic Benefits-community; $\mathrm{EB}=$ Economic Benefits; $\mathrm{TID}=$ Team Identification. 
Although the factor correlations and structural model provided evidence supporting a relationship across the exogenous and endogenous variables, a more focused look at the indirect effect between Team Identification and Stadium Support showed this may not be the case. The measurement model yielded positive and statistically significant relationships across each of the latent variables, signifying positive correlations across each factor (Figure 2). In addition, the full structural model yielded a number of mediating relationships, when considering the influence of all the latent variables in the model (Figure 3). The full structural model showed Team Identification was fully mediated through Perceived Economic Benefits and Stakeholder Influence, given the direct path between Team Identification and Stadium Support was not significant, but the direct paths between Team Identification and Economic Benefits, and Stakeholder influence were significant, and the direct paths between Economic Benefits, and Stakeholder Influence to Stadium Support were significant (see Figure 3). This finding suggests, when considering the other factors, the relationship between Team Identification and Stadium Support is explained through respondents' perception of economic benefits and stakeholder influence. On the other hand, the bootstrap procedure along with the phantom model approach, which controlled for the other latent variables in the model, showed no mediating effect (Figure 4). The results of the bootstrap procedure did not support the mediating relationships found in the full structural model in Figure 3. When taking into account only the latent variables in question (i.e., the exogenous, endogenous, and mediating variables), there was no presence of mediation.

Further, the bootstrap and phantom model approach also aided in addressing the high correlations across the factors. The factor correlations ranged from .545 to .884 . 
Isolating each mediating relationship controlled for those other variables, which were highly related to each other. The phantom model approach provided evidence of the isolated mediating relationship without the influence of the other latent variables.

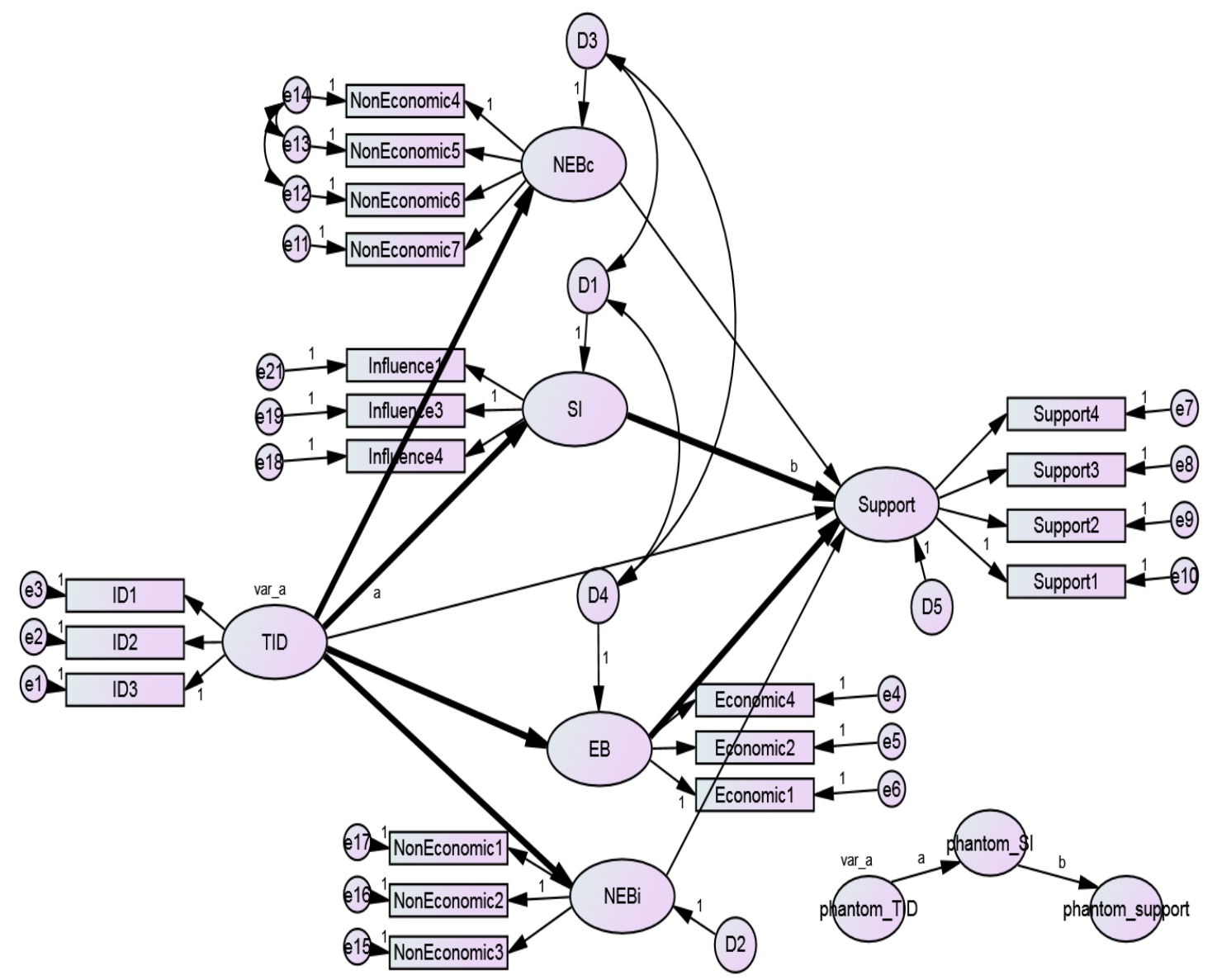

Figure 4. Example of structural model with phantom model included.

\section{Research Question 2}

RQ2: Which stakeholder groups do voters believe are campaigning for or against the stadium referendum? 
To address research question 2, the researcher reviewed frequencies of the categorical data collected through the survey.

Frequencies. Respondents were asked to identify the stakeholders they perceived were in favor and/or against with the stadium construction project. Respondents were given the option to select all the definitive stakeholders that applied (i.e., politicians, the media, the business community, team owners, and proponent groups).

In addition, an open-ended option was provided to further assess the stakeholders involved both in favor and/or against in the San Diego Chargers stadium project. This allowed respondents to list other stakeholders they may have considered in favor and/or against the stadium project in San Diego. Initially, the open-ended responses were categorized into the five definitive stakeholder groups. Thirty-four respondents entered a response for the "in favor" option and 48 for the "against" option, which yielded 563 individual stakeholders campaigning in favor of the project and 269 stakeholders campaigning against the project. Stakeholders who did not fit into a specific definitive stakeholder group were consolidated into an "other" category. There were a total of 83 responses classified as "other" stakeholders. Some of the responses included in the "other" category were: fans, the NFL, players, neighborhood groups, opponent groups, and the general public. In general, 77 respondents indicated they were not aware of stakeholder groups campaigning against the stadium project and 20 respondents who indicated they were not aware of any groups campaigning for the project.

Respondents provided 832 individual stakeholders they perceived to be campaigning in favor and/or against the stadium project in San Diego. Respondents specified more stakeholders campaigning in favor of the stadium project than those 


\section{$\underline{\text { Table } 21}$}

Frequency Chart of the Definitive Stakeholders

\begin{tabular}{llll}
\hline Stakeholder Group & In Favor & Against & Total \\
\hline Politicians & 124 & 77 & 201 \\
Proponent groups & 135 & 15 & 150 \\
Team Owners & 140 & 7 & 147 \\
Business Community & 64 & 65 & 129 \\
The Media & 77 & 43 & 120 \\
Other & 23 & 62 & 85 \\
Total & 563 & 269 & 832 \\
\hline
\end{tabular}

\section{Table 22}

Frequency Chart of the "Other" Category of Stakeholders

\begin{tabular}{llll}
\hline Stakeholder Group & In Favor & Against & Total \\
\hline Locals/Citizens & 3 & 25 & 28 \\
Fans & 14 & 1 & 15 \\
Neighborhood groups & - & 14 & 14 \\
Opponent groups & - & 14 & 14 \\
The NFL & 4 & - & 4 \\
Comic Con & - & 3 & 3 \\
Players & 2 & - & 2 \\
Convention Center supporters & - & 2 & 2 \\
Environment groups & - & 1 & 1 \\
Measure D & - & 1 & 1 \\
Celebrities & - & 1 & 1 \\
Total & 23 & 62 & 85 \\
\hline
\end{tabular}

against it (i.e., 563 and 269 responses, respectively). Based on the definitive stakeholders provided (i.e., politicians, business community, the media, team owners, proponent groups), in combination with an examination of the open-ended responses, team owners were found to be the primary stakeholder perceived to be campaigning in favor of the 
stadium construction project $(n=140)$. Proponent groups $(n=135)$ followed the team owner stakeholder group campaigning in favor of the stadium project, followed by politicians $(n=124)$, the business community $(n=65)$, the media $(n=77)$, and "other" from the open-ended responses $(n=23)$. Overall, the "other" stakeholders perceived to be campaigning in favor of the stadium project included Chargers fans, local citizens, members of the Chargers team, and the NFL. The largest group included in the "other" category campaigning in favor of the stadium project was fans $(n=14)$. Notably, respondents included local labor unions $(n=4)$ and the local chamber of commerce $(n=2)$ as additional stakeholder groups perceived to be campaigning in favor of the project. These two groups were included in the business and local politician stakeholder counts, respectively. Additional information on the "other" category is included in Table 22.

Based on frequencies, respondents perceived the politician stakeholder group to be campaigning against the stadium project the most $(n=77)$. Behind this stakeholder group was the business community $(n=65)$, other $(n=62)$, the media $(n=43)$, proponent groups $(n=15)$, and team owners $(n=7)$. Overall, the "other" stakeholders perceived to be campaigning against the stadium project included citizens, opponent groups, and neighborhood groups. The largest group in the "other" category was local/citizens $(n=25)$. In general, the citizens' listings included downtown residents, San Diego residents, and private citizens. The opponent groups listed by respondents included various taxpayer groups, Citizens Against New Stadiums, and social advocacy groups. The neighborhood group included property owners, community leaders, and Barrio Logan, the neighborhood that would have been directly impacted by the 
construction of the stadium. Again, additional information on the "other" category is included in Table 22.

\section{Summary of Results}

The current study examined how Stakeholder Influence, Perceived Noneconomic Benefits, Perceived Economic Benefits, and Team Identification may influence a constituent's willingness to support a professional sport stadium project. Structural equation modeling (SEM) was utilized to analyze research question 1 and the corresponding hypotheses (1-9) to examine the relationship among the latent variables (i.e., Stakeholder Influence, Perceived Noneconomic Benefits, Perceived Economic Benefits, Team Identification, and Stadium Support). The measurement model yielded an acceptable model fit after a number of iterations were completed (i.e., removal of Influence2, splitting Perceived Noneconomic Benefits into two factors, correlating the error between Noneconomic4 and Noneconomic6). The initial five factors evolved to six constructs, where each was positively correlated and revealed significant factor loading. Observed model fit statistics for the measurement model yielded acceptable fit after a one model respecification (i.e., added correlation between e12 and e14).

The structural model also required a few respecifications to reach acceptable model fit (i.e., initial removal of the correlation between e12 and e14, a correlation between D4 and D3, D1 and D4, e13 and e14, D1 and D3, and e12 and e14). Model statistics showed two statistically significant paths: (a) Stakeholder Influence to Support and (b) Perceived Economic Benefits to Support, supporting hypotheses 1 and 4 . The structural model also provided evidence for a mediating relationship between Team Identification and Stadium Support through Perceived Economic Benefits and 
Stakeholder Influence. A further examination of the mediating relationships through the phantom model approach and bootstrapping found there was only one significant path coefficient between Team Identification and Stadium Support, where Perceived Noneconomic Benefits-individual was the mediator, yielding a direct only nonmediation relationship between the constructs. There was no other significant mediating relationship in the model according to the bootstrap results.

Frequencies were examined for research question 2. Team owners were listed as the stakeholder respondents perceived to be campaigning most in favor of the stadium project, and politicians were perceived to be the stakeholders to be campaigning most against the stadium project. Other stakeholder groups such as fans, neighborhood groups, the general public, and opponent groups also emerged. 


\section{CHAPTER V \\ DISCUSSION}

This final chapter contextualizes the findings from Chapter IV in terms of the research purpose, questions, and hypotheses. Following the review of the research questions and summary of results, an interpretation of the results is presented, followed by theoretical implications, and suggestions for practitioners. Lastly, limitations and future research related to the study and its findings are discussed, and the summary of the study is presented.

\section{Research Purpose and Questions}

Professional stadium construction in the United States continues to flourish as new facilities are built at high costs. The public funds many of these. Key stakeholders continue to support and promote these projects, and voters often approve them, despite the extant academic research against stadium development and economic impact. Researchers have shifted to suggest a focus on the noneconomic benefits a professional sport stadium can bring to a city such as quality of life and civic pride. As such, the purpose of this study was to examine how Stakeholder Influence, Perceived Noneconomic Benefits, Perceived Economic Benefits, and Team Identification may influence a constituent's willingness to support a professional sport stadium referendum. To address the purpose of the study along with the research questions, data were collected from residents of the city of San Diego, California as they were posed with a 
stadium referendum for the NFL Chargers in November 2016. The research questions and hypotheses that guided this study were:

Research Question 1. What effects do Stakeholder Influence, Perceived Economic Benefits, Perceived Noneconomic Benefits, and Team Identification have on constituents' willingness to support a stadium referendum?

H1. Stakeholder Influence has a direct positive effect on Stadium Support. H2. Perceived Noneconomic Benefits-individual has a direct positive effect on

\section{Stadium Support.}

H3. Perceived Noneconomic Benefits-community has a direct positive effect on

\section{Stadium Support.}

H4. Perceived Economic Benefits has a direct positive effect on Stadium Support. H5. Team Identification has a direct positive effect on Stadium Support.

H6. Team Identification has an indirect positive effect on Stadium Support through Stakeholder Influence.

H7. Team Identification has an indirect positive effect on Stadium Support through Perceived Noneconomic Benefits-individual.

H8. Team Identification has an indirect positive effect on Stadium Support through Perceived Noneconomic Benefits-community.

H9. Team Identification has an indirect positive effect on Stadium Support through Perceived Economic Benefits.

Research Question 2. Which stakeholder groups do voters believe are campaigning for or against the stadium referendum? 


\section{Summary of Results}

Structural equation modeling (SEM) was utilized to address research question 1 and the corresponding hypotheses (1-9) in order to examine the relationships among Stakeholder Influence, Perceived Noneconomic Benefits, Perceived Economic Benefits, Team Identification, and Stadium Support. An analysis of the structural model showed two statistically significant paths: (a) Stakeholder Influence to Support, and (b) Perceived Economic Benefits to Support, supporting hypotheses 1 and 4. Though the structural model presented a significant mediating relationship between Team Identification and Stadium Support through Perceived Economic Benefits and Stakeholder Influence when all other variables were present, the specific mediation analysis utilizing the phantom model approach and bootstrapping showed no significant mediating relationship between the latent variables. Therefore, hypotheses 5-9 were not supported.

Frequencies were examined for research question 2. Each of the definitive stakeholders (i.e., politicians, team owners, business community, the media, and proponent groups) was present in the current case. Respondents perceived team owners as the stakeholder group mostly campaigning in favor of the stadium project. On the other side, respondents perceived politicians as the stakeholder group mostly campaigning against the stadium project. Respondents also indicated other stakeholder groups such as fans, local citizens, opponent groups, and neighborhood groups campaigning for and/or against the stadium project.

\section{Interpretation of Results}

The current study sought to extend the previous research utilizing the sport-based contingent valuation method (CVM) (Atkinson et al., 2008; Castellanos et al., 2011; Fenn 
\& Crooker, 2009; Groothuis et al., 2004; Johnson \& Whitehead, 2000; Johnson et al., 2001; Johnson et al., 2006, 2007; Owen, 2006; Santo, 2007) by addressing a respondent's willingness to support a stadium project. The current study also considered and included other potential influencing variables such as stakeholder influence (Brown \& Paul, 2002; Friedman \& Mason, 2004) and team identification (Fenn \& Crooker, 2009; Johnson \& Whitehead, 2000; Johnson et al., 2001; Owen, 2006) to examine how these additional factors may also influence a constituent's willingness to support a stadium project.

\section{Hypothesis 1: Stakeholder Influence Has a}

\section{Direct Positive Effect on Stadium Support.}

Respondents in this study were influenced by their perceptions of the stakeholders in the community in relation to the stadium project; therefore, this hypothesis was supported. Based on the findings, voters' perceptions of the community leaders associated with the stadium project influenced their willingness to support the project, extending the research on stakeholder influence (Lupia \& McCubbins, 1998; Paul \& Brown, 2006). Lupia and McCubbins theorized voters must perceive community leaders to be both trustworthy and knowledgeable in order for the voter to be influenced in a certain way. The current study supported this notion, as Stakeholder Influence was found to be one of the influencing factors on respondents' willingness to support the stadium project.

A review of the items included in Stakeholder Influence displayed interesting results. The items addressing trust and common interests yielded a low mean $(M=2.81$, $M=2.81$, respectively), signifying a lack of trust and common interest with the community leaders associated with the stadium project. On the other hand, the correlation between Stakeholder Influence and Stadium Support provided evidence of a 
strong, positive underlying relationship between the two constructs $(r=.806)$. Simply, respondents may not have trusted with the community leaders associated with the stadium project, but the relationship between trust affected their willingness to support the stadium project.

Research has found voters rely on opinions and messages of local elites and stakeholders when considering local issues at the ballot box (Brady \& Sniderman, 1985; Carmines \& Kuklinski, 1990; Fort, 1997; Lupia, 1994; Mondak, 1993). The current study extends this research in the area of stadium referendums. The findings indicated when faced with a referendum, respondents may rely upon and are influenced by their community leaders who were associated with the project.

In addition, the supplemental qualitative data on the specific stakeholder groups addressed in research question 2 indicated there were a number of stakeholders in this community with differing opinions and messaging on the stadium project in question. Paul and Brown (2001) found a positive relationship between the degree of local elite unity in favor of a stadium referendum and the local electoral support to pass the measure. The existence of stakeholder influence in combination with the mixed messaging potentially surrounding this particular case could have yielded the unsuccessful results with the San Diego NFL Chargers project, as the referendum failed to yielded enough votes for it to pass. The referendum needed to be approved by a majority of $66.7 \%$ votes, but was only able to obtain support from $43 \%$ of voters in the city of San Diego (Garrick, 2016b). Thus, it becomes important to recognize the role of stakeholder influence in terms of stadium projects. 


\section{Hypothesis 2: Perceived Noneconomic Benefits-}

individual has a direct positive effect on Stadium

\section{Support.}

\section{Hypothesis 3: Perceived Noneconomic Benefits-- \\ Community Has a Direct Positive Effect on \\ Stadium Support.}

Some sport economists have recommended a shift of focus from measureable economic benefits to noneconomic benefits in order to garner support for stadium construction projects (Baade \& Dye, 1988a, 1990; Coates \& Humphreys, 1999; Euchner, 1993; Johnson, 1986; Noll \& Zimbalist, 1997; Rosentraub, 1996; Sanderson, 2000;

Siegfried \& Zimbalist, 2000; Swindell \& Rosentraub, 1998; Zipp, 1996). Johnson (1986) emphasized this by stating the psychological health of a city is just as important as its fiscal health. The current study found that perceptions of noneconomic benefits did not influence respondents' willingness to support the stadium project; therefore, hypotheses 2 and 3 were not supported. These results were inconsistent with previous sport-based CVM research which suggested that the public good variable (i.e., reading about the team, watching the team on television, talking about the team with friends, family, and/or co-workers, and quality of life improvement), which held as the measure for noneconomic benefits, was a significant factor in determining how much constituents were willing to pay for a stadium project (Atkinson et al., 2008; Castellanos et al., 2011; Fenn \& Crooker, 2009; Groothuis et al., 2004; Johnson \& Whitehead, 2000; Johnson et al., 2006, 2007; Owen, 2006; Santo, 2007). The results of the current study suggested that respondents' perceptions of noneconomic benefits may not influence their willingness to support a stadium project when given the opportunity to vote. Residents 
may not perceive value in the existence of a professional sports team in the local community. Respondents may have considered other factors of quality of life within the community higher than the presence of a professional sports franchise.

A closer examination of perceptions of community and individual noneconomic benefits showed further inconsistencies with the literature. Previous literature and stadium construction case studies have implied that the focus and promotion of community noneconomic benefits such as civic pride can yield constituent support (Castellanos et al., 2011; Fenn \& Crooker, 2009; Johnson \& Whitehead, 2000; Johnson et al., 2001; Santo, 2007; Wilkerson, 1996 as cited by Brown \& Paul, 1999). On contrary, the current study found that an individual's perception of community noneconomic benefits such as making the city a better place to live, improving its national reputation, increasing the city's status, and increasing its prestige were not influential factors in a resident's willingness to support a stadium project.

Further, this finding may relate to the existing quality of life value in a city. Residents may value other factors within a community beyond the existence of a sports team. For example, San Diego has been ranked in the top 25 best places to live according to US News (Czajkowski, 2017), suggesting the residents have a generally pleasant quality of life. Over $70 \%$ of the respondents in this study lived in San Diego longer than 10 years, which may be related to perceptions of quality of life. Additionally, over $82 \%$ of the respondents in this study live within 20 miles of the proposed stadium location, which also may contribute to their perceptions of quality of life and how it may relate to traffic, parking, and other factors. 
Researchers have also examined other factors that may contribute to quality of life. For example, Johnson (2008) presented compensating differentials such as rent, home costs, and wages as a reflection of the quality of life in a community. Carlino and Coulsen (2004) attempted to measure how much people would be willing to pay for a perceived higher quality of life through an examination of rent and wages in a city that hosts an NFL franchise. Tu (2005) also attempted to measure quality of life through home values surrounding an NFL stadium. These studies attest to the possibility that in relation to a sport stadium, respondents may perceive other elements and factors that positively or negatively affect their quality of life such as an increase in property values, going above and beyond game attendance and other sport consumption behaviors. In the current study, these nonsports factors, including tenure in the city or home distance from stadium location, may have been more applicable when respondents considered their perceptions of economic benefits associated with the stadium project and how it may affect their quality of life.

Findings in the current study also indicated that an individual's perception of individual noneconomic benefits such as reading about the team, talking about the team with others, and watching the team on television did not influence their willingness to support a stadium project, contradicting previous research. Johnson et al. (2001) and Castellanos et al. (2011) found that local residents actually gained more value from the noneconomic benefits of the local team than from attending games. Despite previous research suggesting perceptions of both community and individual noneconomic benefits were influential factors, the current study yielded opposing results suggesting these benefits do not influence a residents' willingness to support a stadium project. 


\section{Hypothesis 4: Perceived Economic Benefits Has \\ a Direct Positive Effect on Stadium Support.}

Results of this study suggest respondents' perceptions associated with economic benefits of the stadium such as job creation, new businesses, and overall improved local economy influenced respondents' willingness to support the stadium project, consistent with previous research (Santo, 2007). This hypothesis was supported.

Despite what has been established in the academic field supporting the idea that sport teams do not generate positive measurable economic impact on a municipality (see Baade, 1994, 1996; Baade \& Dye, 1988a, 1990; Baade et al., 2008; Coates \& Humphreys, 1999, 2002; Zipp, 1996), this continues to be the driving point behind proponent stakeholder campaigns. Additionally, previous research has highlighted some of the core economic benefits of the presence of a professional team and a new stadium such as an increase in local jobs and spending, and increased foot traffic in the city (Lansing \& Casper, 2000), dispelling other previous studies suggesting little economic benefits exist.

Respondents' willingness to support the stadium project was influenced by their perceptions of its ability to improve the city's economy, create jobs, and bring business to the area. Economic impact reports typically boast job creation in the stadium's construction, within the stadium, and on the peripheral exterior. Respondents in this study demonstrated they not only value the perception of these economic benefits in general, but specifically in relation to job creation. The mean score for the item addressing stadium job creation was high (i.e., 4.09), suggesting that this may be what respondents valued the most in terms of the stadium project. 


\section{Hypothesis 5: Team Identification Has a}

Direct Positive Effect on Stadium Support.

Hypothesis 6: Team Identification Has an

Indirect Positive Effect on Stadium Support

Through Stakeholder Influence.

Hypothesis 7: Team Identification Has an Indirect

Positive Effect on Stadium Support Through

Perceived Noneconomic Benefits--Individual.

\section{Hypothesis 8: Team Identification Has an Indirect \\ Positive Effect on Stadium Support Through \\ Perceived Noneconomic Benefits--Community.}

\section{Hypothesis 9: Team Identification Has an Indirect \\ Positive Effect on Stadium Support Through \\ Perceived Economic Benefits.}

Sport economists suggested team identification as a key measurement tool in justifying stadium projects (Baade \& Dye, 1988a; Walker \& Mondello, 2007). The current study examined Team Identification as a potential precursor to a respondent's willingness to support a stadium project as hypothesized. The results were quite inconsistent. Primarily, Team Identification was not an influencing factor when respondents were considering their willingness to support a stadium project; therefore, hypothesis 6 was not supported. Further, respondents in the current study did not appear to highly identify with the team, which may have impacted the results. 
When considering all of the potential influencing factors in conjunction with Team Identification in the structural model (see Figure 3), an indirect and positive effect on Stadium Support existed through Perceived Economic Benefits and Stakeholder Influence. Simply, the inclusion of a respondent's perception of either stakeholder influence or associated economic benefits contributed to the relationship between Team Identification and respondent's willingness to support the stadium project, given their perceptions of noneconomic benefits as well. Though Team Identification was not an influencing factor in a respondent's willingness to support a stadium project directly, holistically speaking, a respondent's perception of the economic benefits and stakeholder influence and their connection to the team led them to support the stadium project through the full structural model.

The mediation analysis for hypotheses 6-9 yielded different results (see Figure 4). When considering only three influencing variables at a time as presented in the hypotheses (e.g., Team Identification, Stakeholder Influence, and Stadium Support) and utilizing the phantom model approach and bootstrap resampling method, the results showed no mediating relationship; therefore, hypotheses 6-9 were not supported. There was no indirect relationship between Team Identification and Stadium Support. Team Identification did not influence Stadium Support through Perceived Noneconomic Benefits-individual, Perceived Noneconomic Benefits-community, Economic Benefits, or Stakeholder Influence. When considering one factor at a time in conjunction with team identification, respondent's perceptions were not influenced enough to develop a willingness to support the stadium project. 
Previous sport-based CVM research also yielded inconsistent results surrounding team identification and willingness to pay (Fenn \& Crooker, 2009; Johnson et al., 2001; Johnson \& Whitehead, 2000; Owen, 2006). Owen (2006) was the only study of the aforementioned research that found team identification was a positive and statistically significant predictor of willingness to pay. This finding suggested team interest was a crucial element in the public's willingness to pay for a sports stadium, though the cases examined were based on a hypothetical situation. On the contrary, the current study did not find Team Identification to influence voters' perspectives in terms of their willingness to support a stadium project when faced with an actual referendum. This finding may lend itself to negating the bias of using a hypothetical situation. The current study presented respondents with an actual situation they would face, calling them to consider their feelings and perceptions of the project. Overall, the findings of the current study indicated Team Identification may not be a necessary factor when attempting to garner voter support for a professional stadium project, inconsistent with the sport-based CVM research.

Additional research in the area of team identification and stadium financing has yielded other results. In his endeavor to measure fan loyalty as it related to stadium outcomes in MLB, Depken (2000) found that team identification may or may not affect the public's willingness to pay for a stadium. MLB stadiums on the upper half of fan loyalty (i.e., Baltimore, Maryland and Cleveland, Ohio) as well as on the lower half (i.e., Cincinnati, Ohio and Detroit, Michigan) were successful in retaining public funds for a stadium project. Given the results of the current study and findings presented by Depken, team identification may not be necessary to gain support of a stadium project from the 
local constituents. In addition, other factors may influence a voter's perceptions of these projects beyond and/or in conjunction with team identification, especially given the specific market and team.

Though team identification was not a significant influencer on willingness to support directly or indirectly, it did have a significant and positive relationship with Perceived Noneconomic Benefits, Perceived Economic Benefits, and Stakeholder Influence within the structural model (see Figure 3), denoting the influence a connection with the team can have other related factors. Team identification should not be discounted as an influencer, but ultimately, findings in the current study suggest it does not directly or indirectly influence a person's willingness to support a stadium project.

\section{Theoretical Implications}

Findings in the current study indicated residents' perceptions of Stakeholder Influence and Perceived Economic Benefits influenced their willingness to support a stadium project. The findings in the current study bridge these two conceptsstakeholder influence and economic benefits—and provide empirical evidence insinuating that perceived economic benefits influence a person's willingness to support a stadium project. Further, research in this area has stated key stakeholders in the community often promote the economic benefits of a stadium project in order to justify the investment (Crompton, 1995; Danielson, 1997; Sanderson, 2000), as key stakeholders often promote these projects as catalysts for municipal growth within the community (Duquette \& Mason, 2008). Additionally, Fort (1997) posited that citizens are typically uninformed regarding ballot measures and are more susceptible to being influenced by 
external factors such as proponent groups, providing an additional connection between stakeholder influence and economic benefits in stadium projects.

Stadium projects have been promoted as a beacon for municipal growth, especially in cities that are attempting to establish a higher level of status. The tenets of urban regime theory suggest that a community focused on pro-growth strategies and status can brand the local community as an attractive place to work and live through a display of growth, economic stability, and additional amenities in the area in order to attract businesses and improve quality of life for the citizens (Duquette \& Mason, 2008). A sport-based approach to municipal growth may provide additional status and attract residents to a municipality specifically in relation to competition (Duquette \& Mason). Ultimately, stakeholders see stadium projects as a part of a pro-growth strategy that will give the municipality improved quality of life while attracting new residents and businesses to the area (Duquette \& Mason).

In addition, sport economists have proposed "sports-led development strategies may not be effective engines of economic growth, but the presence of professional sports in a city may increase the overall well-being of the residents" (Coates \& Humphreys, 1999, p. 622). The existence of a professional sports team may spur municipal growth as teams have the potential to increase the city's revenue, put a city's name on the map (Kotler et al., 1993), and increase the city's status and prestige (Duquette \& Mason, 2008), balancing both the noneconomic and economic benefits of a professional sports team. This study demonstrates residents' perception of noneconomic benefits were outweighed by their perception of economic benefits, which could have been a result of stakeholder messaging and propaganda employed in order to justify the investment 
(Crompton, 1995; Danielson, 1997). Stakeholders gain from focusing on the tried and true argument of economic benefits over the noneconomic benefits of the stadium project. Residents' perceptions of economic benefits and stakeholders associated with the project were a significant factor in their willingness to support the stadium project.

The current study sought to extend the sport-based CVM stadium research through an examination of a current case study, utilizing a referendum approach to address what influences citizens' perceptions of a stadium project. CVM research aims to measure how much a person would be willing to pay for a good or service not sold in the market (Carson, 2000). Relying on the public good variable (i.e., reading about the team, watching the team on television, talking about the team with friends, family, and/or co-workers, and quality of life improvement), researchers have attempted to place an existence value on professional sports team to gauge if residents would be willing to pay enough to cover the stadium subsidy. Sport-based CVM research consistently found the aggregated amount of respondent's willingness to pay value provided was not enough to pay for the stadium project in question (Atkinson et al., 2008; Castellanos et al., 2011; Fenn \& Crooker, 2009; Groothuis et al., 2004; Johnson \& Whitehead, 2000; Johnson et al., 2001; Johnson et al., 2006, 2007; Owen, 2006; Santo, 2007). Simply, residents were willing to pay to build a stadium for their local professional teams, but they were not willing to pay the entire subsidy. These results, in conjunction with the current study, indicated there is a level of support from local residents given certain factors, but full support continues to lack.

The current research relied on CVM as the conceptual framework, focusing on residents' willingness to support a stadium project through a referendum and providing 
respondents with a current and real situation to consider. This approach addressed some of the suggested best practices to CVM research and attempted to avoid some of the pitfalls surrounding this method (see Arrow et al., 1993; Diamond \& Hausman, 1994; Hanemann, 1994; Niewik, 1992; Portney, 1994; Walker \& Mondello, 2007). The findings in the current study suggest that perceptions of noneconomic benefits may not be the top priority for a resident when considering the value of an actual stadium project being presented to a community via a referendum. Diamond and Hausman (1994) stated, "Expressed preferences are not an expression of true economic preferences" (p. 48), which also supports the notion of shift from hypothetical to actual situations. The realistic and bona-fide situation presented to residents in this study lends itself to focus future research on current and forthcoming stadium projects. Previous research in this area highlighted the noneconomic benefits of a stadium, though they were mostly dealing with hypothetical situations (Castellanos et al., 2011; Groothuis et al., 2004; Johnson \& Whitehead, 2000; Johnson et al., 2001; Johnson et al., 2006, 2007; Owen, 2006; Santo, 2007). The current study presented respondents with a forthcoming issue that their community was facing, and the results suggested they valued perceived economic benefits over noneconomic benefits. The difference here may be due to the presentation of an actual stadium situation.

A deeper examination of the specific stakeholders involved with the San Diego stadium project yielded results consistent with stakeholder groups theorized by Friedman and Mason (2004, 2005). Based on respondent's feedback, the results showed that each definitive stakeholder group presented by Friedman and Mason (2004) (i.e., business community, politicians, proponent groups, the media, and team owners) existed within 
this specific stadium project. These groups have historically been proponents of stadium projects (Brown \& Paul, 2002), further warranting specific examination and their potential influence in the success of this project. In addition, previous literature has found politicians (Danielson, 1997; Paul \& Brown, 2001, 2006; Sage, 1993), the media (Brown \& Paul, 1999; Buist \& Mason, 2010; Delaney \& Eckstein, 2007, 2008; Sage, 1993; Turner \& Marichal, 1998), stadium proponent groups (Brown \& Paul, 2002; Paul \& Brown, 2001), the business community (Danielson, 1997; Delaney \& Eckstein, 2007; Friedman \& Mason, 2004; Kalich, 1998; Mason \& Buist, 2013; Sage, 1993), and team owners (Brown \& Paul, 1999; Fort, 1997) involved in local stadium construction projects.

In this study, politicians were perceived as a stakeholder group highly involved campaigning both in favor of and against the stadium project (i.e., respondents listed this group campaigning in favor 124 times, and listed this group campaigning against the stadium project 77 times). While other definitive stakeholders are involved in stadium construction projects, mayors and governors typically lead the political coalitions, as seen in a number of cases across the United States (Danielson, 1997). This support from politicians provides the stadium projects with the credibility they need, often leading to their success (Brown \& Paul, 1999), further supporting the large frequency for politicians both in favor and against the stadium project. While the politician stakeholder group was perceived to be one of the largest groups campaigning in favor of the stadium project, team owners were included as the top. This finding is reflective of the specific case in San Diego as the Chargers sponsored the stadium ballot initiative by collecting enough signatures from registered voters and submitting the measure to city council 
(Schrotenboer, 2016). In addition, the business community stakeholder group was identified by respondents almost evenly in terms of in favor and against the stadium project (i.e., respondents listed 64 of this group in favor, and listed 65 of this group against the stadium project), providing indication of divergent interests and opinions in this matter.

Given the platform and influence the definitive stakeholders have in the development and success of stadium projects (see Brown \& Paul, 2002; Friedman \& Mason, 2004, 2005; Sage, 1993), it is important to examine and recognize the structure of these groups, especially from the perspective of the local constituents. As previous research has suggested, an increased level of unity amongst stakeholders can be related to the levels of public support for stadium projects. That is, stakeholder groups, when working cohesively, may have the influence to shift public opinion, and ultimately the public vote, on stadium projects (Delaney \& Eckstein, 2007, 2008; Duquette \& Mason, 2008; Mason \& Buist, 2013; Paul \& Brown, 1999, 2001, 2006; Sage, 1993). In this study, respondents may have recognized a divide among the business community and the politicians in terms of the San Diego stadium project, given the split frequency counts in favor of and against for these two groups, highlighting a potential lack of unity both within these stakeholder groups and across them. The stadium project in San Diego ultimately failed at the ballot box. Given the important role of Stakeholder Influence in the quantitative analysis in addition to the qualitative evidence regarding the stakeholder groups, the current study suggests respondent's perceptions regarding stakeholder involvement potentially led to the referendum's demise. 
In addition to politicians and the business community, the current study affirmed many of the stakeholder groups presented by Friedman and Mason $(2004 ; 2005)$. Other stakeholder groups emerged from the results. Respondents perceived fans $(n=15)$, general public $(n=28)$, opponent groups $(n=14)$, and neighborhood groups $(n=14)$ to be campaigning either for or against the stadium project, despite their lack of power, legitimacy, and/or urgency to make them a definitive stakeholder (Mitchell et al., 1997). These four groups did not yield high frequency counts like the definitive stakeholders. Yet given the opportunity to freely list other groups associated with the stadium project, respondents perceived the existence of other groups in relation to the stadium project. Further, these four stakeholder groups were vocal enough in this case to catch the attention of the respondents, but fell short of the level of influence the definitive stakeholders may possess, given their lack of power, legitimacy, and urgency in the matter. For example, opponent groups almost instinctively appear as conversations of stadium projects arise (Fort, 1997; Freidman \& Mason, 2005; Sage, 1993), but seldom gain enough power to become a definitive stakeholder in these cases (Friedman \& Mason, 2005). Friedman and Mason (2005) suggested that stakeholder groups can move fluidly across the stakeholder map, gaining and losing attributes as the stadium situation progresses because stakeholder analysis is situationally unique (Mitchell et al.). These groups potentially gained or lost momentum as the referendum approached, gaining or losing attributes providing them a platform to be recognized by the respondents.

Friedman and Mason $(2004,2005)$ posited the sport leagues are definitive stakeholders, maintaining power, urgency, and legitimacy within the local stadium project issue. As discussed in the literature review, the league involved with the project 
may lack urgency in the project; therefore, it should be considered a dominant stakeholder, maintaining only legitimacy and power. Findings in the current study suggest that the NFL may not be a dominant stakeholder. Not only does the frequency of this stakeholder lack substantially $(n=4)$ when compared to the listed definitive stakeholders in the current study $(n=747)$, the NFL was also listed less frequently than other less salient stakeholder groups (i.e., fans, general public, neighborhood groups, opponent groups). This suggests the NFL may lack salience in local stadium projects, and should not be maintained as a definitive stakeholder group. Though the NFL in general may garner additional media attention in stadium development situations involving a local team or additional revenues based on the success of the local stadium referendum, they may remain silent. The league's influence may hinder the case, though it may also provide support the local team needs.

Stakeholder groups posited by Friedman and Mason (2004) not specified in the current study by respondents were: competing cities, the federal government, and lower income residents. It is somewhat surprising that competing cities were not included as a stakeholder against the stadium project, as the Chargers were openly discussing a relocation to Los Angeles, California concurrently with its venture to fund a new stadium in San Diego. However, it should be noted that Los Angeles - the closest city and likely most viable option — was not actively seeking to recruit an NFL team to the area compared to other attempts (see Friedman \& Mason, 2005).

\section{Practical Implications}

Respondents valued the perceived economic benefits associated with the potential stadium project. That is, they considered the associated economic benefits of the project 
such as job creation and local economic development as key factors in their support. Respondents were also influenced by community leaders associated with the project, individuals. With this in mind, stakeholders who support stadium projects should continue to commission economic impact reports to provide quantitative evidence that supports this investment to the community. The perceived economic benefits associated with a professional stadium project include jobs, new businesses in the area, and general economic improvement for the city. Stakeholders should create public relations campaigns surrounding these benefits, especially data surrounding job creation, in order to gain support from the local constituents. These benefits should be at the core of all talking points, press releases, and public relations materials surrounding the project. Also, it is important for stakeholders to build community trust with their constituents in terms of the stadium projects. Focusing on presenting the facts of the economic impact reports (given the data is factual), may also help develop trust between the voters and the community leaders. As stakeholders, especially those in politics and in the media, move forward to gain trust and support from their constituents, it is important to consider how the "fake news" phenomenon may potentially influence the perceptions of stadium construction projects.

Stakeholders who do not support stadium projects should attempt to dispel the statements of economic impact, as academic research consistently indicates this approach does not provide economic growth and offers little economic value to a community. Again, this point should be at the core of all public relations materials. Those against the stadium project should work diligently with other salient stakeholders such as politicians, the media, and business men and women within the community. Stakeholders with 
inconsistent messaging within their groups will likely affect the outcome of the referendum. Further, unity both within and across stakeholder groups may help shift public opinion, and ultimately shift the vote for the stadium project. Ultimately, residents will be influenced by statements regarding the economic benefits of a stadium in terms of their willingness to support the project; therefore, it would behoove stakeholders to focus on these key benefits (or lack thereof) for the community.

Though team identification is an important factor in developing a strong and faithful fan base, it may not play a significant role in influencing respondent's willingness to support the stadium project. To support the stadium project, sport organizations should invest their time promoting the long-term economic benefits of the stadium project. Sport organizations can develop additional community relations programs where the team and organization is aiding in the economic growth and development of the area. The sport organization can also build a public relations campaign surrounding various ways the team and organization have invested into the community. These acts can provide additional evidence indicating that the sport organization supports the economic growth of the city.

\section{Limitations and Future Research}

The current study aimed to fill a gap in the research to provide additional empirical evidence of voter's perceptions of local stadium projects. Extant research exists on the economic impact of these projects, and a separate research area has developed in addressing how much residents would be willing to pay for a stadium.

This study sought to understand what factors influence voter perceptions in terms of willingness to support the stadium project in a referendum through the development of 
a unique instrument. This instrument was developed by the researcher to assess citizens' perceptions of their local professional stadium projects through a compilation of various potential influential variables. Previous research has examined influential variables in terms of stadium projects, but no research has been found to bring these variables together and address voters' perceptions. Also, the present study aimed to develop a sound instrument that could be used to address stakeholder influence. Future research can further test and develop this instrument in other municipalities that are faced with professional stadium referendums. Applying the instrument to other cities and other professional sport leagues may provide a broader view of voter perceptions, as well as bring additional attention to factors that may establish cases starkly different from each other. Future research can also help refine this scale and approach to empirically measuring stakeholder influence, including collecting data over a longer period of time. Data collection for this study was concentrated right before a presidential election, and could have covered a time frame where a number of nondefinitive stakeholders were making their stance known. For example, data collection for the Friedman and Mason's (2005) case study on the stakeholders involved in Nashville, Tennessee's attempt to recruit an NFL team covered about 10 months, while the data collection for the current study covered about one month. Future research and data collection in this area should extend to longer than one month in order to gain better insight on the fluidity of stakeholders.

Additionally, the reliance on a specific city (San Diego) limited the generalizability of the study. The specifics of this case may be too narrow to be generalized to the population. For example, the specific dealings within the San Diego 
market may be different from other comparable markets in the United States. For example, San Diego was ranked $22^{\text {nd }}$ in US News Best Places to Live ranking (Czajkowski, 2017). One may argue that the addition or subtraction of a professional sports team would shift the quality of life minimally; therefore, respondents' perceptions may be skewed. Future research should test this study's survey instrument in other markets of different sizes, quality of life, resident demographics, and other factors to further develop generalizability of the findings.

The current study relied on participants to consider how they would vote for the stadium referendum. The referendum was held the same day as the 2016 presidential election with nominees Hillary Clinton and Donald Trump; therefore, voter predisposition should be considered. There were a number of matters being discussed during this campaign, which may have led respondents to consider the stadium referendum taboo or unimportant in the grand scheme of the election because of its small overall impact or potentially a lack of interest in sports. In addition, the time frame to complete the survey was limited to a few weeks before the election, which was also a heavy presidential campaigning time frame. This may have influenced how the respondents addressed and answered the survey. Future research should strive to collect data over an extended period of time to allow for a more accurate and fuller account of respondents' perceptions of the stadium project.

There was the issue of low response rate, which could be attributed to a number of factors. Data collection occurred the month prior to the 2016 presidential election. During this time, citizens are typically bombarded with political advertising and messaging as election day approaches, and this survey may have been considered one of 
those communications. Another potential reason for the low response rate was a poor email contact list. There were almost 200 email returns/kick-backs from the dissemination of the main study. The accuracy of email addresses purchased was in question. The sample was purchased from a third-party company that specializes in voter data. This company promised to provide the data at random. Unfortunately, the voter data provider could not guarantee the number of deliverable email addresses, though it typically expects an 85-95\% deliverable rate (P. Graham, personal communication, October 26, 2016). Future research should rely on voter data obtained from municipal voter offices, where the data for registered voters (i.e., mailing address) can be obtained. Additionally, a mailer is the suggested approach for future research to mitigate issues with contact accuracy.

Finally, further research in the area of stakeholder influence and presence is warranted. The current study found that stakeholder influence was a key factor in a respondent's willingness to support a stadium project. In addition, respondents indicated a number of stakeholders within this case that were perceived to be campaigning either for or against the stadium project. Therefore, future research can explore which of the stakeholder have more influence than others.

\section{Summary of Study}

Professional stadium projects are abundant across the United States, where the public has paid for a substantial portion of the investment in many cases (Chambers, 2016; Kellison \& Mondello, 2014; Siegfried \& Zimbalist, 2000). Politicians and key stakeholders in a community often support these measures despite extant academic research stating these projects provide little to no economic value to the community (see 
Baade, 1994, 1996; Baade \& Dye, 1988a, 1990; Baade et al., 2008; Coates \& Humphreys, 1999, 2002; Euchner, 1993; Zipp, 1996). These stakeholders continue to commission local economic impacts reports which promote economic benefits and provide quantitative evidence that the investment is sound. This data, along with other messaging, suggest stadium projects are the key to municipal growth and increased quality of life for citizens, present and future. Ultimately, these projects are often presented to the voting public through a referendum and are approved (Kellison \& Mondello, 2014; Mondello \& Anderson, 2004). Therefore, the purpose of this study was to better understand the potential factors that may influence a voter to support local stadium projects. Relying on sport-based CVM in addition to stakeholder influence and team identification provided insight into this phenomenon.

Previous literature in this area has focused on economic impact through a quantitative examination of economic indicators. Stakeholder influence has primarily been examined through a qualitative case study approach. Team identification has been applied inconsistently to research surrounding stadium support. Sport economists have suggested and attempted to examine noneconomic benefits in relation to stadium projects, each with similar results: residents were willing to pay for the stadium project, but not enough to cover the entire subsidy. The current study combined these three areas to study how perceptions of economic indicators, stakeholder influence, noneconomic benefits, and team identification may influence a voter's willingness to support a stadium project.

In an examination of the city of San Diego and the NFL Chargers attempt to obtain public funding for a new downtown stadium, it was ultimately found that voters 
value the perceived economic benefits associated with the potential professional sport stadium project. Voters' perceptions of community leaders associated with the project also influenced their willingness to support the stadium project. Team identification had no effect on their willingness to support the stadium project. Perceptions surrounding noneconomic benefits such as civic pride and quality of life also had no effect on respondents' willingness to support the stadium project.

Additionally, stakeholder involvement was assessed. Politicians, team owners, the business community, proponent groups, and the media were all perceived to somehow be involved with the stadium project — both in favor and against it. Other stakeholders found to be involved with the stadium project included fans, the general public, neighborhood groups, and opponent groups. The politician and business community stakeholder group were perceived to be heavily involved both in favor and against the stadium project. Given previous research has shown that elite unity can influence the outcome of a stadium referendum, and the current study indicated stakeholder influence is an influential factor in willingness to support the stadium project, stakeholder unity can be a critical part of the success or failure of a stadium project.

The current study provided a clearer understanding of what variables may influence a constituent's willingness to support a local stadium project. Given the current state of professional sport stadium development in the United States, the findings provide deeper insight for sport organizations, stakeholders, and researchers. The findings highlight the value of perceived economic benefits for constituents, and the lack of value of noneconomic benefits. Voters want to ensure public funds are being efficiently and effectively invested back into the community, and seem to care less about the "warm and 
fuzzy" feeling a professional team may provide a community. The current study also highlighted the role and influence stakeholders have with these types of projects. Stakeholders such as politicians and team owners are typically vocal concerning stadium projects, and their potential influence on the voting population should not go ignored. These results contribute to future research in voter perceptions regarding professional sport stadium projects and referendums. Additionally, the current study extends and expands the literature on stadium financing by providing empirical evidence from the voter's perspective. 


\section{REFERENCES}

About us. (2016). L2. Retrieved from http://www.12political.com/about/

Adelson, J. L. (2012). Examining relationships and effects in gifted education research: An introduction to structural equation modeling. Gifted Child Quarterly, 56, 4755.

Ahlfeldt, G., \& Maennig, W. (2012). Voting on a NIMBY facility: Proximity cost of an "iconic" stadium. Urban Affairs Review, 48(2), 205-237. doi:10.1177/1078087411423644

Alexander, D., Kern, W., \& Neil, J. (2000). Valuing the consumption benefits from professional sports franchises. Journal of Urban Economics. 48, 321-337.

Anderson, J. C., \& Gerbing, D. W. (1984). The effect of sampling error on convergence, improper solutions, and goodness-of-fit indices for maximum likelihood confirmatory factor analysis. Psychometrika, 49, 155-172.

Anderson, J. C., \& Gerbing, D. W. (1988). Structural equation modeling in practice: A review and recommended two step approach. Psychological Bulletin, 103, 411423.

ANES. (n.d.). 2012 Direct democracy study. Retrieved from http://electionstudies.org/studypages/anes_specialstudy_2012_directdem/anes_sp ecialstudy_2012_directdem.htm

ANES. (2016). The ANES mission. Retrieved from http://electionstudies.org/overview/overview.htm

Arrow, K., Solow, R., Leamer, E., Portney, P., Radner, R., \& Schuman, H. (1993). Report of the NOAA Panel on contingent valuation. U.S. Department of Commerce Federal Register, 58, 4602-4614.

Atkinson, G., Mourato, S., Szymanski, S., \& Ozdemiroglu, E. (2008). Are we willing to pay enough to 'back the bid'?: Valuing the intangible impacts of London's bid to host the 2012 Summer Olympic Games. Urban Studies, 45(2), 419-444. doi:10.1177/0042098007085971

Baade, R. A. (1994). Stadiums, professional sports, and economic development: Assessing the reality (A Heartland policy study, no. 62). Detroit, Mich.: Heartland Institute. 
Baade, R. A. (1996). Professional sports as catalysts for metropolitan economic development. Journal of Urban Affairs, 18(1), 1-17.

Baade, R. A. (2000). The impact of sports teams and facilities on neighborhood economics: What is the score? In W. Kern (Ed.), The economics of sports (pp. 21-49). Kalamazoo, MI: W.E. Upjohn Institute for Employment Research.

Baade, R. A. (2003). Evaluating subsidies for professional sports in the United States and Europe: A public-sector primer. Oxford Review of Economic Policy, 19(4), 585-597.

Baade, R. A. (2006). A primer on the economic impact of mega-sports events and investments in sports infrastructure. In P. Rodríguez, S. Késenne, \& J. García (Eds.), Sports economics after fifty years: Essays in honour of Simon Rottenberg (pp. 51-68). Oviedo, Spain: Ediciones de la Universidad de Oviedo.

Baade, R. A., \& Dye, R. F. (1988a). An analysis of the economic rationale for public subsidization of sports stadiums. Annals of Regional Science, 22(2), 37-47.

Baade, R. A., \& Dye, R. F. (1988b). Sport stadiums and area development: A critical review. Economic Development Quarterly, 2(3), 265-275.

Baade, R. A., \& Dye, R. F. (1990). The impact of stadiums and professional sports on metropolitan area development. Growth and Change, 21(2), 1-14.

Baade, R. A., Baumann, R., \& Matheson, V. A. (2008). Selling the game: Estimating the economic impact of professional sports through taxable sales. Southern Economic Journal, 74(3), 794-810.

Bate, R. (1994). Pick a number: A critique of contingent valuation methodology and its application in public policy. Competitive Enterprise Institute, 1-25.

Bentler, P. M., \& Chou, C. (1987). Practical issues in structural modeling. Sociological Methods and Research, 16, 78-117.

Body-Gendrot, S. N. (1987). Grass-roots mobilization in the thirteenth arrondissement of Paris: A cross-national view. In Stone, C.N. \& Sanders, H.T. (Eds.). The Politics of Urban Development (p. 125-143). Lawrence, KS: University Press of Kansas.

Bollen, K. A., \& Stine, R. (1990). Direct and indirect effects: Classical and bootstrap estimates of variability. Sociological Methodology, 20, 115-40.

Brady, H. E., \& Sniderman, P. M. (1985). The attitude attribution: A group basis for political reasoning. American Political Science Review, 79, 1061-78.

Brown, T. A. (2015). Confirmatory factor analysis for applied research ( $2^{\text {nd }}$ ed.). New York, NY: Guilford Press. 
Browne, M. W., \& Cudeck, R. (1993). Alternative ways of assessing model fit. In K. A. Bollen \& J. S. Long (Eds.). Testing structural equation models (pp. 136-162). Newbury Park, CA: Sage Publications.

Brown, C., \& Paul, D. M. (1999). Local organized interests and the 1996 Cincinnati sports stadia tax referendum. Journal of Sport \& Social Issues, 23(2), 218-237.

Brown, C., \& Paul, D. M. (2002). The political scorecard of professional sports facility referendums in the United States, 1984-2000. Journal of Sport \& Social Issues, 26(3), 248-267.

Bryne, B. (2001). Structural equation modeling with AMOS: Basic concepts, applications, and programming. Mahwah, NJ: Lawrence Erlbaum Associates.

Buist, E. A., \& Mason, D. S. (2010). Newspaper framing and stadium subsidization. American Behavioral Scientist, 53, 1492-1510.

Capps, K. (2015, March 11). The inglorious history of Los Angeles football. Retrieved from http://www.citylab.com/work/2015/03/insert-football-team-name-ismoving-to-los-angeles/386878/

Carlino, G., \& Coulson, N. E. (2004). Compensating differentials and the social benefits of the NFL. Journal of Urban Economics, 56(1), 25-50.

Carmines, E. G., \& Kuklinski, J. H. (1990). Incentives, opportunities, and the logic of public opinion in American political representation. In J. A. Freejohn and J. H. Kuklinkski, eds., Information and Democratic Processes. Urbana, IL: University of Illinois Press.

Carson, R. T. (1995). A bibliography of contingent valuation papers and studies. La Jolla, CA: NRDA.

Carson, R. T. (2000). Contingent valuation: A user's guide. Environmental Science \& Technology, 34(8), 1413-1418. doi: 10.1021/es990728j.

Carson, R. T., Flores, N. E., \& Meade, N. F. (2001). Contingent valuation:

Controversies and evidence. Environmental and Resource Economics, 19(2), 173-210.

Castellanos, P, García, J., \& Sánchez, J. M. (2011). The willingness to pay to keep a football club in a city: How important are the methodological issues? Journal of Sports Economics, 12(4), 464-486.

Chambers, M. (2016, June 17). Falcons stadium to cost an extra $\$ 200$ million. SB Nation. Retrieved from http://www.thefalcoholic.com/2016/6/17/11963486/falcons-stadium-to-cost-anextra-200-million 
Check your registration status. (n.d.). San Diego Registrar of Voters. Retrieved from http://www.sdvote.com/content/rov/en/Registration.html

Chema, T. V. (1996). When professional sports justify the subsidy, a reply to Robert A. Baade. Journal of Urban Affairs, 18(1), 19-22.

Chronology 1959-1969. (2016). San Diego Chargers. Retrieved from http://www.chargers.com/team/history/chronology/1959-1969

City of San Diego. (2016). Economic development. Retrieved from https://www.sandiego.gov/economic-development/sandiego/population

Cialdini, R. B., Borden, R. J., Thorne, A., Walker, M. R., Freeman, S., \& Sloan, L. R. (1976). Basking in reflected glory: Three (football) field studies. Journal of Personality and Social Psychology, 34, 366-375.

Clarkson, M. B. (1994). A risk-based model of stakeholder theory. Proceedings of the Second Toronto Conference on Stakeholder Theory. Toronto: Centre for Corporate Social Performance \& Ethics, University of Toronto.

Clarkson, M. B. (1995a). A stakeholder framework for analyzing and evaluating corporate social performance. The Academy of Management Review, 20(1), 92117.

Clarkson, M. B. (1995b). A risk based model of stakeholder theory. Paper presented at the Society of Business Ethics Conference, Vancouver, British Columbia.

Coates, D. (2007). Stadiums and arenas: Economic development or economic redistribution? Contemporary Economic Policy, 25(4), 565-577. doi:10.1111/j.1465-7287.2007.00073.x

Coates, D., \& Humphreys, B. (1999). The growth effects of sport franchises, stadia, and arenas. Journal of Policy Analysis \& Management, 18(4), 601-624.

Coates, D., \& Humphreys, B. (2002). The economic impact of postseason play in professional sport. Journal of Sports Economics, 3(3), 291-299.

Coates, D., Humphreys, B. R., \& Zimbalist, A. (2006). Compensating differentials and the social benefits of the NFL: A comment. Journal of Urban Economics, 60(1), 124-131.

Conventions, Sports, \& Leisure. (2009). Economic and jobs impact of Metrodome Next multipurpose facility. Retrieved from http://prod.static.vikings.clubs.nfl.com/assets/docs/csl-full-021511.pdf

Covell, D. (2005). Attachment, allegiance and a convergent application of stakeholder theory: Assessing the impact of winning on athletic donations in the Ivy League. Sport Marketing Quarterly, 14(3), 168-176. 
Crompton, J. L. (1995). Economic impact analysis of sports facilities and events: Eleven sources of misapplication. Journal of Sport Management, 9, 14-35.

Crompton, J. L. (2004). Beyond economic impact: An alternative rationale for the public subsidy of major league sports facilities. Journal of Sport Management, $18,40-58$.

Czajkowski, D. (2017). San Diego, California. US News. Retrieved from http://realestate.usnews.com/places/california/san-diego

Danielson, M. N. (1997). Home Team. Princeton, NJ: Princeton University Press.

Davis, J. S. (2002). Urban regime theory: A normative-empirical critique. Journal of Urban Affairs, 24(1), 1-17.

Delaney, K. J., \& Eckstein, R. (2003) . The devil is in the details: Neutralizing critical studies of publicly subsidized stadiums. Critical Sociology, 29(2), 189-210.

Delaney, K. J., \& Eckstein, R. (2007). Urban power structures and publicly financed stadiums. Sociological Forum, 22, 331-353. doi:10.1111/j.15737861.2007.00022.x

Delaney, K. J., \& Eckstein, R. (2008). Local media coverage of sports stadium initiatives. Journal of Sport \& Social Issues, 32(1), 72-93.

DelReal, J. (2014, November 10). Voter turnout in 2014 was the lowest since WWII. The Washington Post. Retrieved from https://www.washingtonpost.com/news/post-politics/wp/2014/11/10/voterturnout-in-2014-was-the-lowest-since-wwii/

Depken. C. (2000). Fan loyalty and stadium funding in professional baseball. Journal of Sports Economics, 1(2), 124-138.

Diamond, P. A., \& Hausman, J. A. (1994). Contingent valuation: Is some number better than no number? Journal of Economic Perspectives, 8(4), 45-64.

Dillman, D. A., Smith, J. D., \& Christian, L. M. (2009). Internet, mail, and mixed mode surveys: The tailored design method. Hoboken, NJ: John Wiley \& Sons, Inc.

Dietz-Uhler, B., \& Lanter, J. R. (2008). The consequences of sports fan identification. In L. W. Hugenberg, P. M. Haridakis, \& A. C. Earnheardt (Eds.), Sports mania: Essays on fandom and the media in the 21st century (p. 103-113). Jefferson, N.C.: McFarland \& Co.

Ding, L., Velicer, W.F., \& Harlow, L.L. (1995). Effects of estimation methods, number of indicators per factor, and improper solutions on structural equation modeling fit indices. Structural Equation Modeling, 2, 119-144. 
Donaldson, T., \& Preston, L. E. (1995). The stakeholder theory of the corporation: Concepts, evidence, and implications. The Academy of Management Review, 20(1), 65-91.

Dressman, D. (1990, August 12). The final innings. Rocky Mountain News, p. 103.

Dunnavant, K. (1989, March 13). The impact of economics. Sports Inc, 31-33.

Duquette, G., \& Mason, D. (2008). Urban regimes and sport in North American cities: Seeking status through franchises, events, and facilities. International Journal of Sport Management and Marketing, 3, 221-241.

Eckstein, R., \& Delaney, K. (2002). New sports stadiums, community self-esteem, and community collective conscience. Journal of Sport \& Social Issues, 26(3), 235247.

Eitzen, D. (1999). Fair and foul: Beyond the myths and paradoxes of sport. Lanham, MD: Rowman \& Littlefield.

Elkin, S. L. (1987). City and regime in the American republic. Chicago, IL: University of Chicago Press.

ESPN. (2016a). MLB attendance report. ESPN. Retrieved from http://espn.go.com/mlb/attendance

ESPN. (2016b). NFL attendance report. ESPN. Retrieved from http://espn.go.com/nfl/attendance

Etzioni, A. (1964). Modern organizations. Englewood Cliffs, NJ: Prentice Hall.

Euchner, C. (1993). Playing the field: Why sports tams move and cities fight to keep them. Baltimore, MD: The Johns Hopkins University Press.

Fan, X., Thompson, B., \& Wang, L. (1999). Effects of sample size, estimation methods, and model specification on structural equation modeling fit indexes. Structural Equation Modeling, 6 (1), 56-83.

Farmer, S., \& Fenno, N. (2016, January 12). NFL will return to Los Angeles for 2016 season. Los Angeles Times. Retrieved from http://www.latimes.com/sports/nfl/la-sp-nfl-la-chargers-rams-20160113story.html

Fenn, A. J., \& Crooker, J. R. (2009). Estimating local welfare generated by an NFL team under credible threat of relocation. Southern Economic Journal, 76(1), 198223.

Fort, R. (1997). Direct democracy and the stadium mess. In R.G. Noll and A. Zimbalist, Sports, Jobs, and Taxes (pp. 146-177). Washington DC: Brooking Institution Press. 
Freeman, R. E. (1984). Strategic management: A stakeholder approach. Boston, MA: Harper Collins.

Freeman, A. M. (2003). The measurement of environmental and resource values: Theory and methods ( $2^{\text {nd }}$ ed.). Washington DC: Resources for the Future.

Friedman, M., \& Mason, D. (2004). A stakeholder approach to understanding economic development decision making: Public subsidies for professional sport facilities. Economic Development Quarterly, 18, 236-254.

Friedman, M., \& Mason, D. (2005). Stakeholder management and the public subsidization of Nashville's Coliseum. Journal of Urban Affairs, 27(1), 93-118.

Friedman, M., Parent, M., \& Mason, D. (2004). Building a framework for issues management in sport through stakeholder theory. European Sport Management Quarterly, 4, 170-190.

Garrick, D. (2016a, July 9). Chargers stadium plan heading to ballot. San Diego UnionTribune. Retrieved from http://www.sandiegouniontribune.com/news/2016/jul/09/chargers-stadium-ballotinitiative-signatures/

Garrick, D. (2016, November 9). Stadium measures lose badly. San Diego Union Tribune. Retrieved from http://www.sandiegouniontribune.com/news/elections/sd-me-election-chargers20161106-story.html

Gaskin, J. (2012). Data screening. Gaskination's StatWiki. http://statwiki.kolobkreations.com

Gaskin, J. (2013). Multigroup analysis. Gaskination's Statistics. http://youtube.com/Gaskination

Gaskin, J. (2016). Validity master. Stats Tools Package. http://statwiki.kolobkreations.com

Gerbing, D. W., \& Anderson, J. C. (1984). On the meaning of within-factor correlated measurement errors. Journal of Consumer Research, 11(1), 572-580.

Greene, R. (2016, May 13). Happy with 4 percent of your fellow citizens deciding for you? Fort Worth Star-Telegram. Retrieved from http://infoweb.newsbank.com/resources/doc/nb/news/15CDB6D48FC016D8?p= AWNB

Greene, W. H. (1995). Frontier production functions. In H. Pesaran \& P. Schmidt (Eds.), The handbook of applied econometrics: Volume 2. Microeconomics. Cambridge, MA: Blackwell. 
Groothuis, P. A., Johnson, B. K., \& Whitehead, J. C. (2004). Public funding of professional sports stadiums: Public choice or civic pride? Eastern Economic Journal, 30(4), 515.

Hair, J. F., Tatham, R. L., Anderson, R. E., \& Black, W. (1998). Multivariate data analysis $\left(5^{\text {th }}\right.$ ed.). London: Prentice-Hall.

Halverstadt, L. (2015, March 18). Five lessons from the Padres' stadium push. Voice of San Diego. Retrieved from http://www.voiceofsandiego.org/topics/land-use/5lessons-from-the-padres-stadium-push/

Halverstadt, L., \& Keatts, A. (2016, March 30). San Diego politicos pan Chargers' convadium plan. Voice of San Diego. Retrieved from http://www.voiceofsandiego.org/must-reads/san-diego-politicos-pan-chargersconvadium-plan/

Hanemann, M. (1994). Valuing the environment through contingent valuation. Journal of Economic Perspectives, 8(4), 19-43.

Harrington, R., \& Gould, S. (2016, December 21). Americans beat one voter turnout record-here's how 2016 compares with past elections. Business Insider. Retrieved from http://www.businessinsider.com/trump-voter-turnout-recordshistory-obama-clinton-2016-11

History. (2016). San Diego Chargers. Retrieved from http://www.chargers.com/team/history

Hooper, D., Coughlan, J., \& Mullen, M. R. (2008). Structural equation modelling: Guidelines for determining model fit. The Electronic Journal of Business Research Methods, 6(1), 53-60

Hudson, I. (2001). The use and misuse of economic impact analysis: The case of professional sports. Journal of Sport \& Social Issues, 25(1), 20-39.

Hu, L. T., \& Bentler, P. M. (1999). Cutoff criteria for fit indexes in covariance structure analysis: Conventional criteria versus new alternatives. Structural Equation Modeling: A Multidisciplinary Journal, 6(1), 1-55.

Hunn, D. (2015, November 13). Chamber study calls new stadium 'critical,' adds 7,500 jobs. St. Louis Post-Dispatch. Retrieved from http://www.stltoday.com/business/local/chamber-study-calls-new-stadiumcritical-adds-jobs/article_a67ecd75-d543-5bea-9e73-57e0ed4df393.html

Iacobucci, D. (2010). Structural equations modeling: Fit indices, sample size, and advanced topics. Journal of Consumer Psychology, 20(1), 90-98.

Irani, D. (1997). Public subsidies to stadiums: Do the costs outweigh the benefits? Public Finance Review, 25(2), 238-253. 
Johnson, A. T. (1986). Economic and policy implications of hosting sports franchises: Lessons from Baltimore. Urban Affairs Quarterly, 21, 411-434.

Johnson, B. K. (2008). The valuation of nonmarket benefits in sport. In B. R. Humphreys and D. R. Howard (Eds.), The Business of Sport (pp. 207-233). Westport, CT: Praeger Publishers.

Johnson, B. K., \& Whitehead, J. C. (2000). Value of public goods from sports stadiums: The CVM approach. Contemporary Economic Policy, 18(1), 48-58.

Johnson, B. K., Groothuis, P. A., \& Whitehead, J. C. (2001). The value of public goods generated by a major league sports team: The CVM approach. Journal of Sports Economics, 2(1), 6-21.

Johnson, B. K., Mondello, M., \& Whitehead, J. C. (2006). Contingent valuation of sports: Temporal embedding and ordering effects. Journal of Sports Economics, 7(3), 267-288.

Johnson, B. K., Mondello, M., \& Whitehead, J. C. (2007). The value of public goods generated by a National Football League team. Journal of Sport Management, $21,123-136$.

Jöreskog, K., \& Sörbom, D. (1993) . LISREL 8: Structural Equation Modeling with the SIMPLIS Command Language. Chicago, IL: Scientific Software International Inc.

Kalich, V. Z. (1998). A public choice perspective on the subsidization of private industry: A case study of three cities. Journal of Urban Affairs, 20(2), 199-219.

Kellison, T. (2013). Civic paternalism in political policymaking: The justification for no-vote stadium subsidies and the public response. (Doctoral dissertation). Available from ProQuest Dissertations and Theses database. (UMI NO. 3564908)

Kellison, T., \& Mondello, M. (2013). In the continued pursuit of stadium initiatives following past failures: An analysis of the Los Angeles Farmers Field proposal. Journal of Venue \& Event Management, 4(2), 36-46.

Kellison, T., \& Mondello, M. (2014). Civic paternalism in political policymaking: The justification for no-vote stadium subsidies. Journal of Sport Management, 28(2), 162-175.

Kenny, D.A. (2016). Mediation. Retrieved from http://davidakenny.net/cm/mediate.htm

Kenny, D.A., \& McCoach, D.B. (2003). Effect of the number of variables on measures of fit in structural equation modeling. Structural Equation Modeling, 10(3), 33351.

Kline, R. B. (2011). Principles and practice of structural equation modeling (3rd ed.). New York, NY: Guilford Press. 
Knight Ridder News Service. (1999, March 25). Final Four's financial impact hard to gauge. Enquirer Sports Coverage. Retrieved from http://enquirer.com/editions/1999/02/25/spt_final_fours.html

Kotler, P., Haider, D. H., \& Rein, I. (1993). Marketing places: Attracting investment, industry, and tourism to cities, states, and nations. New York, NY: The Free Press.

Lansing, P., \& Casper, J. (2000). The costs and benefits of publicly-funded stadiums. International Sports Journal, 4(1), 60-79.

Lewis, S. (2015, November 23). The offer San Diego made to the NFL-and the League's response. Voice of San Diego. Retrieved from http://www.voiceofsandiego.org/topics/land-use/the-offer-san-diego-made-to-thenfl-and-the-leagues-response/

Logan, J., \& Molotch, H. (1987). Urban fortunes. The political economy of place. Los Angeles, CA: University of California Press.

Loomis, J. B., \& Walsh, R. G. (1997). Recreation economic decisions: Comparing benefits and costs (2nd ed.). State College, PA: Venture Publishing.

Lupia, A. (1994). Shortcuts vs. encyclopedias: Information and voting behavior in California insurance reform elections. American Political Science Review, 88, 63-76.

Lupia, A., \& McCubbins, M. D. (1998). The democratic dilemma: Can citizens learn what they need to know? Cambridge, UK: Cambridge University Press.

Macho, S., \& Ledermann, T. (2011). Estimating, testing, and comparing specific effects in structural equation models: The phantom model approach. Psychological Methods, 16, 34-43.

Mahon, J. F., \& Waddock, S. A. (1992). Strategic issues management: An integration of issue life cycle perspectives. Business and Society, 31(1), 19-32.

Mason, D., \& Buist, E. (2013). "Domed" to fail? Diverging stakeholder interests in a stadium referendum. Journal of Urban History, 39, 1146-1162.

Mason, D. S., \& Slack, T. (1997). Appropriate opportunism or bad business practice? Stakeholder theory, ethics, and the franchise relocation issue. Marquette Sports Law Journal, 7(2), 399-426.

McDonald, A. (2015, November 14). Residents speak out against proposed NFL stadium $K M O V$. Retrieved from http://www.kmov.com/story/30519968/residents-speak-out-against-proposed-nflstadium 
McSwain, D., \& Weisberg, L. (2016, March 29). Chargers unveil NFL stadium financing plan. San Diego Union-Tribune. Retrieved from http://www.sandiegouniontribune.com/news/2016/mar/29/chargers-releasestadium-initiative-financing/

Metropolitan and Metropolitan. (2016). U.S. Census Bureau. Retrieved from http://www.census.gov/population/metro/about/

Miles, J., \& Shevlin, M. (2007). A time and a place for incremental fit indices. Personality and Individual Differences, 42(5), 869-874.

Mitchell, R., Agle, B., \& Wood, D. (1997). Toward a theory of stakeholder identification and salience: Defining the principle of who and what really counts. Academy of Management Review, 22(4), 853-886.

Mitchell, R. C., \& Carson, R. T. (1989). Using surveys to value public goods: The contingent valuation method. Washington, DC: Resources for the Future.

Molotch, H. (1976). The city as a growth machine. American Journal of Sociology, 2, 302-330.

Mondak. J. (1993). Source cues and policy approval: The cognitive dynamics of public support for the Regan agenda. American Journal of Political Science, 37, 186212.

Mondello, M., \& Anderson, P. (2004). Stadiums, arenas, and sports referendums: A comparative analysis of cities involved in the stadium game. International Journal of Sport Management 5, 43-71.

Muthén, L. K., \& Muthén, B. O. (2002). How to use a Monte Carlo study to decide on sample size and determine power. Structural Equation Modeling, 9(4), 599-620.

National Sports Law Institute of Marquette University Law School. (2014). Sports facility reports: Major League Baseball. Retrieved from https://law.marquette.edu/assets/sportslaw/pdf/MLB\%20Facility\%20Reports\%20(Ben\%20Fri.\%209.19.14).pdf

Niewik, R. K. (1992). ‘Ask a silly question . . ’: Contingent valuation of natural resource damages. Harvard Law Review, 105, 1981-2000.

Noll, R. G., \& Zimbalist, A. (1997). The economic impact of sports teams and facilities. In Sports, Jobs, and Taxes, edited by R. G. Noll \& A. Zimbalist. Washington, DC: Brookings Institute.

Nunnally, J. C. (1967). Psychometric theory. New York, NY: McGraw-Hill.

Nunnally, J. C., \& Bernstein, I. H. (1994). Psychometric theory ( $3^{\text {rd }}$ ed.). New York, NY: McGraw-Hill. 
Owen, J. (2006). The intangible benefits of sports teams. Public Finance and Management, 6(3), 321-345.

Parent, M. (2008). Evolution and issue patterns for major sport event organizing committees and their stakeholders. Journal of Sport Management, 22, 135-164.

Parent, M., \& Deephouse, D. (2007). A case study of stakeholder identification and prioritization by managers. Journal of Business Ethics, 75, 1-23.

Paul, D., \& Brown, C. (2001). Testing the limits elite influence on public opinion: An examination of sports facility referendums. Political Research Quarterly, 54, 871-887.

Paul, D., \& Brown, C. (2006). The dynamics of elite endorsements in professional sports facility referendums. State Politics \& Policy Quarterly, 6, 272-299.

Pelissero, J., Henschen, B., \& Sidlow, E. (1991). Urban regimes, sport stadiums, and the politics of economic development agendas in Chicago. Policy Studies Review, 10(2/3), 117-129.

Perera, H. N. (2013). A novel approach to estimating and testing specific mediation effects in educational research: Explication and application of Macho and Ledermann's (2011) phantom model approach. International Journal of Quantitative Research in Education, 1(1), 39-60.

Phillips, R. (1999). On stakeholder delimitation. Business and Society, 38, 32-34.

Pistor, N. (2015, November 13). Stadium proponents present financing plan to St. Louis aldermanic committee. St. Louis Post-Dispatch. Retrieved from http://www.stltoday.com/news/local/govt-and-politics/stadium-proponentspresent-financing-plan-to-st-louis-aldermanic-committee/article_8a21c038-0cba59b4-9885-f4012e94a316.html

Portney, P. R. (1994). The contingent valuation debate: Why economists should care. Journal of Economic Perspectives, 8(4), 3-17.

Potter, M. (2015, February 12). Taxpayers on \$271 million Petco hook. San Diego Reader. Retrieved from http://www.sandiegoreader.com/news/2015/feb/12/ticker-taxpayers-271-millionpetco-hook/

Preacher, K. J., \& Hayes, A. F. (2008). Asymptotic and resampling strategies for assessing and comparing indirect effects in multiple mediator models. Behavior Research Methods, 40(3), 879-891.

Putler, D. S., \& Wolfe, R. A. (1999). Perceptions of intercollegiate athletic programs: Priorities and tradeoffs. Sociology of Sport Journal, 16(4), 301-325.

Rappaport, J., \& Wilkerson, C. (2001). What are the benefits of hosting a major league sports franchise? Economic Review, 86(1), 55-91. 
Rosentraub, M. S. (1996). Sport and downtown development strategy. Journal of Urban Affairs, 16(3), 228-239.

Rosentraub, M. S. (1997). Major league losers: The real cost of sports and who's paying for it. New York: Basic Books, Harper Collins.

Rosentraub, M. S., Swindell, D., Przybylski, M., \& Mullins, D. R. (1994). Sport and downtown development strategy: If you build it, will jobs come? Journal of Urban Affairs, 16(3), 221-239.

Rowley, T. (1997). Moving beyond dyadic ties: A network theory of stakeholder influences. The Academy of Management, 22(4), 887-910.

Sage, G. (1993). Stealing home: Political, economic, and media power and a publiclyfunded baseball stadium in Denver. Journal of Sport and Social Issues, 17, 110124.

Sanderson, A. (2000). In defense of new sports stadiums, ballparks and arenas. Marquette Sports Law Review, 10(2), 173-192.

Santo, C. (2007). Beyond the economic catalyst debate: Can public consumption benefits justify a municipal stadium investment? Journal of Urban Affairs, 29(5), 455-479.

Schrotenboer, B. (2016, July 11). Chargers' make-or-break stadium proposal cleared for November vote. USA Today. Retrieved from http://www.usatoday.com/story/sports/nfl/chargers/2016/07/09/chargers-stadiumtax-proposal-november-ballot-make-or-break/86909930/

Schumacker, R. E., \& Lomax, R. G. (2016). A beginner's guide to structural equation modeling $\left(4^{\text {th }}\right.$ ed.). New York, NY: Routledge.

Scott, S. G., \& Lane, V. R. (2000). A stakeholder approach to organizational identity. The Academy of Management Review, 25(1), 43-62.

Shepard, T. (2014, February 20). What Petco Park can teach us about a new Chargers Stadium. Voice of San Diego. Retrieved from http://www.voiceofsandiego.org/topics/news/what-petco-park-can-teach-usabout-a-new-chargers-stadium/

Shrout, P. E., \& Bolger, N. (2002). Mediation in experimental and nonexperimental studies: New procedures and recommendations. Psychological Methods, 7, 422445.

Siegfried, J., \& Zimbalist, A. (2000). The economics of sports facilities and their communities. Journal of Economic Perspectives, 14(3), 95-114.

Spirou, C. (2010). Cultural policy and the dynamics of stadium development. Sport in Society, 13(10), 1423-1437. 
Sposito, V. A., Hand, M. L., \& Skarpness, B. (1983). On the efficiency of using the sample kurtosis in selecting optimal lpestimators. Communications in StatisticsSimulation and Computation, 12(3), 265-272.

Stadium history. (2016). City of San Diego. Retrieved from https://www.sandiego.gov/qualcomm/about/history

Stevens, J. P. (2009). Applied multivariate statistics for the social sciences (5th ed.). New York, NY: Routledge/Taylor \& Francis Group.

Stoker, G., \& Mossberger, K. (1995). The post-Fordist local state: The dynamics of its Development. In J. Stewart and G. Stoker (Eds.), Local Government in the 1990’s (pp. 210-227). London: Macmillan.

Stone, C. N. (1980). Systemic power in community decision making: A restatement of stratification theory. American Political Science Review, 74, 978-990.

Stone, C. N. (1988). Pre-emptive power: Floyd Hunter's community power structure reconsidered. American Journal of Political Science, 32(1), 82-104.

Stone, C. N. (1989). Regime politics: Governing Atlanta 1946-1988. Lawrence, KS: University Press of Kansas.

Stone, C. N. (1993). Urban regimes and the capacity to govern: A political economy approach. Journal of Urban Affairs, 20(3), 249-260.

Suchman, M. (1995). Managing legitimacy: Strategic and institutional approaches. Academy of Management Review, 20, 571-610.

Sutton, W. A., McDonald, M. A., Milne, G. R., \& Cimperman, J. (1997). Creating and fostering fan identification in professional sports. Sport Marketing Quarterly, 6, $15-22$.

Swindell, D., \& Rosentraub, M. S. (1998). Who benefits from the presence of professional sports teams? The implications for public funding of stadiums and arenas. Public Administration Review, 58(1), 11-20.

Tabachnick, B. G., \& Fidell, L. S. (2001). Using Multivariate Statistics (4th ed.). Boston, MA: Allyn \& Bacon.

Tatro, S., \& Togerson, D. (2016, July 12). Voters to face two competing tax hikes: Citizen's plan qualifies for November ballot. $N B C$ 7. Retrieved from http://www.nbcsandiego.com/news/local/Citizens-Plan-Cory-Briggs-Qualifiesfor-November-Ballot-386555551.html

Tinsley, H. E. \& Tinsley, D. J. (1987). Uses of factor analysis in counseling psychology research. Journal of Counseling Psychology, 34, 414-424.

Trail, G., \& Chelladurai, P. (2002). Perceptions of intercollegiate athletic goals and processes: The influence of personal values. Journal of Sport Management, 16, 
289-310.

Trail, G. T., Fink, J. S., \& Anderson, D. F. (2003). Sport spectator consumption behavior. Sport Marketing Quarterly, 12, 8-17.

Trail, G., \& James, J. (2001). The motivation scale for sport consumption: Assessment of the scale's psychometric properties. Journal of Sport Behavior, 24, 108-127.

Tu, C. C. (2005). How does a new sports stadium affect housing values? The case of FedEx Field. Land Economics, 81(3), 379-395.

Turner, R., \& Marichal, J. (1998). Exploring politics on the sports page: The role of local media in sports stadium developments. Policy Studies Review, 15(1), 31-44.

Ullman, J. B. (2006). Structural equation modeling: Reviewing the basics and moving forward. Journal of Personality Assessment, 87(1), 35-50.

U.S. Census Bureau. (n.d.). Quick facts. Retrieved from https://www.census.gov/quickfacts/table/PST045215/00

Vallerand, R. J., Blanchard, C., Mageau, G. A., Koestner, R., Ratelle, C. F., Leonard, M., \& Gagne, M. (2003). Les passions de l'âme: On obsessive and harmonious passion. Journal of Personality and Social Psychology, 85,756-767. doi:10.1037/0022-3514.85.4.756

Vallerand, R. J., Paquet, Y., Philippe, F. L., \& Charest, J. (2010). On the role of passion in burnout: A process model. Journal of Personality, 78(1), 289-312. doi:10.1111/j.1467-6494.2009.00616.x

Vrooman, J. (1997). Franchise free agency in professional sports leagues. Southern Economic Journal, 64, 191-209

Walker, M., \& Mondello, M. (2007). Moving beyond economic impact: A closer look at the contingent valuation method. International Journal of Sport Finance, 2(3), 149-160.

Wann, D. L. (1997). Sport psychology. Upper Saddle River, NJ: Prentice Hall.

Wann, D. L., \& Branscombe, N. R. (1993). Sports fans: Measuring degree of identification with their team. International Journal of Sport Psychology, 24(1), $1-17$.

Wann, D. L., \& Schrader, M. P. (1997). Team identification and the enjoyment of watching a sporting event. Perceptual and Motor Skills, 84(3), 954.

Weber, M. (1947). The theory of social and economic organization. New York, NY: Free Press. 
Weisberg, L. (2016, July 12). Hotel tax hike measure makes November ballot. San Diego Union-Tribune. Retrieved from http://www.sandiegouniontribune.com/news/2016/jul/12/citizens-plan-hotel-taxhike-november-ballot/

Whelan, R. K. (1987). New Orleans: Mayoral politics and economic development policies in the postwar years, 1945-86. In Stone, C.N. \& Sanders, H.T. (Eds.), The Politics of Urban Development (pp. 216-229). Lawrence, KS: University Press of Kansas.

Whitehead, J. C. (1995). Willingness to pay for quality changes: Comparative statistics and theoretical interpretations of empirical results. Land Economics, 71, 207-215.

Wilkerson, H. (1996, March 21). Sales-tax support cut across all lines. Cincinnati Enquirer, p. A10.

Wolf, E. J., Harrington, K. M., Clark, S. L., \& Miller, M. W. (2013). Sample size requirements for structural equation models: an evaluation of power, bias, and solution propriety. Educational and Psychological Measurement, 73(6), 913-934.

Wolfe, R., \& Putler, D. (2002). How tight are the ties that bind stakeholder groups? Organization Science, 13(1), 64-80.

Wu, A. D., \& Zumbo, B. D. (2008). Understanding and using mediators and moderators. Social Indicators Research, 87(3), 367-392.

Zhao, X., Lynch, J. G., \& Chen, Q. (2010). Reconsidering Baron and Kenny: Myths and truths about mediation analysis. Journal of Consumer Research, 37(2), 197-206.

Zipp, J. (1996). The economic impact of the baseball strike of 1994. Urban Affairs Review, 32(2), 157-185. 
APPENDICES 


\section{APPENDIX A}

\section{RECRUITMENT LETTER}

\section{CIVIC PRIDE OR CIVIC DUTY? AN EXAMINATION OF WILLINGNESS TO VOTE IN SUPPORT OF A PROFESSIONAL SPORT STADIUM REFERENDUM.}

October 1, 2016

Dear Participant:

You are being invited to participate in a research study by answering the attached survey about your thoughts and perceptions of stadium construction projects. There are no known risks for your participation in this research study. The information collected may not benefit you directly. The information learned in this study may be helpful to others. The information you provide will help gain insight about what potential factors influence constituents to vote in support of local professional sport stadium construction projects. Your completed survey will be stored at the University of Louisville in the Department of Health and Sport Sciences in a secured office. The survey will take approximately 15-20 minutes to complete.

Individuals from the Department of Health and Sport Sciences, the Institutional Review Board (IRB), the Human Subjects Protection Program Office (HSPPO), and other regulatory agencies may inspect these records. In all other respects, however, the data will be held in confidence to the extent permitted by law. Should the data be published, your identity will not be disclosed.

Taking part in this study is voluntary. By completing this survey, you agree to take part in this research study. You do not have to answer any questions that make you uncomfortable. You may choose not to take part at all. If you decide to be in this study you may stop taking part at any time. If you decide not to be in this study or if you stop taking part at any time, you will not lose any benefits for which you may qualify.

If you have any questions, concerns, or complaints about the research study, please contact: Alicia Cintron at (513) 556-8475.

If you have any questions about your rights as a research subject, you may call the Human Subjects Protection Program Office at (502) 852-5188. You can discuss any questions about your rights as a research subject, in private, with a member of the Institutional Review Board (IRB). You may also call this number if you have other questions about the research, and you cannot reach the research staff, or want to talk to someone else. The IRB is an independent committee made up of people from the 
University community, staff of the institutions, as well as people from the community not connected with these institutions. The IRB has reviewed this research study.

If you have concerns or complaints about the research or research staff and you do not wish to give your name, you may call 1-877-852-1167. This is a 24-hour hot line answered by people who do not work at the University of Louisville.

Sincerely,

Alicia M. Cintron,

T.C. Greenwell, $\mathrm{PhD}$ 


\section{APPENDIX B}

\section{FINAL INSTRUMENT}

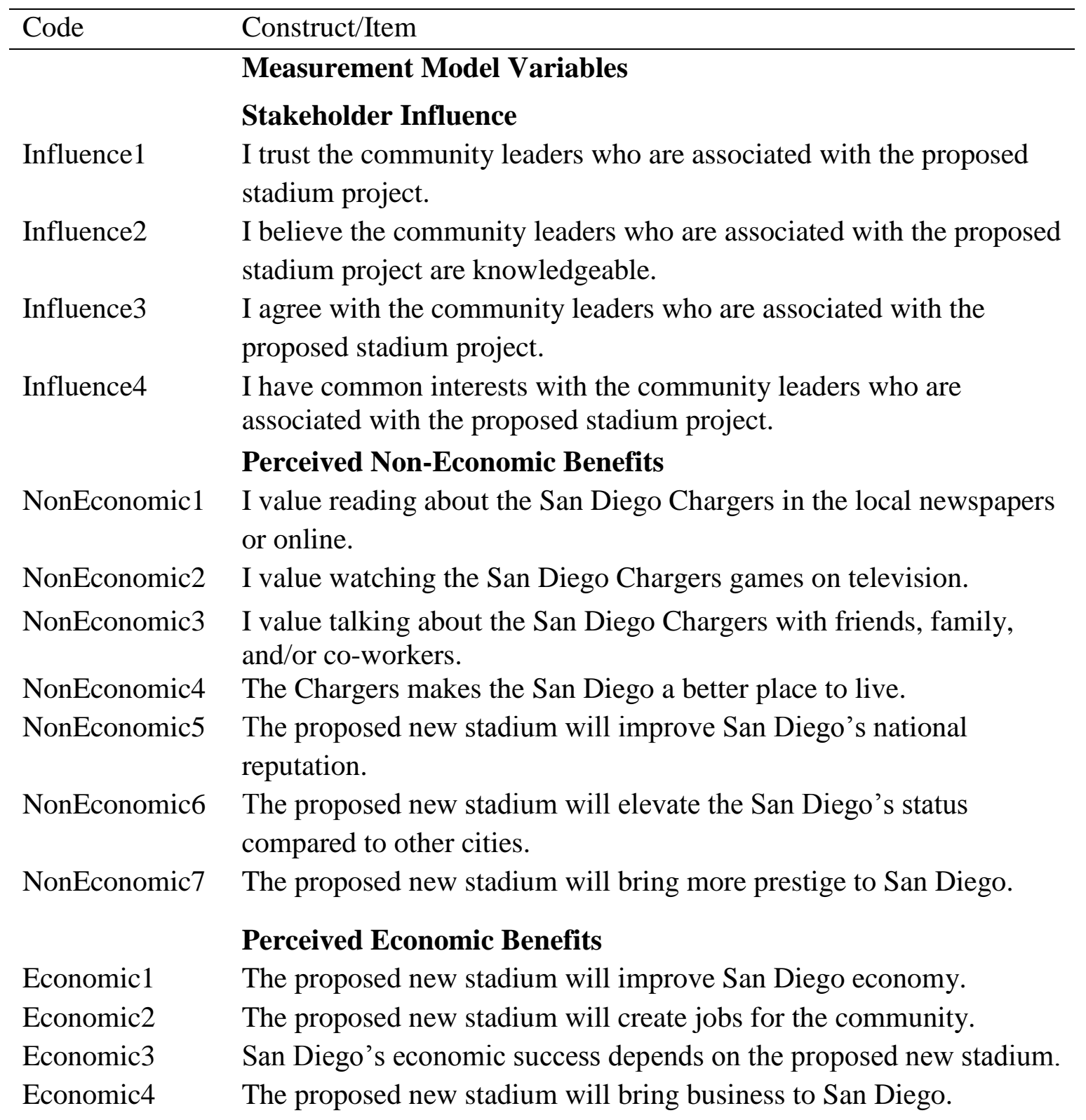




\begin{tabular}{|c|c|}
\hline Code & Construct/Item \\
\hline & Team Identification \\
\hline ID1 & I consider myself to be a "real" fan of the San Diego Chargers. \\
\hline ID2 & $\begin{array}{l}\text { I would experience a loss if I had to stop being a fan of the San Diego } \\
\text { Chargers. }\end{array}$ \\
\hline Code & Construct/Item \\
\hline ID3 & Being a fan of the San Diego Chargers is very important to me. \\
\hline & Stadium Support - Dependent Variable \\
\hline Support 1 & I support the proposed tax plan to build the new stadium. \\
\hline Support2 & I am in favor of the proposed tax plan to build the new stadium. \\
\hline Support3 & Using hotel tax to build the new stadium is an idea I can endorse. \\
\hline Support4 & $\begin{array}{l}\text { Building the new stadium with funds from the proposed tax plan is a } \\
\text { favorable plan. }\end{array}$ \\
\hline VoteYN & $\begin{array}{l}\text { In the November election, you will be asked to vote on this } \\
\text { referendum: "REFERENDUM LANGUAGE HERE." If the election } \\
\text { were held today, would you vote for or against the Measure? }\end{array}$ \\
\hline Vote & $\begin{array}{l}\text { I am likely to vote in support of a referendum that would provide } \\
\text { public funding for a new stadium for the San Diego Chargers. }\end{array}$ \\
\hline
\end{tabular}

\section{Non-Measurement Model Variables}

\section{Stakeholder Presence}

Presence1 From the list below, please choose which individuals or groups who you are aware of campaigning IN FAVOR OF the stadium project proposal. Choose all that apply. If you aren't aware any individuals or groups campaigning IN FAVOR OF the stadium project proposal, please select "Not aware of other person or group."

Presence2 Are there any other individuals or groups who you are aware of campaigning IN FAVOR OF the stadium project proposal? Please list. If you aren't aware of any other individuals or groups campaigning IN FAVOR OF the stadium project proposal, please select "Not aware of other person or group".

Presence3 From the list, below please choose which individuals or groups who you are aware of campaigning AGAINST the stadium project proposal. Choose all that apply. If you aren't aware any individuals or groups campaigning AGAINST the stadium project proposal, please select "Not aware of other person or group."

Presence4 Are there any other individuals or groups who you are aware of campaigning AGAINST the stadium project proposal? If you aren't aware of any other individuals or groups campaigning AGAINST the stadium project proposal, please select "Not aware of other person or group". 
Code Construct/Item

\section{Additional Influencing Variables}

OppCost The city has other, more pressing social issues that should be addressed before public money is spent on this proposed stadium project.

Relocation The San Diego Chargers may relocate to another city if they do not get a new stadium.

Knowledge I consider myself to be knowledgeable of the proposed stadium project.

Referendum I consider myself to be knowledgeable of the referendum to fund the Knowledge new stadium.

\section{Demographics}

Age How old are you (in years)?

HHIncome What was your annual household income in 2015 (in dollars)?

Gender What is your gender?

Registered Are you registered to vote in the City of San Diego?

Resident I am a resident of San Diego.

Race What is your race?

Tenure How many years have you lived in San Diego?

Education What is your highest level of education?

VoteIntentions I intend to vote in the upcoming election on November 8, 2016.

PastVote I have voted in previous elections.

Attendance I intend to go to home games and other events in the proposed new stadium.

Location How many miles do you live from the new proposed stadium site? 


\section{APPENDIX C}

\section{WEBSITES}

https://www.facebook.com/noNFLsubsidy/

https://www.facebook.com/saveourboltsSD/

http://www.voiceofsandiego.org/topics/politics/ultimate-guide-local-ballot-measures/

http://www.voiceofsandiego.org/topics/opinion/vote-citizen-not-fan/

https://www.facebook.com/SanDiegoUnionTribune/

https://www.facebook.com/voiceofsandiego/?fref=ts

https://www.facebook.com/chargers/

https://bolttalk.com/threads/new-chargers-stadium-proposal.30082/ 


\title{
CURRICULUM VITAE
}

\author{
ALICIA M. CINTRON \\ alicia.cintron@uc.edu | (757) 727-3920 | Cincinnati, Ohio 45202
}

\section{EDUCATION}

PhD $\quad$ May 2017

M.S. 2013

B.S. 2007
University of Louisville, Louisville, KY

Educational Leadership, Evaluation and Organizational Development Specialization: Sport Administration

Research area: Professional team facility financing and public policy; student-athlete well-being

University of Louisville, Louisville, KY Sport Administration

Old Dominion University, Norfolk, VA Sport Management major, Marketing minor

\section{ACADEMIC WORK EXPERIENCE}

University of Cincinnati, Cincinnati, $\mathrm{OH}$

July 2016 to present

Sport Administration Program, School of Human Services

Visiting Assistant Professor

- Organize and prepare course materials including syllabi, lectures, exams, major projects and assignments, including Blackboard course design and maintenance for the following courses:

- SMGT 1001 Introduction to Sport Management-120 students (Fall 2016), 75 students (Spring 2017)

- SMGT 2040 Ethical Issues in Sport-75 students (Fall 2016), 120 students (Spring 2017)

- SMGT 4040 Sport Law \& Governance-50 students (Fall 2016, Spring 2017)

- SMGT 7014 Risk Management in Sport-15 graduate students (Spring 2017)

University of Louisville, Louisville, KY

August 2012 to June 2016

Sport Administration Program, Department of Health \& Sport Sciences

Graduate Teaching Assistant

- Instructor experience 
- Organized and prepared all course materials including syllabi, lectures, visual aids, major projects and assignments, and exams, as well as Blackboard course design and maintenance for the following courses:

- SPAD 545 Sport Communication-26 students (Spring 2016)

- Online course fully executed through Blackboard

- SPAD 489 Legal Aspects of Sport-25 students (Fall 2015)

- Online course fully executed through Blackboard

- SPAD 404 Financial Principles of Sport-30 students (Spring 2015)

- SPAD 530 Promotion \& Publicity-30 students (6 weeks-Fall 2014)

- HSS 114 Fitness Walking-30 students (Fall 2012; Spring 2013; Fall 20142 sections; Spring 2016)

- Teaching Assistant experience

- Overall teaching duties includes student internship supervision, guest lectures in undergraduate and graduate core courses, and teaching assistance such as grading, lecturing, and classroom management for the following courses:

- SPAD 281 Principles of Sport Administration-large lecture course (Spring 2013; Fall 2014; Spring 2015; Spring 2016)

- SPAD 284 Ethics and Issues in Sport Administration-large lecture course (Fall 2012)

- SPAD 401 Career Development in Sport Administration (Spring 2013; Summer 2013; Summer 2015)

- Faculty Intern Supervisor, SPAD 402 Internship in Sport Administration5-10 students per semester (Fall 2013; Spring 2013; Summer 2013; Summer 2015)

- Guest Lecturer experience

- Central High School/SPAD Sport Marketing Magnet Program-4 P's (Spring 2016)

- SPAD 281 Principles in Sport Administration-Financial \& Economic Principles in Sport (Spring 2016)

- SPAD 561 Sport for Development: Botswana (Service Learning Trip)-Curriculum Development (Spring 2016)

- SPAD 561 Sport Entrepreneurship-Lean Start Up (Spring 2016)

- SPAD 604 Financial Principles of Sport (Masters level)-NHL Expansion Case Study (Spring 2016)

- SPAD 561 Sport Entrepreneurship-Marketing Your Product (Summer 2015; Fall 2015; Spring 2016)

- SPAD 401 Career Development-Final Tips (Summer 2015)

- SPAD 383/683 Sport Marketing-Public Relations (Summer 2015)

- SPAD 604 Financial Principles of Sport (Masters level)-Facility Financing (Spring 2015)

- SPAD 281 Principles in Sport Administration-APA (Spring 2014, Fall 2016)

- SPAD 281 Principles in Sport Administration-Professional Sport (Fall 2014)

- SPAD 281 Principles in Sport Administration-College Sport (Fall 2014; Spring 2016) 
- SPAD 281 Principles in Sport Administration-Sport Marketing (Fall 2014, Spring 2016)

- SPAD 281 Principles in Sport Administration-Sport Broadcasting (Fall 2014; Spring 2016)

- SPAD 382 Organizational Behavior in Sport-Management \& Leadership (Fall 2014)

- SPAD 382 Organizational Behavior in Sport-Communication (Fall 2014)

- SPAD 404 Financial Principles of Sport-Player/Team Finances (Fall 2014)

- SPAD 281 Principles in Sport Administration-Professional Sports (Spring 2014)

- SPAD 383 Sport Marketing-Sponsorship (Spring 2013)

- SPAD 401 Career Development-Interviewing \& Dress (Spring 2013)

- SPAD 281 Principles in Sport Administration-Interviewing (Spring 2013)

- SPAD 281 Principles in Sport Administration-Facility Management (Spring 2013; Fall 2014; Spring 2016)

- SPAD 281 Principles in Sport Administration-Facilitator: Marketing and Sports Panel (Spring 2013)

- SPAD 284 Issues and Ethics in Sport-Ethics and Social Media (Fall 2012)

- SPAD 284 Issues and Ethics in Sport-Ethical Considerations of Technology and Sport (Fall 2012)

- SPAD 284 Issues and Ethics in Sport-Facilitator: Ethics in Compliance and Academics in Collegiate Athletics Panel (Fall 2012)

- SPAD 284 Issues and Ethics in Sport-Title IX (Fall 2012)

University of Louisville, Louisville, KY

August 2013 to June 2016

Sport Administration Program, Department of Health \& Sport Sciences

Graduate Research Assistant

- Supported full-time faculty members with data collection and literature searches such as:

- Career socialization and development for men

- Mixed Martial Arts and sentiments on Twitter

- Community service and college athletics

- College student-athletes career exploration and interests

- Media reports surrounding Caitlin Jenner's ESPY Award speech

- Social network analysis of sport communication researchers

- Framing and protests at mega sport events

- Supported full-time faculty with data analysis and manuscripts such as:

- Provided feedback on manuscripts in development for Dr. Marion Hambrick and Dr. Meg Hancock

- Transcribed 25 career development interviews, and violence and sport focus groups interviews

- Assisted in the analysis of qualitative interviews for study on intercollegiate athletics career development and career advice for students with Dr. Meg Hancock and Dr. Mary Hums

- Assisted in the content analysis of tweets for Mixed Martial Arts athletes based on the contextual evidence with Dr. Chris Greenwell 
O Data entry of the 2013-2014 and 2014-2015 University of Louisville StudentAthlete Academic Satisfaction surveys for the University of Louisville Athletic Association

\section{RESEARCH AND SCHOLARLY ACTIVITIES}

Publications

Peer Reviewed Journals

1. Cintron, A. M, Levine, J., \& Hambrick, M. (2016). A case study of the National Hockey League: The question of expansion. Case Studies in Sport Management.

2. Darvin, L., Cintron, A. M., \& Hancock, M. G. (2017). ¿Por qué jugar? A study on sport socialization among Hispanic and Latina female student-athletes. Journal of Amateur Sports.

\section{Book Chapters}

1. Kellison, T., \& Cintron, A. M. (2016). Building stadiums, building bridges: Geopolitical strategy in China. In C. Esherick, R. Baker, S. Jackson, \& M. Sam, Case Studies in Sport and Diplomacy. Morgantown, WV: Fitness Information Technology.

2. Grappendorf, H., Hancock, M. H., \& Cintron, A. M. (Submitted). She shoots; she doesn't score: Inequalities that persist with the U.S. Women's soccer team. In B. Pitts \& J. Zhang (Eds.), Global Sport Management: Contemporary issues and inquiries. World Association for Sport Management (WASM) series. London: Routledge.

3. Cintron, A. M., Grappendorf, H., \& Hancock, M. H. (Submitted). The state of media coverage of women's soccer in the United States and beyond. In B. Pitts \& J. Zhang (Eds.), Global Sport Management: Contemporary issues and inquiries. World Association for Sport Management (WASM) series. London: Routledge.

Publications in Review or Progress

1. Hambrick, M. E., Pegoraro, A., Cintron, A. M., \& Budge, S. (In Review). I am Cait: An analysis of top and bottom down framing of Caitlin Jenner's ESPY speech. Submitted to Journal of Sports Media.

2. Schmidt, S. H., Cintron, A. M., Park, J., \& Hancock, M. G. (Revisions in Progress). \#ICantBreathe and \#Ferguson: Race and athlete activism on social media. To be submitted to International Journal of Sport Management.

3. Hancock, M., Cintron, A. M., \& Darvin, L. (Revisions in Progress). Vocational socialization for careers in intercollegiate athletics. To be submitted to Women in Sport and Physical Activity 
4. Hambrick, M. E., Cintron, A. M., \& Schmidt, S. H. (Manuscript in Progress). Why did I sign up for this?: An investigation of recreational sport participants and their leisure constraints, constraint negotiation, and support networks. To be submitted to Journal of Sport Management.

5. Levine, J. F., Cintron, A. M., \& Hambrick, M. E. (Manuscript in Progress). Exploring outcomes in Sport for Development and Peace through experiential learning. To be submitted to Sport Management Educational Journal.

6. Cintron, A. M., Levine, J. L., Williams, D., \& Kobritz, J. (Manuscript in Progress). Las Vegas power play: The gamble on professional sports in Sin City. To be submitted to Journal of Urban Affairs.

Academic Presentations

1. Cintron, A. M., Levine, J. L., Williams, D., \& Kobritz, J. (2017). Las Vegas Power Play: The Gamble on Professional Sports in Sin City. Presented at the annual Sport and Recreation Law Association Conference, Las Vegas, NV.

2. Darvin, L., Cintron, A. M., \& Hancock, M. G. (advisor). (2016). ¿Por qué jugar? A study on sport socialization among Hispanic and Latina female student-athletes. Presented at the annual conference of the North American Society for Sport Management, Orlando, Florida.

3. Schmidt, S. H., Cintron, A. M., Park, J., \& Hancock, M. G. (2015). \#ICantBreathe and \#Ferguson: Race and athlete activism on social media. Presented at the annual conference of the North American Society for the Sociology of Sport, Santa Fe, NM.

4. Park, J., \& Cintron, A. M. (2015). Examining the relationship of gender, sport type, and athletic identity to student athletes' career maturity: Perspectives from career construction theory. Presented at the annual conference of the North American Society for Sport Management, Ottawa, Ontario.

5. Cintron, A. M., Greenwell, T. C., \& Shreffler, M. (2015). Game-day customer service project. Presented at the annual conference of the North American Society for Sport Management, Ottawa, Ontario.

6. Cintron, A. M., \& Levine, J. F. (2015). Student athlete advocacy: The path toward a more meaningful future. Presented at the Third Annual Ali Center Athletes and Social Change Forum, Louisville, KY.

7. Cintron, A.M. (2015). How much are you willing to pay to keep your favorite team around? Presented at the annual Spring Research Conference, University of Louisville, Louisville, KY.

8. Cintron, A. M. (2015). Major League growth: How and why political elites design lease agreements to promote municipal growth. Presented at the annual conference of the Southern Sport Management Association, Baton Rouge, LA. 
9. Levine, J., Cintron, A. M., \& Hanna, C. (2015). Calling your bluff: A case against NHL expansion into Las Vegas. Presented at the annual conference of the Southern Sport Management Association, Baton Rouge, LA.

10. Hancock, M. G., Hums, M. A., \& Cintron, A. M. (2014). Men and women in intercollegiate athletic administration: Career callings or career compromise. Presented at the annual conference of the North American Society for Sport Management, Pittsburgh, PA.

11. Cintron, A. M., \& Greenwell, T. C. (advisor) (2014). Marlins Park: A case study on stadium financing, media coverage, and public perception. Presented at the annual conference of the Sport Marketing Association, Philadelphia, PA.

Grants and Funding Activities

1. Cintron, A. M., \& Hancock, M. H. (2016). President's Commission on Diversity and Racial Equity Graduate Student Grant, University of Louisville in the amount of \$535. Granted.

2. Cintron, A. M. (2016). Travel costs for the North American Society for Sport Management Conference to present. Funded by the Graduate Student Council, University of Louisville in the amount of up to $\$ 300$. Granted.

3. Cintron, A. M. (2016). Registration fee for the North American Society for Sport Management Conference to present. Funded by the Health and Sport Sciences Department, University of Louisville in the amount of \$175. Granted.

4. Hambrick, M. E., Cintron, A. M., \& Schmidt, S. H. (2016). Why did I sign up for this?: An investigation of recreational sport participants and their leisure constraints, constraint negotiation, and support networks. Funded by the University of Louisville College of Education and Human Development Research and Faculty Development Grant in the amount of \$1,000. Granted.

5. Cintron, A. M. (2015). Travel to Ottawa, Ontario for the North American Society for Sport Management Conference to present. Funded by the Graduate Student Council, University of Louisville in the amount of \$150. Granted.

6. Cintron, A. M. (2015). Registration fee for the North American Society for Sport Management Conference to present. Funded by the Health and Sport Sciences Department, University of Louisville in the amount of \$175. Granted.

7. Cintron, A. M. (2015). Registration fee for the Muhammad Ali Athletes for Social Change Forum to present. Funded by the Health and Sport Sciences Department, University of Louisville in the amount of \$50. Granted.

8. Cintron, A. M. (2015). Registration fee for the Southern Sport Management Association Conference to present. Funded by the Health and Sport Sciences Department, University of Louisville in the amount of \$75. Granted. 
9. Cintron, A. M. (2014). Travel to Pittsburgh, Pennsylvania for the North American Society for Sport Management Conference to present. Funded by the Graduate Student Council, University of Louisville in the amount of \$350. Granted.

10. Cintron, A. M. (2013). Travel to Indianapolis, Indiana for the 2013 National Collegiate Athletic Association/National Association of Collegiate Women's Athletics Administrators Women's Leadership Symposium. Funded by the Sport Administration Club, University of Louisville in the amount of \$200. Granted.

\section{SERVICE, MEMBERSHIP, and LEADERSHIP \\ College}

Grawemeyer Award in Education Presentation Volunteer

2015-2016

Honors \& Scholarship Committee Student Representative

2014-2015

Program

UC Women in Sport Administration Advisor (Univ. of Cincinnati)

2016-present

Sport Administration Program Diversity Committee (Univ. of Cincinnati) 2016-present

Black History Month Sports Panel 2016

Sport Administration Masters Admissions Committee 2014-2015

Sport Administration Association Student/Faculty Liaison 2014-2015

Sport Administration Speaker Summit Committee Member 2014

Sport Administration Association President 2013

Sport Administration Tenure-Track and Term Faculty Search Committee 2012-2013

Professional

North American Society for Sport Management 2013-present

Muhammad Ali Conference for Social Change Planning Committee 2015

National Association of Collegiate Women's Athletics Administrators 2013-2015

Southern Sport Management Association 2015 
Sport Marketing Association

Community

Girls on the Run Assistant Coach 2014

Muhammad Ali Conference for Social Change Moderator 2014

Girls on the Run 5K Volunteer 2013

Greater Louisville Classic Volunteer 2012

NCAA Division I Cross Country pre-nationals Volunteer 2012

Louisville Sports Commission Half Marathon Volunteer 2012

NCAA Division I Cross Country National Championships Volunteer 2012

NCAA Division I Women's Volleyball National Championships Volunteer 2012

Tread at the Ted 5k Volunteer Race Coordinator 2011

HONORS

Graduate Student of the Year (Nominated) 2013

Best Charity Event-Tread at the Ted 5k (Global Spectrum) 2011

Best Event within an Event-Hoops for the Cure/Old Dominion Women's 2010

Basketball marketing campaign (Global Spectrum)

Academic Excellence Award in Sport Management (Old Dominion Univ.) 2006

PROFESSIONAL TRAINING

Online Learning Consortium (OLC) Accelerate 2016

Safe Zone Ally Training, University of Cincinnati LGBTQ Center 2016

Entrepreneurship Academy, University of Louisville School of Interdisciplinary 2016 and Graduate Studies

Ideas to Action (i2a) Institute: Sustaining and Deepening Critical Thinking, 2016 University of Louisville Delphi Center for Teaching and Learning

Delphi University: Principles of Online Course Design, Principles of Quality Matters, University of Louisville Delphi Center for Teaching and Learning 


\section{SPORT INDUSTRY EXPERIENCE}

University of Louisville, Louisville, KY

August 2013 to December 2013

University of Louisville Athletic Association

\section{Student-Athlete Development/Administration Intern}

- Assisted in the implementation of programs and events built to instill a wellbalanced lifestyle for student-athletes, encouraging emotional well-being, personal growth, and decision-making skills

- Researched and analyzed the current student-athlete development programs in the Atlantic Coast Conference (ACC) to prepare for transition in 2014

- Assisted in the evaluation of the ACC comprehensive analysis completed for all sports and athletic programs

Louisville Sports Commission, Louisville, KY

September 2012 to April 2013

\section{Operations Intern}

- Assisted with day-of-event responsibilities including set up, maintenance, and break down of various events including the Greater Louisville Cross Country Classic, Louisville Half Marathon, NCAA Division I Men's and Women's Cross Country Pre-Nationals and National Championship, and NCAA Division I Women's Volleyball Championship

- Recruited over 20 companies and sponsors to be included in the Virtual Race Bag for the Louisville Sports Commission Half Marathon and Pure Tap 5k

- Coordinated, recruited, and managed over 35 volunteers for the 2013 National Association for Sport Commissions (NASC) Sport Events Symposium in Louisville

Global Spectrum (renamed Spectra)

Ted Constant Convocation Center, Norfolk, VA December 2009 to July 2012

\section{Director of Marketing}

- Responsible for the promotion of concerts, sporting events, and shows within the Ted Constant Convocation Center as well as handling advertising for Old Dominion's Division I basketball and football programs by creating extensive marketing, public relations, and advertising plans

- Negotiated, placed, and monitored media buys for all special events including Old Dominion Basketball, Football, and NCAA Women's Basketball Tournament including television, radio, print, online, outdoor, and nontraditional media outlets 
- Supervised, trained, and motivated 2 full time positions (Marketing Coordinator and Groups \& Premium Services Manager) to achieve goals set by company, upper management, and clients

- Worked directly with the Assistant Athletic Director for Marketing at Old Dominion University to help achieve sales goals of the Athletic Department through development and execution of ticket driving in-game promotions, day-of game activities, and advertising placement

- Developed and managed marketing department annual budget and payroll

University of Central Florida Arena, Orlando, FL October 2008 to December 2009

\section{Assistant Marketing Manager}

- Developed marketing and advertising plans for various concerts and family shows that included cash, trade and promotional elements in a major advertising market using television, radio, print, and outdoor mediums

- Managed venue and event public relations efforts including writing press releases, creating media drops and public relations events, and pitching stories to media to ensure coverage of events

- Built and maintained relationships with media representatives, program and promotional directors, and general sales managers to help achieve ticket sales goals

Ted Constant Convocation Center, Norfolk, VA January 2007 to October 2008

\section{Marketing \& Club Services Coordinator}

- Created effective grassroots marketing and public relations campaigns for various concerts, family shows, and sporting events

- Maintained strong relationships with major annual sponsor through communication, activation, annual sponsor reports and spearheaded efforts to renew sponsorship through extensive market and venue research, data collection, and sales presentations

- Developed annual premium services marketing plan with focus on building and maintaining relationships with suite and club seat club level clients as well as working with ARAMARK and Old Dominion Athletics to optimize the experience at every event

- Interviewed, hired, trained, and managed 5-6 interns each semester to help assist with grassroots, research, and other essential job functions that helped sell tickets 